\title{
Analysis of autoimmune lesions in grey matter
}

\author{
Dissertation \\ for the award of the degree \\ "Doctor rerum naturalium" \\ of the Georg-August-University Göttingen
}

within the doctoral program "Molecular Biology of Cells"

of the Georg-August University School of Science (GAUSS)

submitted by

Moritz Andreas Hermann

from Tübingen

Göttingen, 2017 


\section{Thesis Committee}

Prof. Dr. Alexander Flügel, Institute for Multiple Sclerosis Research, Institute of Neuroimmunology, University Medical Centre Göttingen

Prof. Dr. Holger Reichardt, Department of Experimental Immunology, Institute for Cellular \& Molecular Immunology, University Medical Centre Göttingen

Prof. Dr. Jürgen Wienands, Institute for Cellular \& Molecular Immunology, University Medical Centre Göttingen

\section{Members of the Examination Board}

Referee: Prof. Dr. Alexander Flügel, Institutes of Multiple Sclerosis Research and Neuroimmunology, University Medical Centre Göttingen

Second Referee: Prof. Dr. Holger Reichardt, Department of Experimental Immunology, Institute for Cellular \& Molecular Immunology, University Medical Centre Göttingen

\section{Further members of the Examination Board}

Prof. Dr. Jürgen Wienands, Institute for Cellular \& Molecular Immunology, University Medical Centre Göttingen

Prof. Dr. Dr. Hannelore Ehrenreich, Department of Clinical Neuroscience, Max Planck Institute of Experimental Medicine

Prof. Dr. Wolfgang Brück, Institute of Neuropathology, University Medical Centre Göttingen

Dr. Sebastian Kügler, Department of Neurology, Viral Vectors Lab, University Medical Centre Göttingen

Date of oral examination: 22.02.2018, 15:00h 


\section{Contents}

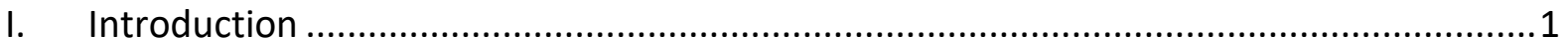

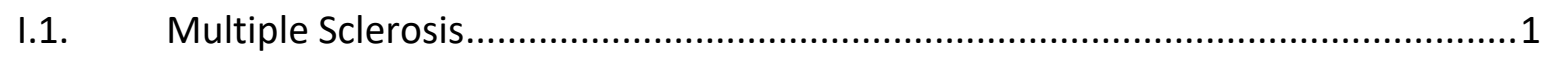

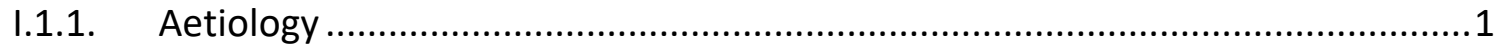

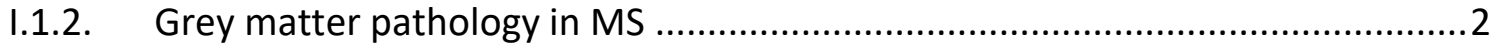

I.2. Experimental Autoimmune Encephalomyelitis - EAE..........................................4

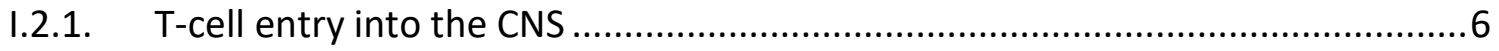

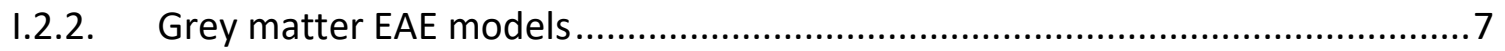

1.2.3. The $\beta$-Synuclein neuronal EAE model ......................................................

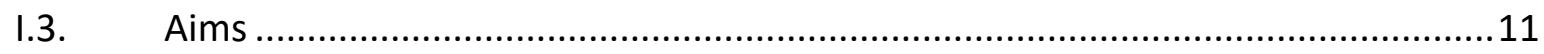

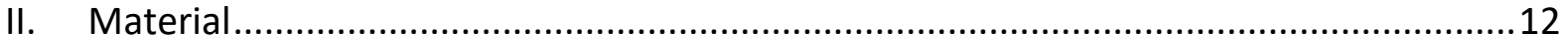

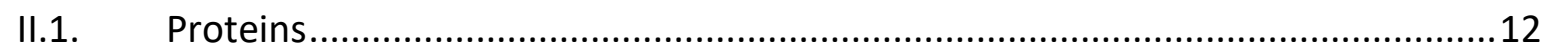

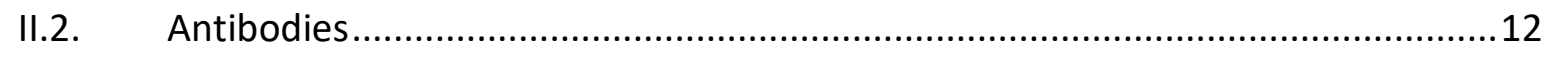

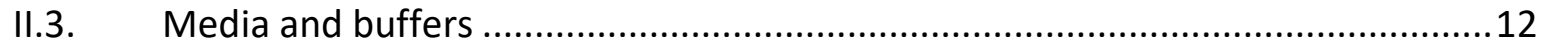

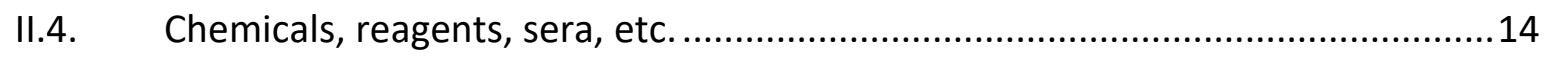

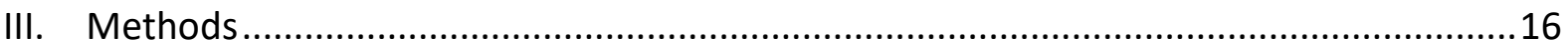

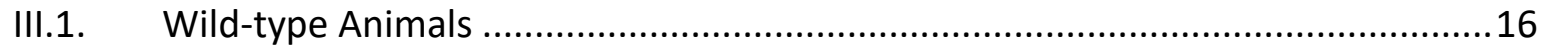

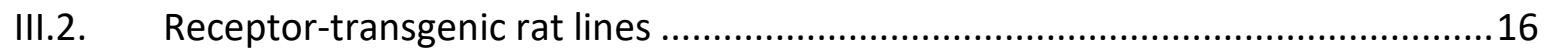

III.3. Active EAE \& Immunization for the generation of T-cell lines ............................16

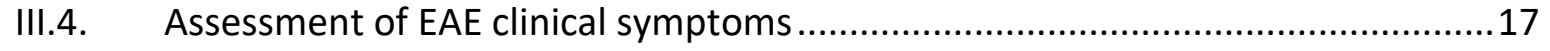

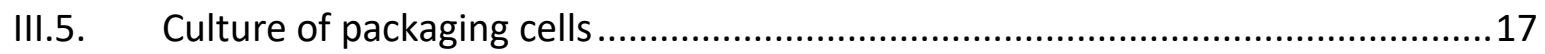

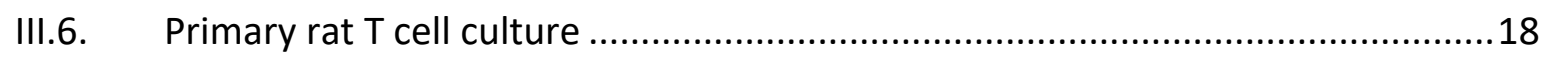

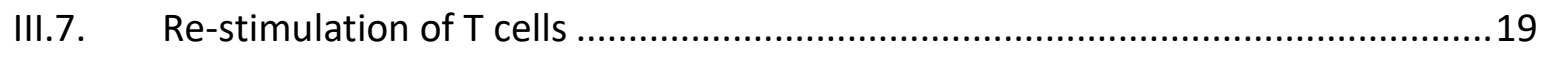

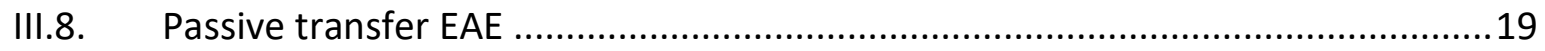

III.9. Intravital imaging with the two-photon laser scanning microscope....................20

III.10. Surgical procedure for intravital two-photon laser scanning microscopy ............20

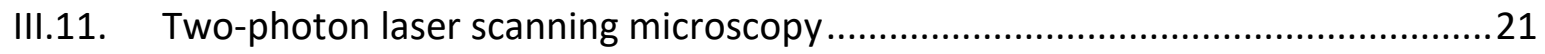

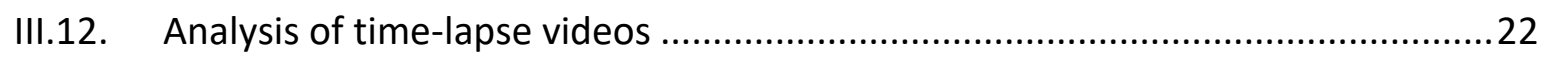

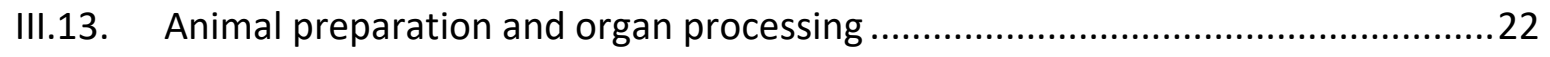

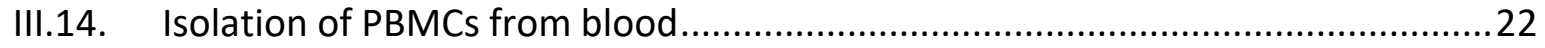

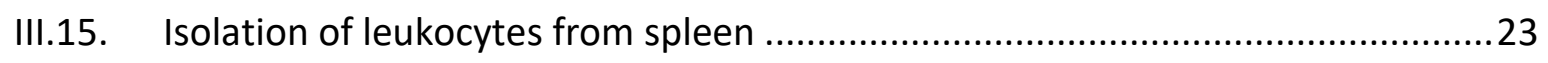

III.16. Isolation of leukocytes from CNS and CNS meninges ...................................23 


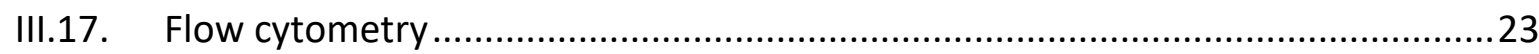

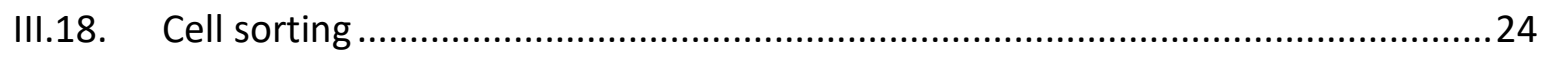

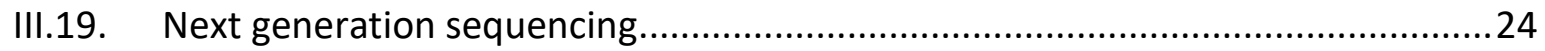

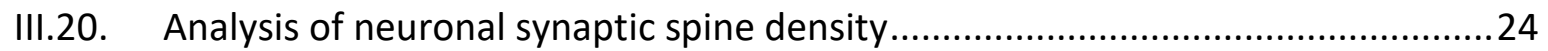

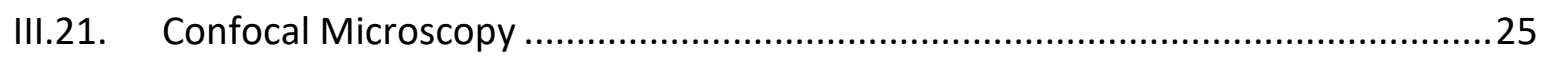

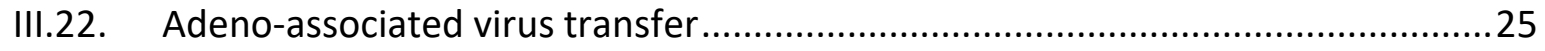

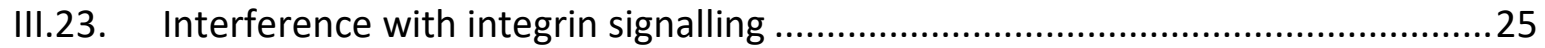

III.24. Interference with chemokine signalling .......................................................26

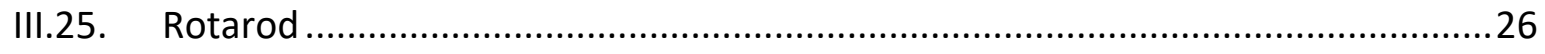

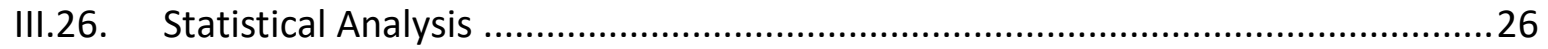

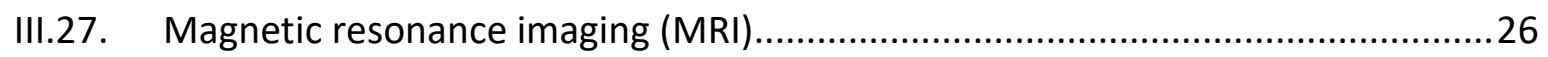

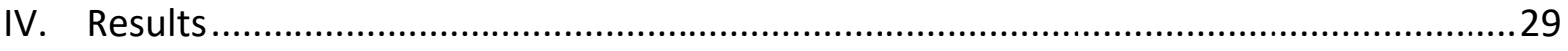

IV.1. Characterization of neuronal and classic active EAE in 8-10 week old rats ..........29

IV.2. Active neuronal EAE can be induced reliably in up to 6 month-old $\beta S y n T G^{(T /+)}$

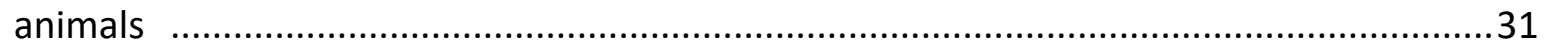

IV.3. EAE induced by transfer of $\beta$-Synuclein-specific T cells of different genetic origins .33

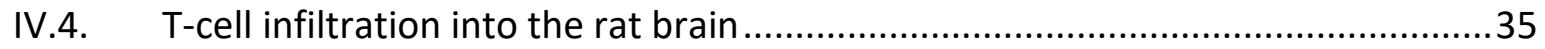

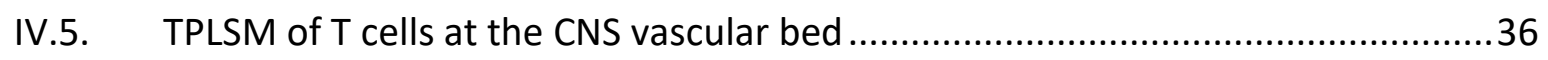

IV.6. Monitoring CD11 $\mathrm{b}^{+}$Monocytes at the CNS vascular bed reveals subtle differences in luminal crawling between brain and SC

IV.7. Blocking integrin \& chemokine receptor signalling affects T-cell crawling and EAE development.

IV.8. Expression profiles of blood-derived T cells are nearly identical between different

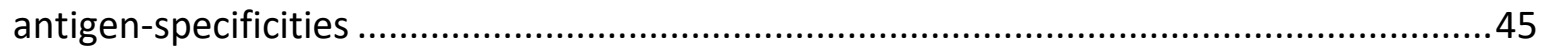

IV.9. Motility behaviour of $\mathrm{T}_{\beta \text { Syn }}$ cells in the brain grey matter .................................46

IV.10. Comparison of expression profiles between blood- and brain-derived $\mathrm{T}_{\beta S y n}$ cells indicates re-activation in situ

IV.11. AAV-mediated antigen-availability influences T-cell recruitment and motility ....49

IV.12. Spine density is reduced in $\mathrm{T}_{\beta S y n}$ - but not $\mathrm{T}_{\mathrm{MBP}}$-cell mediated ptEAE ...................51

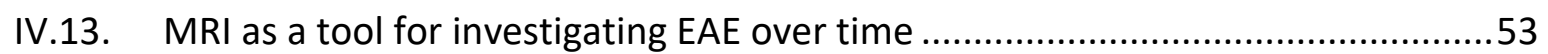

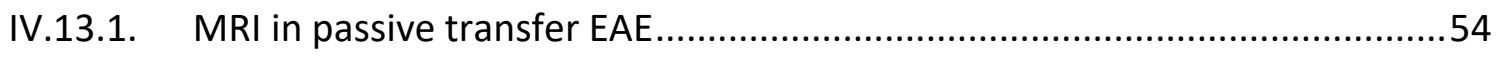

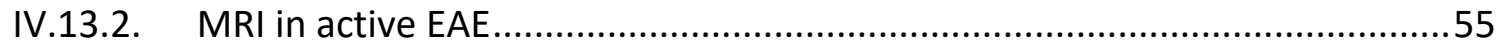


IV.14. Repeated inflammatory bouts aggravate EAE-induced changes in the brain ......57

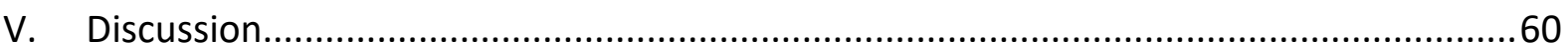

V.1. Invasion of neuron-specific T cells into the grey matter ...................................60

V.2. The brain as a target of autoimmune attack: linking MS and EAE grey matter pathology 66

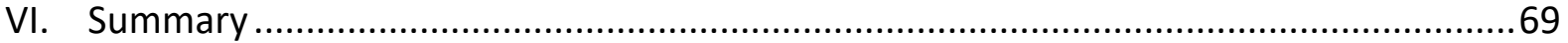

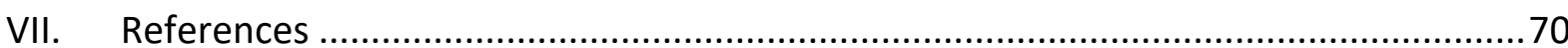

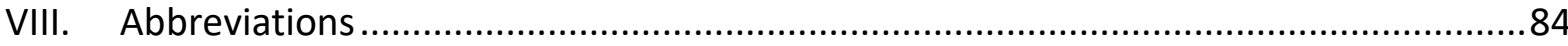

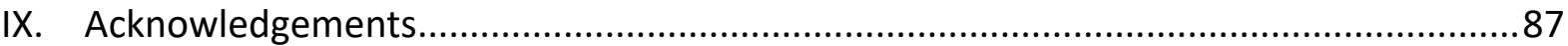

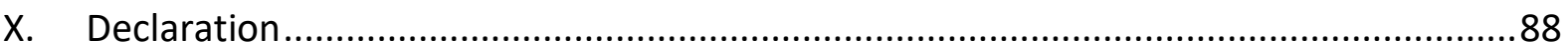

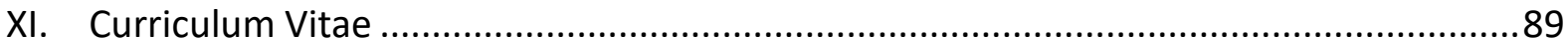




\section{Introduction}

\section{I.1. Multiple Sclerosis}

On the occasion of the $150^{\text {th }}$ anniversary of the first depiction of Multiple Sclerosis (MS) in 1988, Alastair Compston published a highly worthwhile article assessing historical cases and adding his conclusions about who first described the characteristic lesions (Compston, 1988). Today, close to its $180^{\text {th }}$ anniversary, the disease is still not completely understood. MS is the most common inflammatory disease of the central nervous system (CNS) and it affects the female population more strongly, approaching a ratio of 3:1 (Compston \& Coles, 2008). Four clinical courses have been described for MS (Lublin et al., 2014 (latest revision); Ransohoff et al., 2015). The relapsing remitting course (RRMS) is the most common form (about $85 \%$ ) and is described by acute, symptomatic episodes followed by complete or partial remission. This course is often followed by a secondary progressive phase (SPMS), characterised by a gradual increase in symptom severity, while acute episodes occur less frequently. Primary progressive MS (PPMS) is diagnosed in only a fraction of patients (less than $10 \%)$ and during its course symptoms chronically worsen in the absence of acute episodes. Lastly, the diagnosis of clinically isolated syndrome (CIS) describes patients that present with an isolated acute episode, which cannot yet be attributed to MS due to a lack of dissemination in time. However, many (30-70\%) CIS patients are later diagnosed with MS (Miller et al., 2005).

\section{I.1.1. Aetiology}

The aetiology of MS is undoubtedly complex and there have been implications for a large variety of contributing factors. Arguing for a pronounced genetic component, the MS concordance rate was shown to be $25 \%$ between monozygotic twins (Willer et al., 2003). Genome-wide association studies (GWAS) have implicated the human leukocyte antigen alleles as a prominent risk factor. Amongst other susceptibility loci, T-helper cell differentiation genes have been identified (International Multiple Sclerosis Genetics Consortium et al., 2007, 2011). However, despite their sibling's affliction, the majority of monozygotic twins do not develop MS. Therefore, genetics cannot be the sole influencing 
factor. Among the non-genetic risk factors that have been identified are viral infection, smoking, Vitamin D deficiency and traumatic head injury at young age (Marrie, 2004; Montgomery et al., 2017). The identification of these risk factors, GWAS data and the work on MS animal models (most prominently experimental autoimmune encephalomyelitis, EAE, see page 4), have led to the identification of MS as an autoimmune disease. In EAE, CD4 ${ }^{+} \mathrm{T}$ cells have been identified as the mediators of disease induction (Ben-Nun et al., 1981) and the human T-cell repertoire is known to host potentially auto-reactive $\mathrm{CD}^{+}{ }^{+} \mathrm{T}$ helper cells (Martin et al., 1992; O'Connor et al., 2001). Further, inflammatory infiltrates have been identified in all MS lesion types (Lucchinetti et al., 2000). Subsequently, targeting immune cells has become a successful approach in MS therapy (Hohlfeld \& Wekerle, 2004). Two hypotheses have been developed to explain how the immune system could be primed against self-antigens (see also chapter I.2). Pathogens have been proposed to yield antigens that resemble CNS self-antigens and could incite cross-reactions (molecular mimicry). Indeed, it has been shown that human T cell clones specific for MBP can be activated by viral peptides (Wucherpfennig \& Strominger, 1995). Alternatively, Wilkin's primary lesion hypothesis argues that self-antigens could be presented to immune cells as a consequence of debris clearing, following a traumatic event inside the CNS. The identification of head trauma mentioned above argues in support of this hypothesis (Montgomery et al., 2017).

\section{I.1.2. Grey matter pathology in MS}

White matter lesions are an important hallmark of MS development and for most of the $20^{\text {th }}$ century MS was therefore considered a typical white matter disease. Although already described in the late $19^{\text {th }}$ century (e.g. Dejerine, 1884; Brauer, 1898), grey matter pathology only recently re-entered the spotlight of MS research (Kidd et al., 1999). Symptomatic for the ignorance with which it was met during the last century by many in the field of MS research, a highly cited review by Compston and Coles only mentions grey matter pathology on a side note (Compston \& Coles, 2008; 687 citations on PubMed as of 21.12.17). It has been argued comprehensibly that this negligence could mainly be attributed to insufficient power of the available diagnostic tools (Figure 1; Geurts et al., 2012). With the advent of new, high-powered devices for Magnetic Resonance Imaging (MRI) and improved 
immunohistochemistry methods, the research into MS grey matter pathology has experienced an upsurge. Demyelination of the cortex has meanwhile been shown to be very prominent, in extreme cases reaching 70\% (Kutzelnigg et al., 2005) and cortical lesions have been found in $60-80 \%$ of multiple sclerosis patients (Hulst \& Geurts, 2011). Meningeal inflammation and the associated lesions have been linked to neuronal loss and the progression of clinical decline in (primary and secondary) progressive MS patients (Bjartmar et al., 2003; Howell et al., 2011; Choi et al., 2012). Likewise, grey matter pathology has been shown to correlate more strongly with clinical disability than white matter pathology (Schlaeger et al., 2014; Steenwijk et al., 2016). It is very likely that grey matter pathology is not exclusively consequential of white matter pathology, as grey matter lesions can be found already in the early stages of MS, were they have again been strongly associated with meningeal inflammation (Bjartmar et al., 2000; Wegner et al., 2006; Lucchinetti et al., 2011). Neurodegenerative events can also be evident already at the time of diagnosis (Barkhof et al., 2009). For example, cortical atrophy is detectable in early RRMS patients (Chard et al., 2002). Therefore it becomes imperative to develop animal models of autoimmune grey matter pathology in order to allow us to understand and hopefully one day counteract cognitive decline in MS patients.

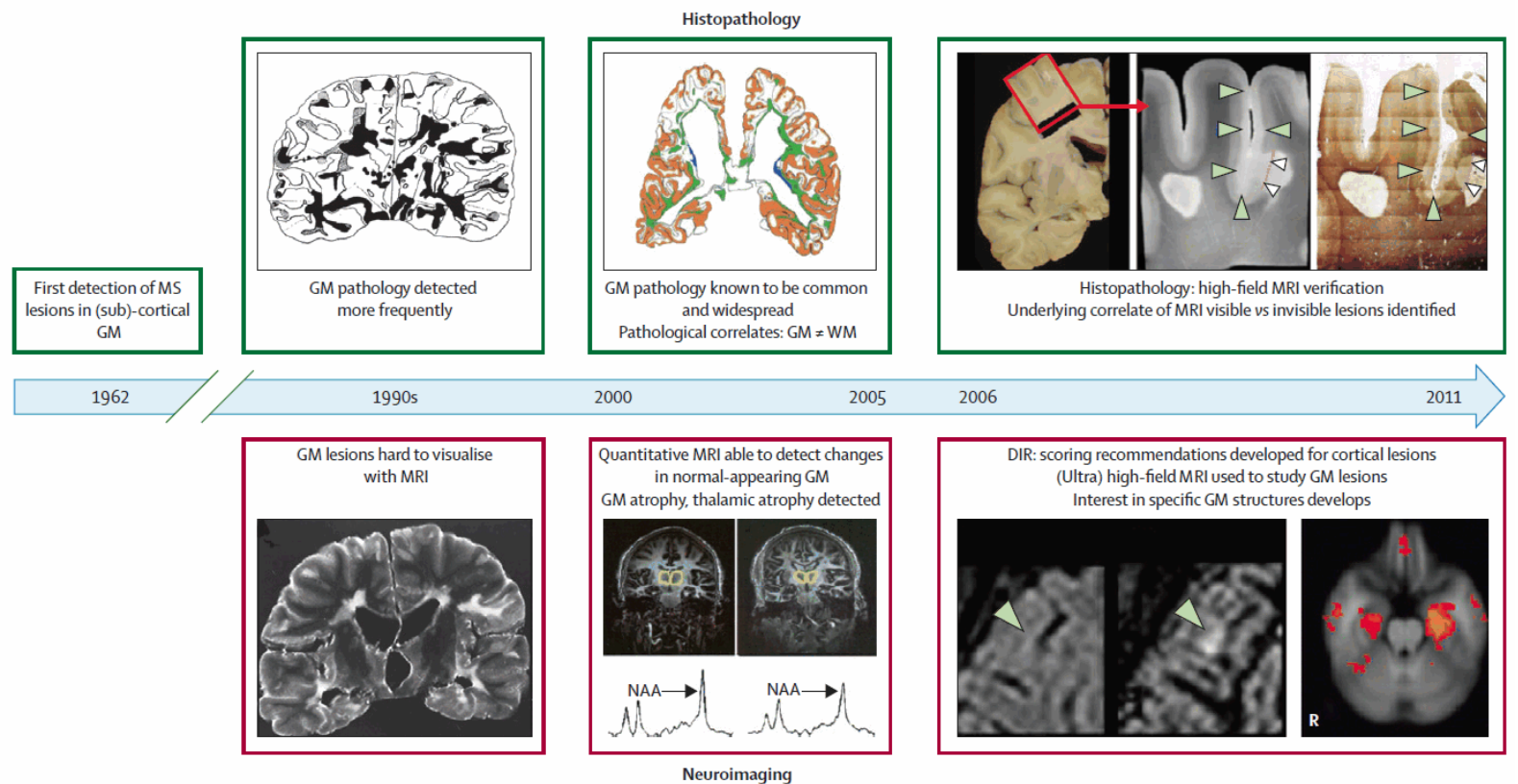

Figure 1: Timeline of developments in grey matter imaging and pathology in multiple sclerosis $\mathrm{MS}=$ multiple sclerosis. $\mathrm{GM}=$ grey matter. $\mathrm{WM}=$ white matter. $\mathrm{NAA}=\mathrm{N}$-acetyl aspartate. $\mathrm{DIR}=$ double inversion recovery. Adapted from Geurts et al., 2012. 


\section{I.2. Experimental Autoimmune Encephalomyelitis - EAE}

As mentioned above, EAE is the prototypic animal model for many aspects of MS. Its development into a proper model started in the 1930s when Thomas Rivers injected rhesus monkeys with rabbit CNS homogenate, tracing perivascular demyelinating lesions back to an immune response against the CNS matter (Rivers et al., 1933). It has since been refined and established in a broad variety of animals reaching from non-human primates to rodents. In rodents, the disease is characterized clinically by an ascending paralysis and pathologically by CNS inflammation caused by the infiltration of auto-reactive immune cells ( $T$ cells and monocytes) into the CNS. Classical (myelin) active EAE (aEAE), as it is used today, is based on an active immunization with myelin proteins or peptides (the most common are myelin basic protein (MBP), myelin oligodendrocyte protein (MOG) and proteolipid protein (PLP)) or CSF homogenate, both together with an immuno-stimulant, for example Complete Freund's Adjuvant (CFA), a mineral oil emulsion containing heat-inactivated Mycobacterium tuberculosis.

Based on the EAE model, the three-compartment model of EAE and MS was proposed (Figure 2; 't Hart et al., 2008, 2009). According to this model, the peripheral lymph nodes (afferent compartment) contain potentially auto-reactive $T$ (and $B$ ) cells. In $E A E$, autoreactive $\mathrm{T}$ cells are induced via immunization with an antigen, while in MS their induction might result from an infection (molecular mimicry) or take place in the draining compartment after the occurrence of a primary lesion inside the CNS (Wilkin's primary lesion hypothesis). After overcoming the BBB, in the target compartment, the effector cells recognize their cognate antigen through interaction with local antigen presenting cells (APCs), triggering an inflammatory cascade that causes local damage. When the resultant debris is cleared to the draining lymph nodes (draining compartment) and presented by local APCs, the generation of new autoreactive T cells is triggered. The circle is closed when these cells are released into the afferent compartment, where they in turn either dampen or aggravate the ongoing autoimmune process. 


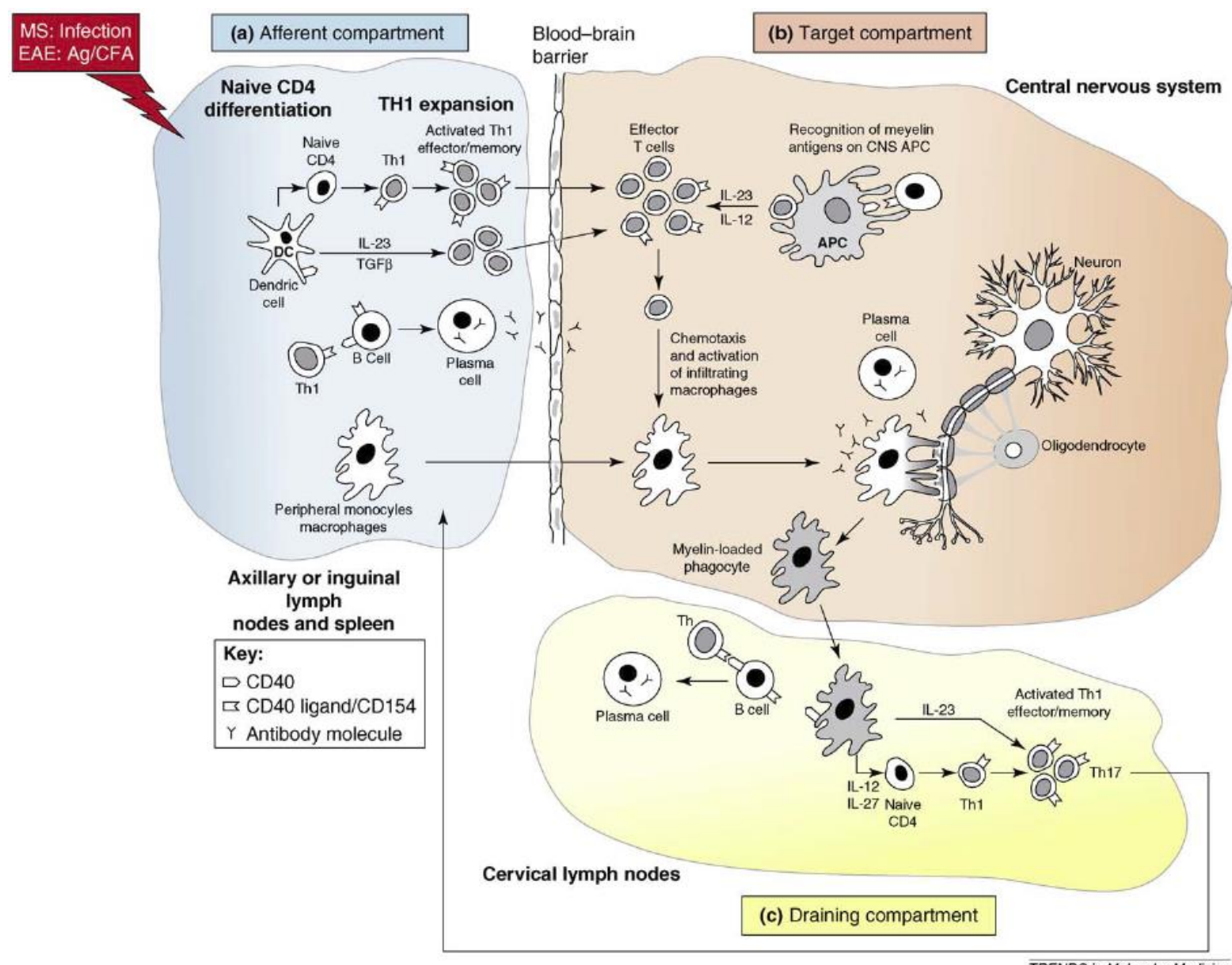

Figure 2: Three-compartment model for the pathogenesis of EAE and MS.

(a) The afferent compartment (blue) contains autoreactive T-cells. In the EAE model, these are actively induced by immunization with antigen $(\mathrm{Ag})$ emulsified in complete Freund's adjuvant (CFA) (red box); whereas in MS, the presumed trigger is infection with an unidentified pathogen. (b) These T cells collect in the spleen before migrating to the target compartment (pink), where they are engaged in cognate interactions with local APCs. The resulting cascade of pathophysiological reactions leads to injury. (c) Tissue debris is cleared from the CNS and emerges within APCs located in the CNS draining compartment (yellow), comprising the cervical and lumbar lymph nodes and spleen. This leads to the activation of new autoreactive T-cell specificities. When released into the afferent compartment, the activated T cells can either mitigate or exacerbate the ongoing autoimmune reaction. Adapted from 't Hart et al. 2009.

The second method of EAE induction is via passive-transfer (ptEAE; Paterson, 1960). Here, T cells are primed against specific CNS antigens by active immunization, isolated from draining lymph nodes, cultured and subsequently transferred into recipient animals. Owing to this approach, $\mathrm{CD}^{+}{ }^{+} \mathrm{T}$ cells were originally identified as the culprits of EAE (Ben-Nun et al., 1981). By in vitro manipulation, cultured T cells can be virally transduced to express fluorescent proteins (Flügel et al., 1999). This labelling introduces the possibility of tracking specific cells on their way to and inside the CNS. After i.v. injection, MBP-specific T cells ( $T_{M B P}$ cells) are not able to directly enter the CNS. Instead, they accumulate in spleen and lung, where their 
phenotype is changed to a migratory profile. This reprogramming consists of an upregulation of chemokines and adhesion molecules (e.g. CXCR3 and Ninurin-1) and a downregulation of activation markers (IFNY, IL-17, CD25, OX40) and allows the T cells to pass the BBB (Flügel et al., 2001; Odoardi et al., 2012). Before infiltrating the CNS, TMBP cells scan the inside wall of leptomeningeal blood vessels prior to extravasation.

\section{I.2.1. T-cell entry into the CNS}

In order to enter the CNS, T cells (and other immune cells) must pass the BBB. Among the proposed sites of this entry are the blood-leptomeningeal barrier, the BBB inside CNS parenchymal vessels and the blood-CSF-barrier in the choroid plexus (Reboldi et al., 2009; Ransohoff \& Engelhardt, 2012; Schläger et al., 2016). Independently of entry route, leukocyte adhesion to the CNS vasculature is a prerequisite for extravasation and consists of a multi-step process, governed by the interaction of signalling and adhesion molecules of leukocytes and endothelial cells of the blood vessels. The first step of this process, rolling of leukocytes on the vessel wall, is signified by transient interactions between selectins on the vascular endothelial cells and their ligands on the leukocytes, drastically reducing their speed. This process has further been shown to be mediated by the interaction of integrins VLA-4 (Very Late Antigen-4, alternatively known as $\alpha 4 \beta 1$ ) and LPAM-1 (lymphocyte Peyer's patch adhesion molecule 1) on leukocytes and adhesion molecules on the vascular side (vascular cell adhesion molecule (VCAM) and mucosal vascular addressin cell-adhesion molecule 1 (MADCAM1)). The next step, leukocyte arrest and crawling, is triggered by the binding of chemokines presented by vascular endothelial cells to G-protein coupled receptors on the leukocyte surface. This results in an increase in integrin-affinity (VLA-4 and lymphocyte function-associated antigen-1 (LFA-1)) to their endothelial ligands (VCAM and intracellular adhesion molecules (ICAMs)), thus facilitating intravascular leukocyte crawling (Ley et al., 2007; Bartholomäus et al., 2009). Of note, the crucial step in this adhesion cascade seems to be VLA-4-dependent, as treatment with VLA-4-blocking antibody has been effective in inhibiting $\mathrm{T}_{\mathrm{MBP}-c e l l}$ adhesion in spinal cord (SC) leptomeningeal vessels and $\mathrm{EAE}-$ development in the Lewis rat; in the human disease, the $\alpha 4$-blocker Natalizumab is efficacious in the treatment of RRMS (Bartholomäus et al., 2009; Goldenberg, 2012). The 
CCR6-CCL20 (Chemokine C-C receptor 6 and -ligand 20) axis is suggested to mediate Th17cell entry into the brain, while the entry of Th1 cells into the SC via the meninges is proposed to be mediated by CXCR3 (Chemokine C-X-C receptor 3) and VLA-4 (Stromnes et al., 2008; Reboldi et al., 2009; Rothhammer et al., 2016). In the Lewis rat EAE model, the method of intravital two-photon laser scanning microscopy (TPLSM) has been used to visualize the entry process of $\mathrm{T}_{\mathrm{MBP}}$ cells into the SC. Three levels of T-cell invasion have been proposed (Figure 3). The first level consists in the intraluminal crawling of $T_{\text {MBP }}$ cells, scanning the inner endothelial vessel wall. After diapedesis through the vessel wall into the SC leptomeninges, $T_{M B P}$ cells scan the perivascular space (level 2), finally detaching from the abluminal vessel wall and migrating through the leptomeninges (level 3). Here, the TMBP cells encounter their antigen at local APCs, become re-activated and subsequently penetrate deeper into the SC parenchyma (Bartholomäus et al., 2009). This local re-activation in SC leptomeninges and parenchyma was visualized in situ by Lodygin and colleagues, using a

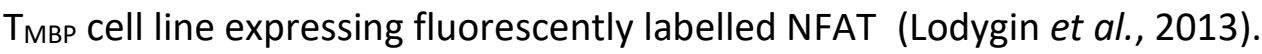

Invasion steps of encephalitogenic T cells into their target organ

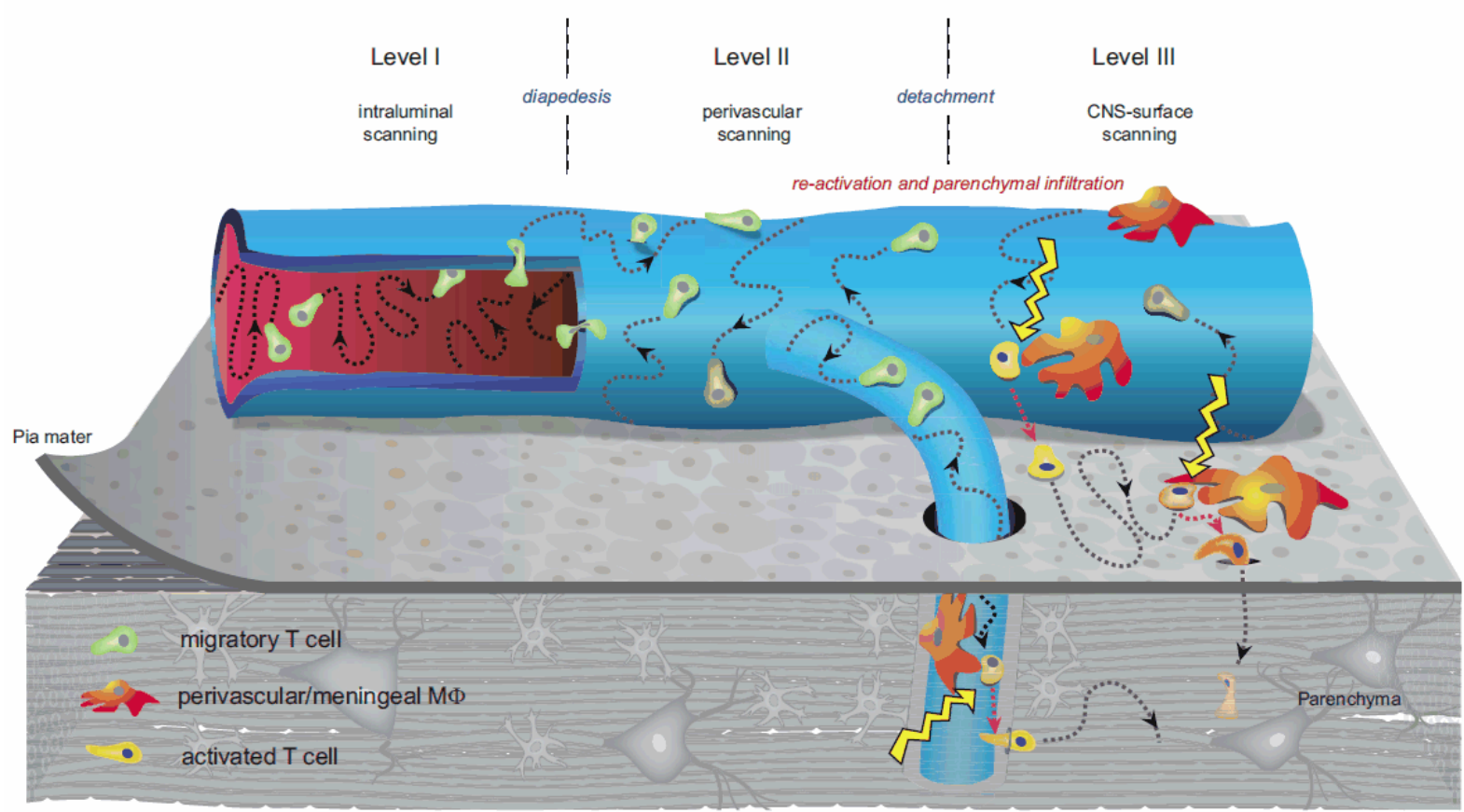

Figure 3: Schematic picture illustrating the invasion steps of $\mathrm{T}_{\text {MBP-GFP }}$ cells into the CNS tissue.

(Level I) TMBP cells move intraluminally, scanning the inner endothelial vessel wall. (Level II) After diapedesis through the vessel wall, $T_{\text {MBP }}$ cells scan the perivascular space, moving on the abluminal vessel wall. (Level III) $T_{M B P}$ cells detach from the vessel and migrate through the leptomeninges. Here, the $T_{M B P}$ cells encounter their antigen at local APCs, become re-activated and subsequently penetrate deeper into the SC parenchyma. Adapted from Bartholomäus et al., 2009 
Despite the prominent need outlined above, few EAE variants exist to model primary grey matter pathology. In marmosets it is possible to induce cortical lesions by inciting immune reactivity against PLP or MOG (Pomeroy et al., 2005; Merkler, Boscke, et al., 2006; 't Hart et al., 2017). However, the general limitations of primate models (husbandry, life-cycle, lack of genetic manipulation) prohibit a widespread use of this approach. In rodents, immunization of Dark Agouty rats with CNS homogenate leads to a disease course with relapsing remitting and chronic characteristics as well as synaptopathy and cortical atrophy (Tambalo et al., 2015). In Lewis rats immunized against MOG, cortical injection of tumour necrosis factor alpha (TNF $\alpha$ ) and interferon gamma (IFN $\gamma$ ) leads to the formation of transient cortical demyelinating lesions (Merkler, Ernsting, et al., 2006). Storch and colleagues further described that some Lewis rat strains are susceptible to the development of cortical lesions in response to active immunization with MOG (Storch et al., 2006). Also astrocytic or neuronal antigens can be used to induce cortical pathology. Indeed targeting astrocytes by the passive transfer of $\mathrm{S} 100 \beta$-specific T cells elicits inflammation in the entire CNS, but only mild clinical symptoms (Kojima et al., 1994). Huizinga and colleagues used neurofilament light protein as an antigen to immunize $A B H$ mice. This protein was chosen, as antibodies against it are frequently found in the CSF of progressive MS patients (Silber et al., 2002). While this approach was successful in the induction of clinical disease and produced prominent grey matter lesions as well as axonal damage in the SC, an affliction of the cortex could not be demonstrated (Huizinga et al., 2007, 2008). Derfuss and colleagues observed that MS patients show autoantibodies and Th1/Th17 cell reactivity against contactin-2/transiently expressed axonal glycoprotein 1 (TAG-1), a protein that is expressed in a variety of neuronal populations (Derfuss et al., 2009). The resulting rat model shows mild clinical symptoms and inflammation is most pronounced in the white matter of brain and SC, whereas grey matter inflammation is mainly restricted to perivascular areas. Finally, the neuronal EAE model this thesis is concerned with is based on the encephalitogenic potential of the neuronal antigen $\beta$-Synuclein; it is described in detail in the next chapter. 


\section{I.2.3. The $\beta$-Synuclein neuronal EAE model}

The small, soluble proteins of the Synuclein family $(\alpha-, \beta-\& \gamma$-Synuclein) are found abundantly in presynaptic terminals throughout the CNS (George, 2002). They were shown to regulate the size of the presynapse and play a role in organizing the synaptic vesicle pool (Murphy et al., 2000; Vargas et al., 2017). Further, they have been implicated in synaptic vesicle exo- and endocytosis, as well as membrane regulation (Middleton \& Rhoades, 2010; Westphal \& Chandra, 2013; Vargas et al., 2014). The most prominent member of the Synuclein family is $\alpha$-Synuclein, notorious for its role in the formation of Lewy bodies in the dopaminergic neurons of sporadic and hereditary forms of Parkinson's disease (Mouradian, 2002). $\beta$-Synuclein, on the other hand, has been shown to counteract the generation of these pathogenic aggregates (Wright et al., 2013; Brown et al., 2016). In humans, $\beta$-Synuclein is most abundantly found in the cortex, thalamus, hippocampus, caudate nucleus and in the amygdala (Lavedan et al., 1998; Galvin et al., 2001; Giasson et al., 2001). In the rat, where $\beta$-Synuclein shares $98 \%$ homology with the human protein (Altschul et al., 1990; SNBC, ID: 6620 \& 113893), the expression is most prominent in the cortex, hippocampus, olfactory bulb, striatum, thalamus and to a lesser extent in the brain stem (Jakes et al., 1994; Iwai et al., 1995; Murphy et al., 2000; Giasson et al., 2001).

Examining potential targets of autoimmune reactivity in the CNS, Mor and colleagues were investigating CNS peptides with an association to neurodegeneration and a predicted fit to the Lewis rat MHC class II I-A molecule RT1.B1 (Mor et al., 2003; Mor \& Cohen, 2006). In two studies they analysed a total of 70 peptides originating from 40 different CNS proteins, such as prion protein, Synaptotagmins, Huntingtin, postsynaptic density proteins and the Synucleins. Only two of the investigated peptides were found to induce an EAE-like phenotype in recipient rats, both subsets of the protein $\beta$-Synuclein. The $\beta$-Synuclein $93-111$ peptide ( $\beta S y n)$ was found to be capable of the induction of active EAE upon immunization and the generation of pathogenic $\beta$ Syn-specific $T$ cell lines ( $T_{\beta S y n}$ cells). In order to induce ptEAE, relatively high numbers of $\mathrm{T}_{\beta \mathrm{Syn}}$ cells were transferred $\left(2 \times 10^{7}\right.$ cells) and a pretreatment with radiation or cyclophosphamide was shown to exacerbate EAE symptoms. One additional work was published on this model, addressing autoimmune spread in $\beta$-Synuclein induced EAE (Kela-Madar et al., 2009). Here, the encephalitogenic potential of the $\beta$-Synucleing2-110 peptide in irradiated or cyclophosphamide-treated rats was confirmed. 
Kela-Madar and colleagues further demonstrated the generation of $\mathrm{T}$ and $\mathrm{B}$ cells specific for other neuron- and myelin-antigens after the primary encephalitogenic attack. While inflammatory infiltrates were described in the cerebral cortex in the original publication, $T_{\beta S y n}$-cell infiltration into the brain or the consequences thereof were never specifically addressed in any of these studies.

Laying the foundations for the work presented here, the neuronal $\beta$ Syn EAE model was examined in our lab by Corinna Schlosser in her dissertation (Schlosser, 2013). Amongst other things, she characterized the cells of the $T_{\beta S y n}$ line as $C D 4^{+} C D 8^{-}$, exhibiting a mixed Th1/Th17 phenotype and identified their expression profile using quantitative real-time PCR (qPCR). Using an ex vivo migration essay, chemokine responses were measured. The cells were found to be very similar to $\mathrm{T}_{\mathrm{MBP}}$ cells, but showed a strikingly different infiltration pattern, homing preferentially into the grey matter of brain and SC. Further, the occurrence of atypical symptoms in a small fraction of $\mathrm{T}_{\beta S y n}$-cell recipient animals was described. 


\section{I.3. Aims}

The aim of this thesis was to characterize active and passive-transfer EAE in the BSyn neuronal EAE model. To this end, wild-type and receptor transgenic Lewis rats were immunized against $\beta$ Syn or transferred with $\beta$ Syn-reactive encephalitogenic T-cell lines. Further, I investigated which factors influenced T-cell homing into the target CNScompartment by following four approaches: (1) Intravital TPLSM to track motility patterns of fluorescently labelled T cells at the CNS vascular bed and inside the target compartment. (2) Interference with integrin- and chemokine-signalling. (3) Transcriptome analysis using next generation sequencing (NGS). (4) Adeno-associated virus-mediated local increase in $\beta S y n-$ antigen availability. Finally, to elucidate the consequences of inflammation on the brain, longitudinal MRI was performed in passive-transfer and active EAE and the density of synaptic spines on neurons of cortical layers $2 \& 3$ was examined. 


\section{II.Material}

\section{II.1. Proteins}

$\beta$-Synuclein $39-111$ peptide (amino acid sequence: LKPEEVAQEAAEEPLIEPL)

Albumin from chicken egg white (OVA)

Myelin basic protein (MBP) from guinea pig
Peptide synthesis service, Biochemical Institute, Charité Berlin

Sigma Aldrich

In-house production

\section{II.2. Antibodies}

CD11a (integrin $\alpha$ L, anti-LFA-1, clone WT.1) Serotec

CD11b-Setau647 (Hybridoma clone OX-42) In-house production

CXCR3 (clone XR3.2) Courtesy of Thomas Issekutz

VLA-4 (anti-CD49d, clone TA-2) Courtesy of Thomas Issekutz

\section{II.3. Media and buffers}

ACK buffer

$0.15 \mathrm{~mol} / \mathrm{L} \mathrm{NH}_{4} \mathrm{Cl}$ (Roth)

$1 \mathrm{mmol} / \mathrm{L} \mathrm{KHCO}_{3}$ (Roth)

$0.1 \mathrm{mmol} / \mathrm{L} \mathrm{Na} 2 \times$ EDTA (Roth)

adjusted to $\mathrm{pH} 7.2$ - 7.4 with $\mathrm{HCl}$ (Roth)

Eagles HEPES (EH) medium

$188.3 \mathrm{~g} / 10 \mathrm{~L}$ DMEM powder (Invitrogen)

HEPES 1M (Roth)

Freezing medium

$80 \%$ heat-inactivated horse serum

(Biochrom AG)

$10 \%$ TCM (in-house production) 
$10 \%$ DMSO (Roth)

Isotonic Percoll

9x Vol. Percoll (GE Healthcare)

1x Vol. 10x PBS (in-house production)

Lymphocyte separation medium LSM 1077

PAA

Percoll Underlay

$7 \mathrm{~mL}$ Isotonic Percoll

3.9 mL 1x PBS (in-house production)

Phosphor buffered salt solution (PBS, 10x)

$8.10 \mathrm{mM} \mathrm{Na}_{2} \mathrm{HPO}_{4}$ (Roth)

$1.47 \mathrm{mM} \mathrm{NaH}_{2} \mathrm{PO}_{4}$ (Roth)

$137 \mathrm{mM} \mathrm{NaCl}$ (Roth)

$2.68 \mathrm{mM} \mathrm{KCl}$ (Roth)

adjusted to $\mathrm{pH} 7.2$

Restimulation Medium

TCM (in-house production)

$1 \%$ rat serum (in-house production)

T cell growth medium (TCGM)

TCM (in-house production)

$10 \%$ heat-inactivated horse serum

(Biochrom AG)

$10 \%$ conditioned medium from splenocytes treated with the mitogen Concanavalin $A$ (ConA supernatant; in-house production)

T cell medium (TCM) DMEM (Invitrogen) $10 \mathrm{ml}$ non-essential amino acids (Invitrogen) 
$10 \mathrm{ml}$ penicillin / streptomycin (Invitrogen)

$10 \mathrm{~mL}$ sodium pyruvate (Invitrogen)

$10 \mathrm{~mL}$ L-glutamine (PAN Biotech $\mathrm{GmbH}$ )

$10 \mathrm{~mL}$ L-asparagine monohydrate (Sigma

Aldrich)

$4 \mu \mathrm{L} 2$ 2- $\beta$-mercaptoethanol (13.6 mol/L)

(Invitrogen)

Thawing medium

$90 \% \mathrm{EH}$ medium (in-house production)

$10 \%$ heat-inactivated foetal calf serum

(Biochrom AG)

II.4. Chemicals, reagents, sera, etc.

Agarose, Low Melt

Beads (BD CaliBRITE ${ }^{\mathrm{TM}}$ )

$\beta$-mercaptoethanol

Dextran Tetramethylrhodamine (2 Mio MW)

Dextran Texas $\operatorname{Red}^{\circledR}(3000 \mathrm{MW})$

Diethylether

Dimethyl sulfoxide (DMSO)

DMEM powder
Roth

BD Bioscience

Roth

Invitrogen

Invitrogen

Roth

Roth

Invitrogen 
Foetal Calf Serum (FCS)

G418-Sulphate (neomycin)

Gadovist $^{\circledR}, 1 \mathrm{mM}$ (Gad)

HEPES

Horse serum

Hydrochloric acid $(\mathrm{HCl})$

Incomplete Freund's Adjuvant

Isoflurane

Isotone sodium chloride solution ( $\mathrm{NaCl} 0.9 \%)$

Ketamine (10\%)

M. Tuberculosis H37Ra

Paraformaldehyde (PFA)

TRI Reagent ${ }^{\circledast}$

Trypsin EDTA (10-fold)

Xylariem
Biochrom AG

Invitrogen

Bayer

Invitrogen

Biochrom AG

Roth

Difco Laboratories

Abbott

B.Braun

Medistar Arzneimittelvertrieb $\mathrm{GmbH}$

Difco Laboratories

Roth

Sigma

PAA

Ecuphar 


\section{Methods}

\section{III.1. Wild-type Animals}

For all experiments Lewis rats on a LEW/Crl background (Rattus norvegicus) were used. The animals were bred and kept at the animal facility of the university medical centre Göttingen or obtained from Janvier (Le Genest St Isle, France). The animals were kept on a 12 hours light-dark cycle. They were provided with food ad libitum. All experiments were performed according to local regulations of animal welfare of Lower Saxony.

\section{III.2. Receptor-transgenic rat lines}

T cell receptor (TCR) cloning for the genesis of transgenic rats ( $\beta$ Syn-specific line $\beta$ SynTG \& MBP-specific line MBPTG) was performed in house by Dr. Alexandra Kitz and Dr. Dmitry Lodygin as described (Kitz, 2013). Briefly, established effector T cell lines were used in the reconstruction of $\beta S y n-$ and MBP-specific TCRs. After single-cell-dilution, clones were expanded and tested by restimulation. TCR $\alpha$ and $\beta$ chains were amplified and sequenced. Recombinant TCR $\alpha$ and $\beta$ chains were tested for successful combination by viral transfer into receptor-negative hybridoma. Lentiviruses carrying genes for two TCR chains and GFP as a fluorescent marker were then used for transduction of early Lewis rat embryos. This transduction was performed as reported (Mullins \& Mullins, 1996) by Dr. Henrike Fischer, then of the Institute of Cellular and Molecular Immunology, Department of Experimental Immunology, University Medical Centre Göttingen. Briefly, a solution containing concentrated lentivirus was injected into the perivetelline space of single cell embryos isolated from superovulated Lewis females. Injected zygotes were cultured overnight and as two-cell stage embryos transferred into the oviduct of pseudo-pregnant recipient Wistar females. Genotyping/Identification of founders was performed by FACS and PCR.

\section{III.3. Active EAE \& Immunization for the generation of T-cell lines}

6-8 week old female Lewis rat were immunized subcutaneously (into the base of the tail and into the hind limb popliteal cavity) with $150 \mu \mathrm{L}$ guinea pig MBP protein, $\beta$-Synuclein ${ }_{93-111}$ 
peptide or OVA $(1 \mathrm{mg} / \mathrm{mL})$ emulsified in an equal volume of complete Freund's adjuvant containing Mycobacterium tuberculosis $(2 \mathrm{mg} / \mathrm{mL})$. For $\mathrm{MBPTG}^{(\mathrm{T} /+)}$ rats, $100 \mu \mathrm{L}$ guinea pig MBP protein $(0.4 \mathrm{mg} / \mathrm{mL})$ and CFA $(1 \mathrm{mg} / \mathrm{mL})$ were used. The emulsion was prepared with the help of tuberculin glass syringes and a custom-made homogenizer. For the generation of primary T-cell culture, animals were sacrificed 10 days after immunization, except $\beta$ SynTG rats, which were sacrificed 6 days after immunization. The body weight of the animals was determined over the whole experimental period and animals were observed for disease symptoms. Clinical signs of classical EAE were measured by daily scoring of the animals according to Table 1. Animals were sacrificed when reaching a score of 3.5.

\section{III.4. Assessment of EAE clinical symptoms}

Clinical signs of EAE were assessed according to the score system indicated in Table 1. Animals were sacrificed when reaching a score of 3.5.

Table 1: Clinical symptoms of EAE

\begin{tabular}{|l|l|l|l|}
\hline \multicolumn{2}{|l|}{ Typical EAE symptoms } & \multicolumn{2}{l|}{ Atypical EAE Symptoms } \\
\hline Score & Symptoms & Score & Symptoms \\
\hline 0 & No clinical symptoms & 0 & No clinical symptoms \\
\hline 0.5 & $\begin{array}{l}\text { Reduced tail tone or partial tail } \\
\text { paralysis }\end{array}$ & $1^{*}$ & $\begin{array}{l}\text { Ataxia, occasional twitches and } \\
\text { scratching }\end{array}$ \\
\hline 1 & Tail paralysis & $2^{*}$ & $\begin{array}{l}\text { Frequent twitches and } \\
\text { scratching, slight imbalance }\end{array}$ \\
\hline 2 & Gait disturbance/Ataxia & $2.5^{*}$ & Pronounced imbalance \\
\hline 3 & Hind limb paralysis & $3^{*}$ & Spastic paresis of hind limbs \\
\hline 4 & Tetraparesis & $4^{*}$ & Tetraparesis \\
\hline 5 & Moribund & $5^{*}$ & Moribund \\
\hline
\end{tabular}

\section{III.5. Culture of packaging cells}

GP+E86 packaging cells, producing a replication-deficient eGFP or mCherry retrovirus, were used to transduce T cells. The retroviral vector pMSCV used for the gene transfer is derived from the murine embryonic stem cell virus (MESV) and promotes the transfer of a resistance to neomycin in combination with the eGFP or mCherry sequence. Before co-culturing with 
primary T cells, packaging cells were cultured in selection medium (T cell medium (TCM) containing $10 \%$ of foetal calf serum (FCS) and neomycin $(2 \mu \mathrm{g} / \mathrm{mL})$ in $10 \mathrm{~mL}$ cell culture dishes). The cells were kept under $5 \% \mathrm{CO}_{2}$ humidified atmosphere in an incubator at $37^{\circ} \mathrm{C}$. During cell culture the adhesive packaging cells form monolayers. Upon reaching a confluence of $70-80 \%$ the packaging cell lines were split. For that purpose the cells were washed once with 1 XPBS and then incubated for 3-5 min with the endopeptidase trypsin (10x stock solution diluted 1:10 with PBS). After detachment of the cells from the cell dish the digestion process by trypsin was stopped by adding medium containing $10 \%$ FCS. The desired amount of cells was taken and centrifuged to remove trypsin residues. After a centrifugation for $5 \mathrm{~min}$ with $1200 \mathrm{rpm}$ at $4^{\circ} \mathrm{C}$ the supernatant was discarded and the pellet was resolved in TCM containing $10 \%$ of FCS and $2 \mu \mathrm{g} / \mathrm{mL}$ neomycin. Before co-culturing with primary $T$ cells, the packaging cells were cultured for 2 days without any specific selection agent until a confluence of $70 \%$ was reached.

\section{III.6. Primary rat $\mathrm{T}$ cell culture}

T cells retrovirally engineered to express fluorescent proteins and reactive against $\beta$ Syn, MBP or OVA ( $T_{\beta S y n}, T_{M B P}$ or TovA) were generated as reported (Flügel et al., 1999). The cells were kept under $10 \% \mathrm{CO}_{2}$ humidified atmosphere at $37^{\circ} \mathrm{C}$. For establishing antigen-specific $\mathrm{CD}^{+} \mathrm{T}$ cell lines, cells of the draining lymph nodes (popliteal, inguinal and paraaortal LNs) of immunized animals were isolated in the preclinical phase of the disease at day 10 after immunization. In $\beta$ SynTG ${ }^{(T / T)}$ rats, the cells were isolated 6 days after immunization. The isolated LNs were minced and separated through a metal mesh. The cell suspension then was centrifuged $\left(1200 \mathrm{rpm}, 8 \mathrm{~min}, 4^{\circ} \mathrm{C}\right.$ ) and the cell pellet was washed once with Eagles HEPES (EH) medium. Subsequently, lymphocytes were adjusted to $2 \times 10^{6}$ per $\mathrm{mL}$ and cocultured with $1.5 \times 10^{5}$ per $\mathrm{mL}$ packaging cells. The cells were kept in a total volume of $100 \mu \mathrm{L}$ re-stimulation medium $(\mathrm{RM})$ in U-bottom 96-well plates containing their respective antigen (7 $\mu \mathrm{g} / \mathrm{mL} \beta$ Syn, $5 \mu \mathrm{g} / \mathrm{mL}$ BSyn for $\beta$ SynTG ${ }^{(\mathrm{T} / \mathrm{T})}$ cells, $10 \mu \mathrm{g} / \mathrm{mL}$ for MBP and OVA). Two days after the start of the primary cell culture, T cell growth medium (TCGF) was added (50 $\mu \mathrm{L}$ per well). TCGF contains the supernatant of murine splenocytes stimulated with the mitogen Concanavalin A (ConA supernatant). ConA supernatant contains the growth factor 
IL-2 which induces the proliferation of T cells in culture. At day 3 or 4 of primary cell culture $50 \mu \mathrm{L}$ of medium per well were removed and cells were transferred into flat bottom 96-well plates. After the transfer $100 \mu \mathrm{L}$ fresh TCGF containing neomycin $(1 \mu \mathrm{g} / \mathrm{mL})$ were added per well. Negative selection with neomycin was maintained for 10 days. The first stimulation of T cells was performed 7 days after start of the culture ( 5 days for $\beta$ SynTG ${ }^{(T / T)}$ cells). Firstly, $100 \mu \mathrm{L}$ medium per well were removed and subsequently $1.4 \times 10^{6}$ irradiated thymocytes in $100 \mu \mathrm{L}$ RM were added per well in the presence of the respective antigen $(7 \mu \mathrm{g} / \mathrm{mL} \beta$ Syn, $5 \mu \mathrm{g} / \mathrm{mL} \beta$ Syn for $\beta$ SynTG(T/T) cells, $10 \mu \mathrm{g} / \mathrm{mL}$ for MBP and OVA). The irradiation dose for the thymocytes (that were used as APCs) was 30 gray (Gy). Two days after re-stimulation $50 \mu \mathrm{L}$ TCGF were added in each well to propagate T-cell proliferation. Three to four days after restimulation, the T cell wells with the best viral transduction rate (measured by fluorescence intensity and the best growth capacity of the cells) were chosen and pooled into $60 \mathrm{~mm}$ dishes.

\section{III.7. Re-stimulation of T cells}

In the further propagation cycles $T$ cells were re-stimulated in $60 \mathrm{~mm}$ dishes in a weekly rhythm. For this purpose $3.5 \times 10^{6}$ resting $T$ cells were co-cultured with $70 \times 10^{6}$ irradiated thymocytes (30 Gy) per dish in RM containing the appropriate concentration of the antigen (7 $\mu \mathrm{g} / \mathrm{mL} \beta$ Syn, $5 \mu \mathrm{g} / \mathrm{mL} \beta$ Syn for $\beta$ SynTG(T/T) cells, $10 \mu \mathrm{g} / \mathrm{mL}$ for MBP and OVA). At day 2 after re-stimulation TCGF was added to the T cell culture to promote further proliferation. To maintain optimal density $T$ cells were transferred into $10 \mathrm{~cm}$ culture dishes and split further when necessary.

\section{III.8. Passive transfer EAE}

Passive transfer EAE (ptEAE) was induced by intravenous injection of activated, encephalitogenic T-cell blasts (day 2 after stimulation) in $1 \mathrm{~mL}$ of EH medium into the tail vein of healthy Lewis rats (between 6-8 weeks of age) that were narcotized with diethlyether. Unless stated differently, the following amount of cells was injected: $T_{\beta S y n}$ 8-9 $910^{6}$ cells, $T_{\beta S y n(T /+)} 6-7 \times 10^{6}$ cells, $T_{\beta S y n(T / T)} 2-3 \times 10^{6}$ cells, TovA $5 \times 10^{6}$ cells, $T_{M B P} 5 \times 10^{6}$ cells. 
The body weight of the animals was determined over the whole experimental period and animals were observed for disease symptoms. Clinical signs of classical EAE were measured by daily scoring of the animals according to Table 1 . Animals were sacrificed when reaching a score of 3.5. The injection of Tova cells did not induce EAE.

\section{III.9. Intravital imaging with the two-photon laser scanning microscope}

Two-photon laser scanning microscopy (TPLSM) was used for imaging motility patterns of fluorescently labelled T cells within CNS compartments in living animals. In order to access the dorsal spinal cord meninges the "open spine window" procedure was performed as previously described (Bartholomäus et al., 2009). To access the parietal cortex the "open skull window" preparation was performed as previously described (Schlosser, 2013).

\section{III.10. Surgical procedure for intravital two-photon laser scanning microscopy}

Animals were anaesthetized by intra-muscular injection of $10 \mathrm{mg} / \mathrm{kg}$ xylazine combined with $50 \mathrm{mg} / \mathrm{kg}$ ketamine. Thereafter, animals were intubated via a small incision of the trachea and immediately ventilated with $1.5-2 \%$ isoflurane using a custom built ventilation system. This system was driven by an Inspira Advanced single animal pressure-controlled ventilator (Harvard Apparatus, Holliston, USA). Medical oxygen and pressurized air were routed through an isoflurane vaporizer (Uno Roestvaststaal BV, Zevenaar, Netherlands) and several gas reservoirs. During imaging, animals were stabilized in a custom-made microscope stage and their body temperature regulated and maintained $\left(36-37^{\circ} \mathrm{C}\right)$ via a heated pad connected to a custom-built thermo-controller. Fluid supply during imaging sessions was warranted by using a perfusor (Ismatec SA, Wertheim, Germany) device. For intravital TPLSM recordings in the dorsal spinal cord meninges, the "open spine window" procedure was performed as previously described (Bartholomäus et al., 2009). Briefly, a midline skin incision of $2-3 \mathrm{~cm}$ was performed followed by subsequent detachment of the paravertebral musculature from the spine. Thereafter, a laminectomy on one of the three exposed vertebral bodies was performed. To access the parietal cortex the "open skull window" preparation was performed as previously described (Schlosser, 2013). Briefly, the connective tissue attached 
to the skull was carefully removed. Subsequently, a high-speed micro-drill with a prophyclean dental drill tip was used to cut an ellipsoid area of the skull between the coronal, transverse and sagittal suture and the dura mater carefully removed. For all preparations, tissue was immediately covered with sodium-chloride solution (B.BRAUN, Melsungen, Germany) after exposure in order to prevent dehydration.

\section{III.11. Two-photon laser scanning microscopy}

Two photon laser scanning microscopy (TPLSM) was performed using a Zeiss Laser Scanning Microscope 710 (Carl Zeiss AG, Oberkochen, Germany) combined with a Coherent $10 \mathrm{~W}$ Ti:Sapphire chameleon laser (Coherent Inc., Santa Clara, USA), running the Zeiss ZEN 2012 software (Carl Zeiss AG). The excitation wavelength was tuned to $880 \mathrm{~nm}$ or $1010 \mathrm{~nm}$ and routed through a 20x water NA1.0 immersion objective W Plan Apochromat (Carl Zeiss AG). Typically, areas of $424.27 \times 424.27 \mu \mathrm{m}$ (512 x 512 pixel) width were scanned and 50-100 $\mu \mathrm{m}$ z-stacks were acquired. The acquisition rate during bidirectional scanning was approximately $1.3 \mathrm{~s}$ per z-plane including 2 times line-averaging. Importantly, for reproducible motility analyses, the interval time was kept exactly to $32 \mathrm{sec}$ while varying the numbers of z-sections (usually between 18 and 27) or distances between 2 z-planes (stepsize, typically between 2 and $5 \mu \mathrm{m}$ ). Emitted fluorescence was detected using nondescanned detectors equipped with 442/46nm, 550/49nm and 624/40nm band-pass filters. Blood vessels were labelled by injection of 2.000.000 MW dextran tetramethylrhodamine. Meningeal phagocytes were labelled by intrathecal injection of 3000 MW Dextran Texas Red. In general, imaging of the parietal cortex and of the dorsal SC meninges was performed with $10-15 \%(880 \mathrm{~nm})$ or $60-70 \%(1010 \mathrm{~nm})$ of the laser power. For 3D time-lapse movies, scanning intervals of $32 \mathrm{sec}$ and 58 cycles were used. After completion of the imaging session the animals were sacrificed. The brain and SC tissue were used for further histological analysis. To label myeloid cells, a monoclonal antibody against CD11b (Hybridoma clone OX-42) labeled with the fluorescence dye SeTau647 was injected intravenously 16 hours before TPLSM. 


\section{III.12. Analysis of time-lapse videos}

Acquired 3D time-lapse videos were analysed with the help of the Imaris 8.0.1 software (Bitplane AG, Zurich, Switzerland). In a first step, the automatic cell tracking function was used. Afterwards, the automatically generated T cell tracks were evaluated and corrected manually. Quantifications were done manually or in a semi-automated fashion using the cell tracking feature of Imaris. Subsequently, the percentage of rolling and crawling cells was calculated. The track properties of intraluminal and extravasated crawling $\mathrm{T}$ cells were exported to Microsoft Excel 2010 (Microsoft Corp., Redmond, USA) for further analysis. For the analysis of motile extravasated cells, tracks with a lower duration than $10 \mathrm{~min}$ and stationary cells were excluded. The generation of graphs and statistical evaluation was performed using GraphPad Prism 7.03 software (GraphPad Software, Inc., La Jolla, USA). For the generation of figures, single z-stacks or overview image files acquired with the TPLSM were exported as maximum intensity projections in TIF format by using the Zen 2012 software. The TIF files were loaded in the Fiji software (Schindelin et al., 2012) and the images were corrected in tones and contrast for the different channels using the curve function. Moreover, three dimensional z-stacks or overviews of the imaging field were exported into the Imaris 8.0.1 software for 3D reconstruction.

\section{III.13. Animal preparation and organ processing}

Rats were sacrificed at time points of interest after adoptive transfer by $\mathrm{CO}_{2}$ inhalation. All dissected organs were kept in $\mathrm{EH}$ medium on ice. In order to measure the number of infiltrated $T$ cells in organs of interest, the different tissues were first weighed and then further processed as described below.

\section{III.14. Isolation of PBMCs from blood}

Blood was taken by cardiac puncture in $200 \mu \mathrm{L} 80 \mathrm{mM}$ EDTA containing syringes. Blood samples were diluted with equal volume of 1x PBS und layered over 0.5 volume lymphocyte separation medium. Samples were centrifuged at $2000 \mathrm{rpm}, 22^{\circ} \mathrm{C}$ for $30 \mathrm{~min}$ with minimal acceleration ramp and brakes turned off. Peripheral blood mononuclear cells (PBMCs) were 
taken from the interphase between plasma and separation medium, transferred into new Falcon tube and washed with cold $1 \times$ PBS.

\section{III.15. Isolation of leukocytes from spleen}

Single cell suspension from spleen was prepared by homogenizing tissue through a metal grid in $\mathrm{EH}$ medium. After centrifugation at $1200 \mathrm{rpm}$ for 8 minutes at $4^{\circ} \mathrm{C}$, the cell pellet was resuspended and incubated for 4 minutes in $4 \mathrm{~mL}$ ACK-buffer for erythrocyte lysis. Subsequently cells were washed in cold $1 x$ PBS and resuspended in $15 \mathrm{~mL}$ EH medium.

\section{III.16. Isolation of leukocytes from CNS and CNS meninges}

Brain and spinal cord were dissected and the meninges were removed from the parenchyma. Tissues were homogenized in $\mathrm{EH}$ medium through a metal grid und suspension were centrifuged for 8 minutes at $1200 \mathrm{rpm}$ at $4^{\circ} \mathrm{C}$. To remove infiltrated leukocytes from myelin, pellets were resuspended in $25 \mathrm{~mL} \mathrm{EH}$ medium and mixed with $10 \mathrm{~mL}$ isotonic Percoll solution. Afterwards $10 \mathrm{~mL}$ Underlay Percoll was gently pipetted under the cell suspension und centrifuged with $2780 \mathrm{rpm}$ for 30 minutes at RT with minimum acceleration ramp and no brakes. The interphase of the sample was collected and transferred to a new tube und washed with cold 1x PBS. After centrifugation with $1200 \mathrm{rpm}$ for 8 minutes at $4^{\circ} \mathrm{C}$ supernatant was discarded and cell pellet was resuspended in $1 \mathrm{~mL}$ EH medium.

\section{III.17. Flow cytometry}

$1-5 \times 10^{6}$ cells per sample were surface stained in $100 \mu \mathrm{L}$ FACS buffer with combinations of monoclonal antibodies labelled with fluorochromes for 30 minutes on ice. After staining, the samples were washed and resuspended in $100 \mu \mathrm{L}$ FACS buffer. Stained cells were analysed on a BD FACSCalibur flow cytometer (BD Biosciences, San Jose, USA). Final analysis was performed using FlowJo software (BD Biosciences). The transferred T cells could be tracked due to their expression of fluorescent reporters. 


\section{III.18. Cell sorting}

Animals were sacrificed by $\mathrm{CO}_{2}$ inhalation. Organs were dissected and prepared as described. Cell sorting was performed by using a BD FACSAria III (BD Biosciences) with minimum flow speed at $4^{\circ} \mathrm{C}$. The sorted cells were transferred into Eppendorf tubes and centrifuged with $4000 \mathrm{rpm}$ for 4 minutes at $4^{\circ} \mathrm{C}$. Subsequently the cell pellet was resuspended in $250 \mu \mathrm{L}$ TRI Reagent and stored at $-80^{\circ} \mathrm{C}$.

\section{III.19. Next generation sequencing}

Next generation sequencing (NGS) of sorted $\mathrm{T}_{\beta S y n}$ cells was performed at the Microarray and Deep-Sequencing Core Facility of the University Medical Centre Göttingen. The analysis was performed by Kaamini Raithatha, Microarray and Deep-Sequencing Core Facility, University Medical Centre Göttingen. Further readouts, graphs and statistics in Microsoft Excel 2010 (Microsoft Corp.) and GraphPad Prism 7.03 (GraphPad Software, Inc.) were performed by Dr. Francesca Odoardi and Moritz Hermann. TMBP cell NGS data was used with permission from Schläger et al., 2016.

\section{III.20. Analysis of neuronal synaptic spine density}

At EAE peak, animals were trans-cardially perfused with ice-cold 1xPBS ( $2 \mathrm{~min}$ ) and 4\% PFA (8 $\mathrm{min})$. Hemispheres were then separated and post-fixed in 4\% PFA for $30 \mathrm{~min}$. One hemisphere was set aside for histology; the other embedded in 2-3\% low-melt agarose (Roth) and cut into $300 \mu \mathrm{m}$ thick slices on a vibratome. Slices were washed 3x $15 \mathrm{~min}$ in 1xPBS. Dil staining was performed as described (Rauskolb et al., 2010). In brief, Dil-coated tungsten particles were delivered to the slices using a hand-held gene gun (Helios Gene Gun System, Bio-Rad, Hercules, USA). Images were acquired by confocal microscopy (see below). Synaptic spines were counted on the apical dendrites of Dil-stained cortical layer 2/3 neurons using Fiji (6-8 dendrites per animal). Dil staining, mounting of slices and quality control was done by Dr. Marta Zagrebelsky-Holz, Abteilung Zelluläre Neurobiologie, Zoologisches Institut der Technischen Universität Braunschweig. Animal preparation was 
performed by Dr. Francesca Odoardi and Moritz Hermann. Confocal microscopy and analyses were performed by Moritz Hermann.

\section{III.21. Confocal Microscopy}

Confocal microscopy was performed using a Zeiss Laser Scanning Microscope 710 (Carl Zeiss AG), running the Zeiss ZEN 2012 (Carl Zeiss AG) software. Fluorophores were excited using a $488 \mathrm{~nm}$ Argon laser for GFP and a $561 \mathrm{~nm}$ DPSS laser for mCherry or Dil. For DAPI a $405 \mathrm{~nm}$ UV-diode was utilized. Accordingly filters were set from 415 to $470 \mathrm{~nm}$ for DAPI acquisition, 498 to $546 \mathrm{~nm}$ for GFP and 571 to $660 \mathrm{~nm}$ for mCherry/Dil. A 40x oil NA1.3 immersion objective Plan Apochromat objective (Carl Zeiss AG) was used. Images were acquired using a pinhole size of $50 \mu \mathrm{m}$, 8bit scan-depth with $800 \times 256$ pixels resolution and $2 \times$ zoom. A zstep size of $0.5 \mu \mathrm{m}$ was chosen to guarantee optimal z-resolution. For overview pictures, larger scanning areas and higher z-step sizes were used.

\section{III.22. Adeno-associated virus transfer}

In order to express $\beta$ Syn and GFP, or GFP alone in rat brain neurons (under the human synapsin 1 gene promoter), injections of Adeno-associated virus (AAV) into neonatal rats was performed by Dr. Sebastian Kügler, Department of Neurology, Viral Vectors Lab, University Medical Centre Göttingen, as described (Kügler et al., 2003).

\section{III.23. Interference with integrin signalling}

To block integrin-mediated binding, a neutralizing mouse anti-rat monoclonal antibody against VLA-4 (anti-CD49d, clone TA-2; courtesy of Thomas Issekutz) and/or against CD11a (integrin $\alpha$, anti-LFA-1, clone WT.1, Serotec) was injected i.v. at a single dose of $1 \mathrm{mg} / \mathrm{kg}$ during intravital TPLSM recordings or twice, at day 3 and 4 after transfer, for clinical experiments. 


\section{III.24. Interference with chemokine signalling}

Interference with chemokine signalling was achieved by $1 \mathrm{mg} / \mathrm{kg}$ hamster anti-rat CXCR3mAb (clone XR3.2, courtesy of Thomas Issekutz) injected i.v. during intravital imaging. These monoclonal antibodies or blocking agents were shown to be effective in vivo in EAE models (e.g. Sporici \& Issekutz, 2010).

\section{III.25. Rotarod}

To evaluate motor performance, wheel-running tests were performed on a motorized rotarod device (Boenig \& Kallenbach oHG, Dortmund, Germany) as described (Kutschenko et al., 2016). Rats were trained before EAE induction and tested after full recovery. Speed was set successively at 5, 9, 12, 16 and $21 \mathrm{rpm}$. Each training or test run was followed by 5 minutes of rest. For each velocity, rats had 4 tries to walk on the wheel-axis until the goal of 180 seconds was reached. The number of tries needed to reach the goal was recorded. Failure to stay on the wheel-axis until the goal was achieved was counted as 4 tries. Training and testing were performed by Angelika Mönnich, analyses by Moritz Hermann.

\section{III.26. Statistical Analysis}

Statistical evaluation was performed using the GraphPad Prism 7.03 software (GraphPad Software, Inc.). Used tests and confidence intervals are indicated in the figure legends.

\section{III.27. Magnetic resonance imaging (MRI)}

Animals were anaesthetized by intra-muscular injection of $10 \mathrm{mg} / \mathrm{kg}$ xylazine combined with $50 \mathrm{mg} / \mathrm{kg}$ ketamine. Thereafter, animals were intubated with a purpose-built endotracheal tube and artificially ventilated using an animal respirator (TSE, Bad Homberg, Germany) with a respiratory rate of 40 breaths $/ \mathrm{min}$ and a tidal volume of $0.8 \mathrm{~mL}$. The animals were then placed in a prone position on a purpose-built palate holder equipped with an adjustable nose cone. Respiratory movement of the abdomen as well as rectal temperature were 
monitored by a unit supplied by the manufacturer (Bruker Biospin MRI GmbH, Ettlingen, Germany).

At 9.4 $\mathrm{T}$, radiofrequency excitation and signal reception were accomplished with the use of a birdcage resonator (inner diameter $7 \mathrm{~cm}$ ) and a 4-channel phased-array surface coil, respectively (all from Bruker Biospin MRI GmbH). T2-weighted axial MRI with repetition time (TR) of $9286 \mathrm{~ms}$, echo time (TE) of $11 \mathrm{~ms}$, RARE factor of 12, 60 slices, in-plane resolution of $120 \times 120 \mu \mathrm{m}$, slice thickness of $480 \mu \mathrm{m}$, and total acquisition time (TA) of $195 \mathrm{~s}$ as well as sagittal MRI (TR/TE $=4333 / 11 \mathrm{~ms}$, RARE factor $=12,28$ slices, in-plane resolution $=120 \times 60$ $\mu \mathrm{m}$, slice thickness $=480 \mu \mathrm{m}$, and $\mathrm{TA}=182 \mathrm{~s}$ ) were performed with the use of multislice fast spin-echo MRI. T1-weighted fat-suppressed gradient-echo MRI (3D FLASH, TR/TE = 14.8/4.2 $\mathrm{ms}$, flip angle $=25^{\circ}$, and TA $=16 \mathrm{~min}$ ) was performed at an isotropic resolution of $120 \mu \mathrm{m}$ before and after an intravenous injection of a solution of the gadolinium-based contrast agent Gadobutrol ( $30 \mu \mathrm{L}$ of $1 \mathrm{mM}$ Gadovist ${ }^{\circledR}$ dissolved in $0.5 \mathrm{~mL}$ physiological saline). The analysis followed a strategy previously developed for intra-individual comparisons of MR images (Watanabe et al., 2004).

For the evaluation of MRI signal intensities (SI), regions-of-interest were selected in a standardized manner (Figure 4 A-D). Mean signal intensity was measured for all ROIs and normalized to the SI of the thalamus. Subsequently, a ratio was calculated by dividing the normalized SI after gadolinium injection to the normalized SI before injection. To measure the thickness of the cortex and corpus callosum (Figure $4 \mathrm{E}$ ), the corpus callosum was marked, ca $0.5 \mathrm{~mm}$ lateral from the mid-sagittal section, by two parallel lines. The distance between those lines was measured at both end points to determine corpus callosum thickness. The cortex thickness was measured at three points from the corpus callosum. The measurements were taken in both hemispheres and subsequently averaged. Ventricular size was assessed by $3 \mathrm{D}$ reconstruction of the third and lateral ventricles from T2-weighted images (Figure $4 \mathrm{~F}$ ). All readouts were performed with the Fiji software, for 3D reconstruction the 3D Roi Manager plugin was used (Schindelin et al., 2012; Ollion et al., 2013). 
MRI measurements were performed by Dr. Takashi Watanabe (Biomedizinische NMR Forschungs $\mathrm{GmbH}, \mathrm{MPI}$ for biophysical Chemistry). Analyses were performed by Moritz Hermann.

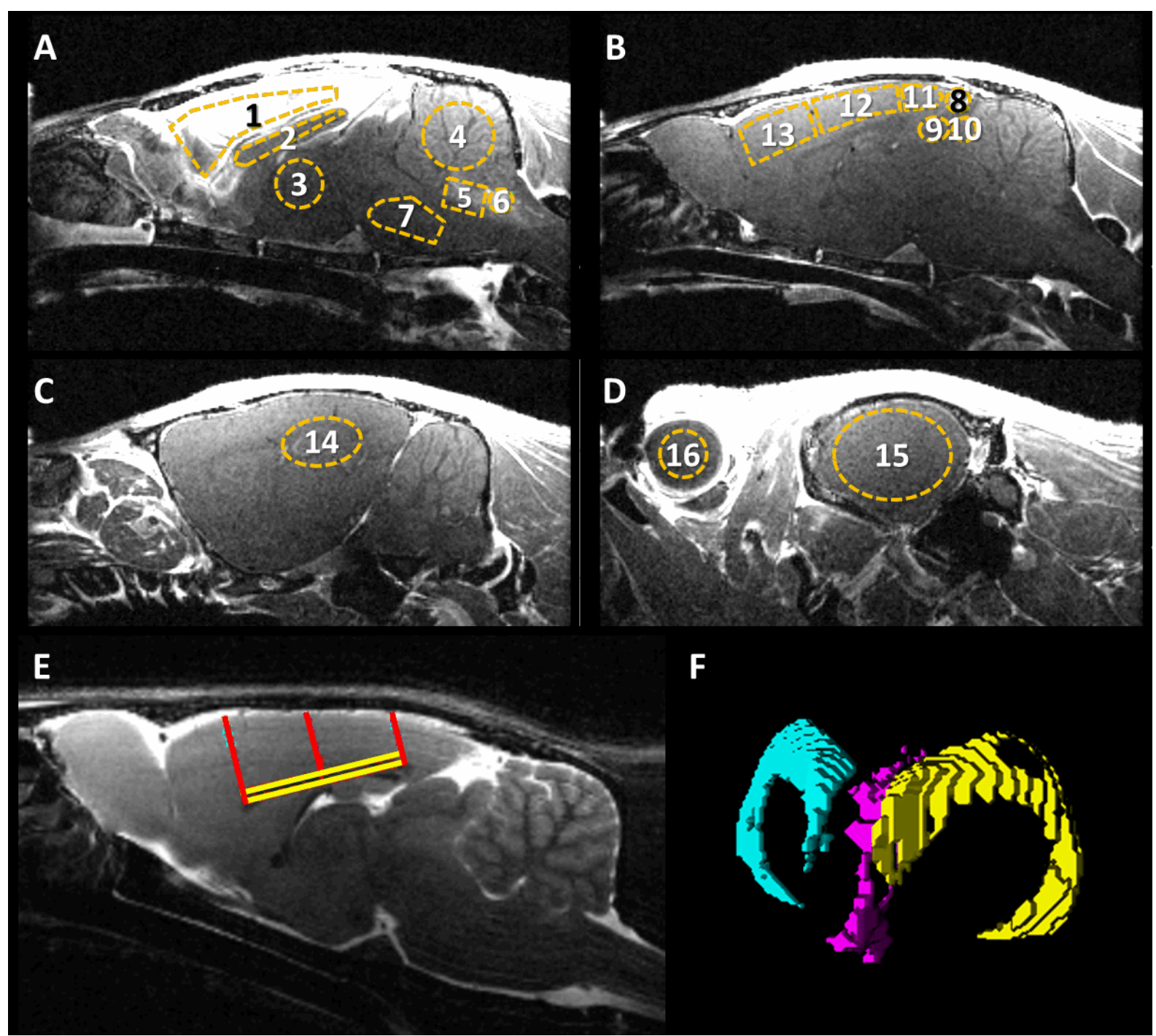

Figure 4: Magnetic Resonance Imaging (MRI)

(A-D) Regions of interest set in T1-weighted sagittal images in order to quantify Gadolinium enhancement. Positions: (A) Mid-sagittal (B) 0.5 mm lateral from mid-sagittal (C) 3 mm lateral from mid-sagittal (D) 1 mm medial from pole. Regions: 1 Meninges, 2 Corpus Callosum, 3 Thalamus, 4 Cerebellum, 5 Choroid Plexus, 6 Area Postrema, 7 Brainstem, 8 Epiphysis, 9 Superior Colliculus, 10 Inferior Colliculus, 11 Occipital Cortex, 12 Parietal Cortex, 13 Frontal Cortex, 14 Hippocampus, 14 Temporal Cortex, 15 Eye. (E) Cortex (red lines) and corpus callosum thickness (yellow lines) is evaluated in sagittal T2 sections, $\sim 0.5 \mathrm{~mm}$ lateral from mid-sagittal. (F) Ventricular volume is determined after 3D reconstruction from coronal T2 sections. Image acquired by Dr. Takashi Watanabe (Biomedizinische NMR Forschungs GmbH, MPI for biophysical Chemistry). 


\section{Results}

\section{IV.1. Characterization of neuronal and classic active EAE in 8-10 week old rats}

Different rat lines were examined concerning their susceptibility to EAE development following active immunization of 8 to 10 week old animals with either the neuronal antigen $\beta$-Synuclein93-111 peptide ( $\beta$ Syn) or the myelin antigen myelin basic protein (MBP). As expected, wild-type Lewis rats immunized with MBP developed $E A E$, characterized by an ascending paralysis as described in Table 1 (Page 17). Shortly after the onset around day 12 after immunization, a peak score of 3 (hind limb paralysis) was reached (Figure 5 B). The disease lasted for 6 days and thereafter the animals recovered completely. EAE incidence was at $100 \%$ (Figure $5 \mathrm{~K}$ ). No measurable symptoms were seen, however, by immunization with $\beta$ Syn (Figure 5A \& K). Receptor transgenic rat lines have been developed in our lab where $\mathrm{T}$ cells are genetically modified to express a $\beta$ Syn-specific $\mathrm{T}$ cell receptor. In heterozygous animals of the $\beta$ SynTG rat line $\left(\beta S_{\text {SynTG }}{ }^{(T /+)}\right)$, about half $(>45 \%)$ of the $T$ cells express a TCR specific for BSyn. A majority of these rats (about $80 \%$, Figure $5 \mathrm{~K}$ ) responded to $\beta$ Syn immunization by classic EAE development with an onset around day 13/14, lasting for 6 days until complete recovery (Figure 5 C). EAE course and severity in these animals was highly similar to classical MBP EAE in wild-type rats. About $60 \%$ of rats of the $\beta S y n T G^{(T /+)}$ genotype also developed a fully-fledged EAE in response to immunization with MBP (Figure $5 \mathrm{D} \& \mathrm{~K}$ ). Surprisingly, homozygous $\beta$ SynTG ${ }^{(\mathrm{T} / \mathrm{T})}$ rats (where $>85 \%$ of $\mathrm{T}$ cells express the $\beta$ Synspecific receptor) did not develop EAE when immunized with BSyn and only scarcely (12.5\%) when immunized with MBP (Figure 5E, F \& K). Following these observations, heterozygous $\beta$ SynTG ${ }^{(T /+)}$ rats were chosen for all active EAE (aEAE) experiments in this thesis.

Similar to BSynTG rats, MBPTG rats, previously established in our lab, harbour T cells specific for MBP. After substantial MBP/CFA dose reduction in comparison to wild-type, all $\mathrm{MBPTG}^{(T /+)}$ rats developed a fulminant EAE (Figure $5 \mathrm{H} \& \mathrm{~K}$ ). First clinical symptoms were detected at day 6 and the classical disease course reached its peak around day 9/10. At day 16 no more signs of EAE could be detected. Unsurprisingly, as in wild-type rats, no reaction was evoked by immunizing with $\beta$ Syn (Figure $5 G \& \mathrm{~K}$ ). Rats of the homozygous $\mathrm{MBPTG}^{(\mathrm{T} / \mathrm{T})}$ line showed no response to $\beta$ Syn either, but react strongly to MBP immunization (Figure 5I, $\mathrm{J} \& \mathrm{~K})$. Dose-adjustment was only performed for $\mathrm{MBPTG}^{(\mathrm{T} /+)}$ rats, since they are the 
appropriate counterpart for $\beta$ SynTG ${ }^{(\mathrm{T} /+)}$ rats and as such will be used for aEAE induced by MBP immunization in later experiments.
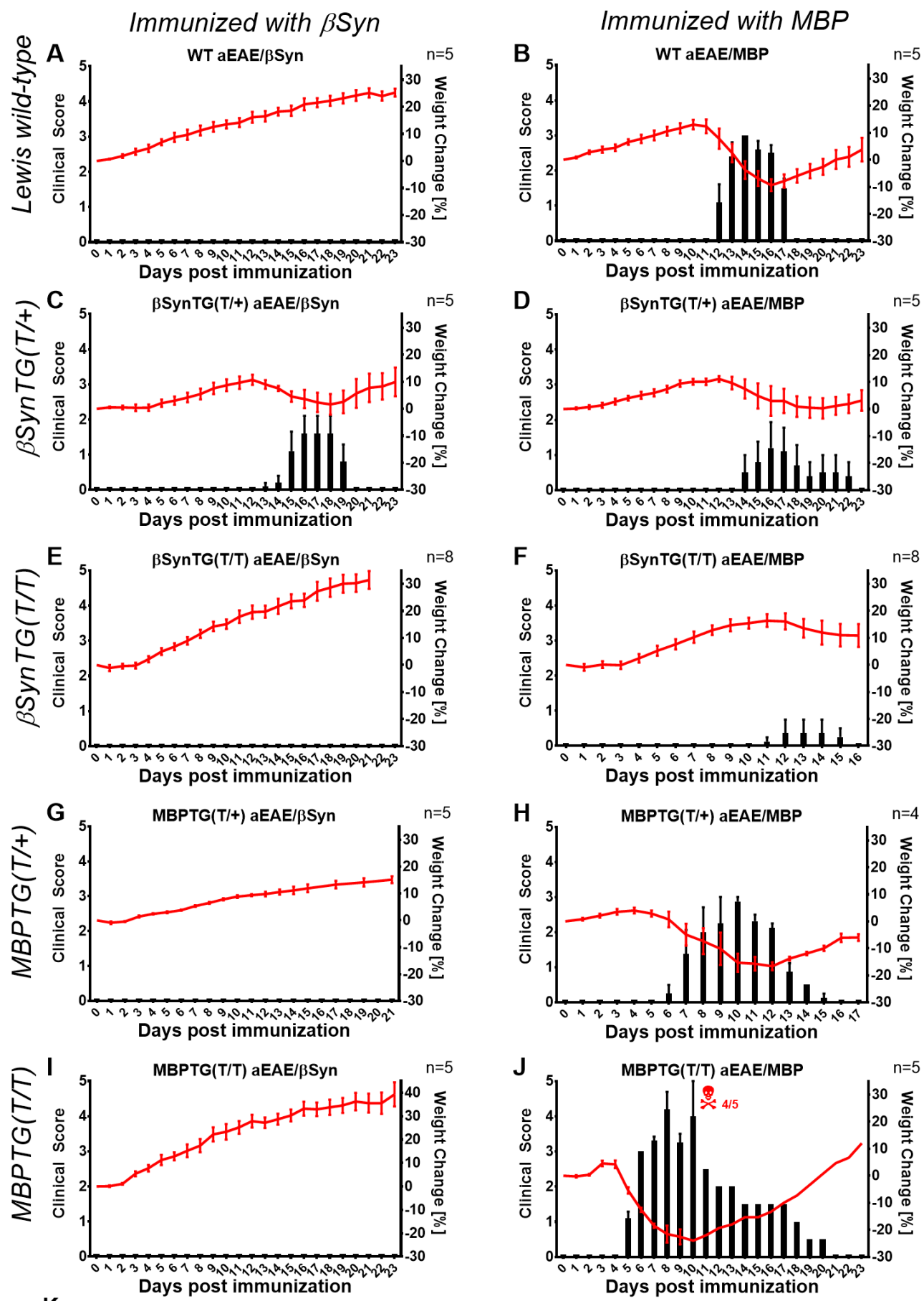

K

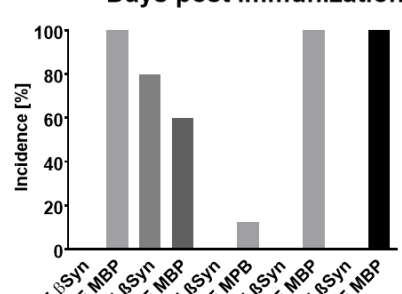


Figure 5: Active EAE in different Lewis rat lines aged 8-10 weeks.

(A+B) Wild-type Lewis rats develop aEAE when immunized with MBP, but not $\beta$ Syn. (C+D) $\beta$ SynTG(T/+) rats

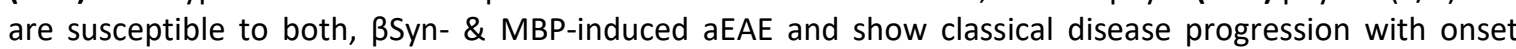
around day 14 . (E+F) $\beta$ SynTG(T/T) rats are not susceptible to $\beta$ Syn-induced aEAE, while a small percentage develop aEAE upon MBP immunization. $(\mathbf{G}+\mathbf{H}) \mathrm{MBPTG}(\mathrm{T} /+)$ rats do not respond to $\beta$ Syn immunization, but develop fulminant aEAE upon immunization with a reduced MBP/CFA dosage. (I+J) MBPTG(T/T) rats do not respond to $\beta S y n$ immunization, but develop severe aEAE in upon MBP immunization. (K) aEAE incidences. (A-J) Data presented as mean \pm SEM, bars show clinical score, lines indicate weight change. Sample size indicated in graphs. Scores: $0=$ No clinical symptoms; $0.5=$ Reduced tail tone or partial tail paralysis; 1 = Tail paralysis; 2 = Gait disturbance/Ataxia; 3 = Hind limb paralysis; 4 = Tetraparesis; 5 = Moribund.

\section{IV.2. Active neuronal EAE can be induced reliably in up to 6 month-old BSynTG(T/+) animals}

To test whether active neuronal EAE could be induced reliably in $\beta$ SynTG ${ }^{(T /+)}$ rats older than 10 weeks, cohorts of 14, 18, 25, 30 and 36 weeks were subjected to $\beta$ Syn immunization. Indeed, in animals up to an age of half a year (or more precisely 25 weeks), aEAE could be induced reliably in a majority (75\% or more) of animals (Figure $6 \mathrm{~A}-\mathrm{C} \& \mathrm{~F}$ ). In these groups, EAE development and severity was comparable to younger animals of the same genotype (see Figure 5 C): onset was around day 13/14 and the symptoms lasted about 6 days until remission. Above this age, incidence rates declined $(66.6 \%$ in rats aged 30 weeks at induction and $60 \%$ in rats aged 36 weeks; Figure 6 D-F). Furthermore, the day of onset was less reliable in those groups. While some rats still displayed the first clinical symptoms at day 13 , others remained symptom free until day 17 or 18 post immunization. 

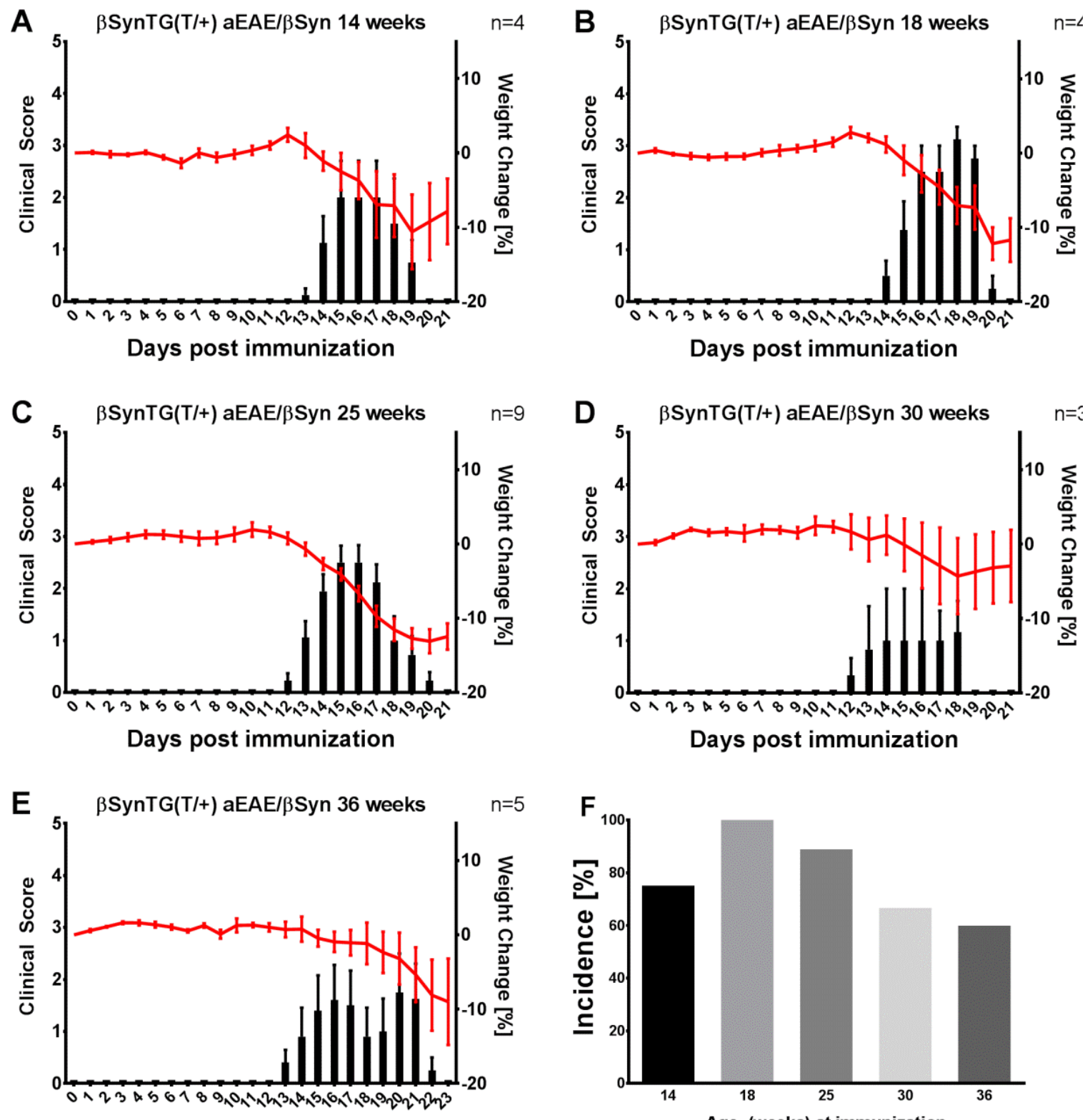

Days post immunization

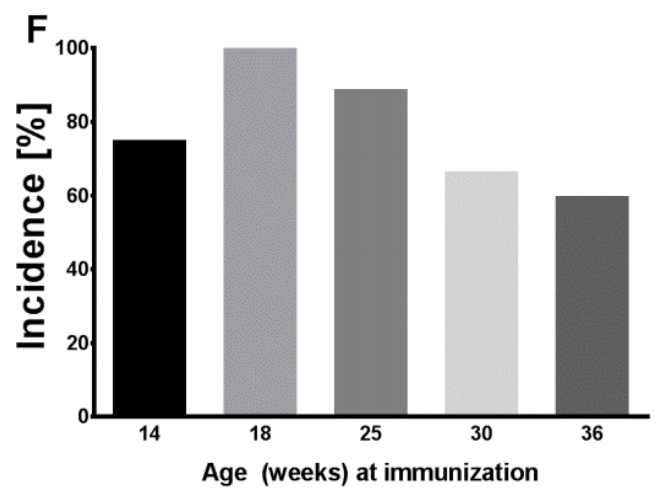

Figure 6: Active neuronal EAE can be induced in up to 9 months old $\beta$ SynTG(T/+) rats.

$\beta$ SynTG(T/+) rats of 14 weeks and older were subjected to immunization with the neuronal antigen $\beta$ Syn. (A-C) Rats of 14, 18 and 25 weeks of age showed the same disease course as their younger littermates (see Figure $5 \mathrm{C}$ ): ascending paralysis starting at 13/14 days after immunization, recovering completely after 6 days of disease. (D\&E) Rats aged 30 and 36 weeks still developed EAE, but the day of onset varied between day 13 to 18. (F) EAE incidence was $75 \%$ at 14 weeks of age, 100\% at 18 weeks, $89 \%$ at 25 weeks and thus at comparable levels to younger littermates (see Figure $5 \mathrm{C}$ ). Hereafter, we observed a notable drop in incidence to $66.6 \%$ at 30 weeks and $60 \%$ at 36 weeks of age. (A-E) Data presented as mean \pm SEM, bars show clinical score, lines indicate weight change. Sample size indicated in graphs. Scores: $0=$ No clinical symptoms; $0.5=$ Reduced tail tone or partial tail paralysis; 1 = Tail paralysis; $2=$ Gait disturbance/Ataxia; $3=$ Hind limb paralysis; 4 = Tetraparesis; 5 = Moribund. 


\section{IV.3. EAE induced by transfer of $\beta$-Synuclein-specific T cells of different genetic origins}

The use of passive transfer EAE (ptEAE) offers the possibility to trace fluorescently labelled T cells through the recipient organism, as well as an earlier onset compared to active EAE. Transfer of $\left(8-9 \times 10^{6}\right)$ in vitro activated $\beta$ Syn-specific T cells ( $T_{\beta \text { Syn }}$ cells), generated from wildtype Lewis rats, led to an EAE course comparable to the classic $T_{M B P}$ induced ptEAE (Figure 7A \& E). At day 4 after transfer, weight loss and the occurrence of the first symptoms of ascending paralysis marked the beginning of clinical EAE. Disease peak was reached on day 6 post transfer (mean score 2.4), after which symptoms abated until at day 10 all outward signs of disease had disappeared (Figure $7 \mathrm{~A}$ ). Of note, a small fraction (<3\%) of $\mathrm{T}_{\beta S y n} \mathrm{ptEAE}$ rats presented with atypical clinical symptoms such as isolated front limp paresis (Schlosser, 2013). T cells of receptor-transgenic origin could also be used to establish fluorescently labelled cell lines. EAE course and severity after transfer of $\left(6-7 \times 10^{6}\right) \mathrm{T}_{\beta \mathrm{SynTG(T/+)}}$ cells was similar to wild-type ptEAE: symptoms manifested on day 4 post transfer and reached their peak on day 6 (mean score 2.5; Figure 7 B). Weight loss was more pronounced (peak at day 8 with an average weight loss of $14.98 \%$ versus day 7 with $7.86 \%$ in $T_{\beta S y n}$ recipients), but the most notable difference was the manifestation of atypical symptoms in $10-20 \%$ of $T_{\beta S y n T(T /+)}$ cell recipient rats. Even more striking was the observation that the transfer of homozygous $T_{\beta S y n T G(T / T)}$ cells caused an atypical EAE course in virtually all recipient animals. This atypical course (denominated by an asterisk behind the score) was dominated by abnormal scratching and twitching behaviour as well as progressing imbalance sometimes followed by spastic paresis (Figure $7 \mathrm{C}$ ). The exact properties and triggers of these unique EAE symptoms of course warrant further investigation, will however not be addressed in detail in this thesis. EAE peak in $T_{\beta S y n T(T / T)}$ recipient animals was reached on day 5 post transfer with a mean atypical score of $2.4^{*}$, weight loss was most pronounced on day 6 with $17.19 \%$. This was achieved with the transfer of a mere $2-3 \times 10^{6} \mathrm{~T}$ cells and the transfer of higher numbers inevitably induced an EAE course with of unsustainable severity (Figure 7 D, mean atypical score on day 4 post transfer $\left.3.9^{*}\right)$. Unless explicitly stated, all ptEAE experiments in this thesis were conducted with fluorescently labelled T cells of wild-type origin. 
A
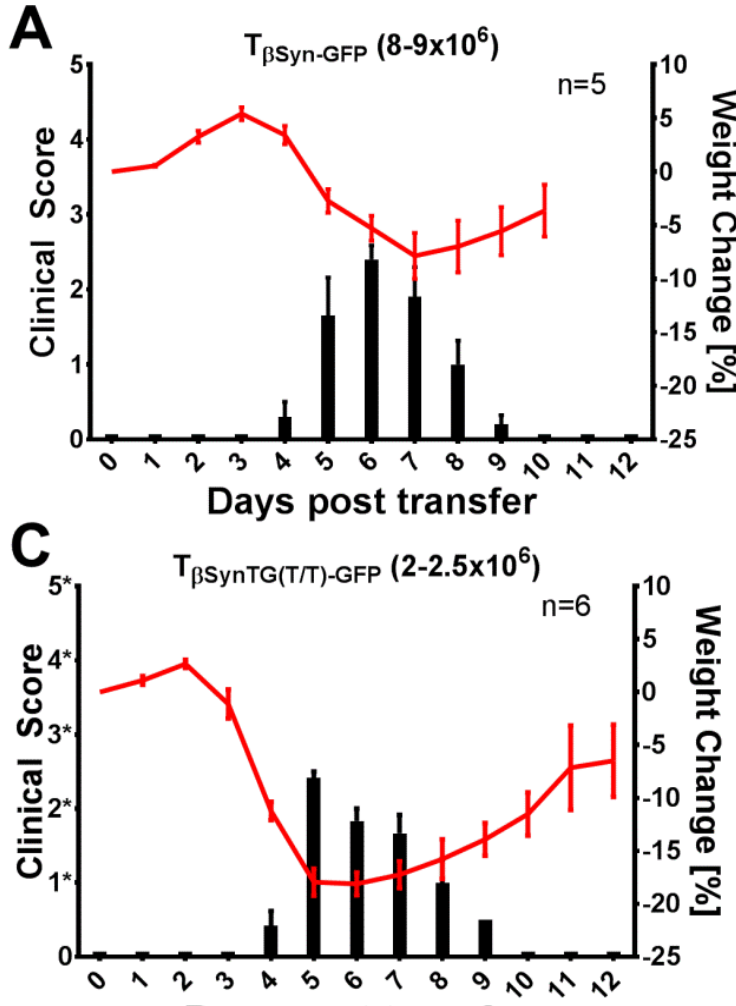

Days post transfer

E

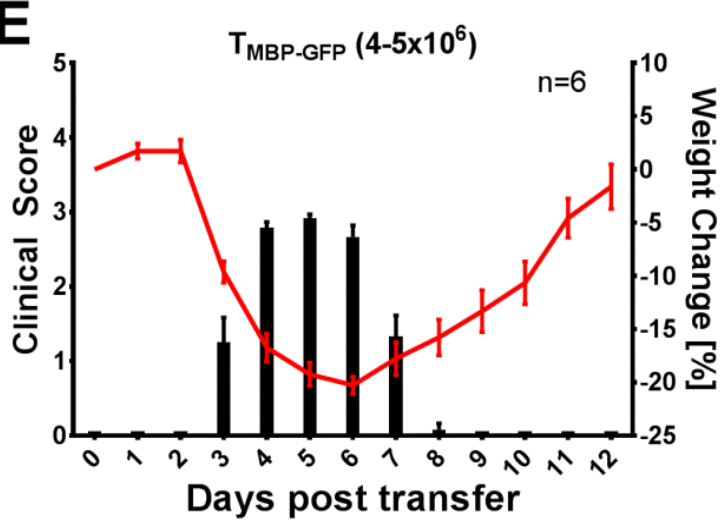

B
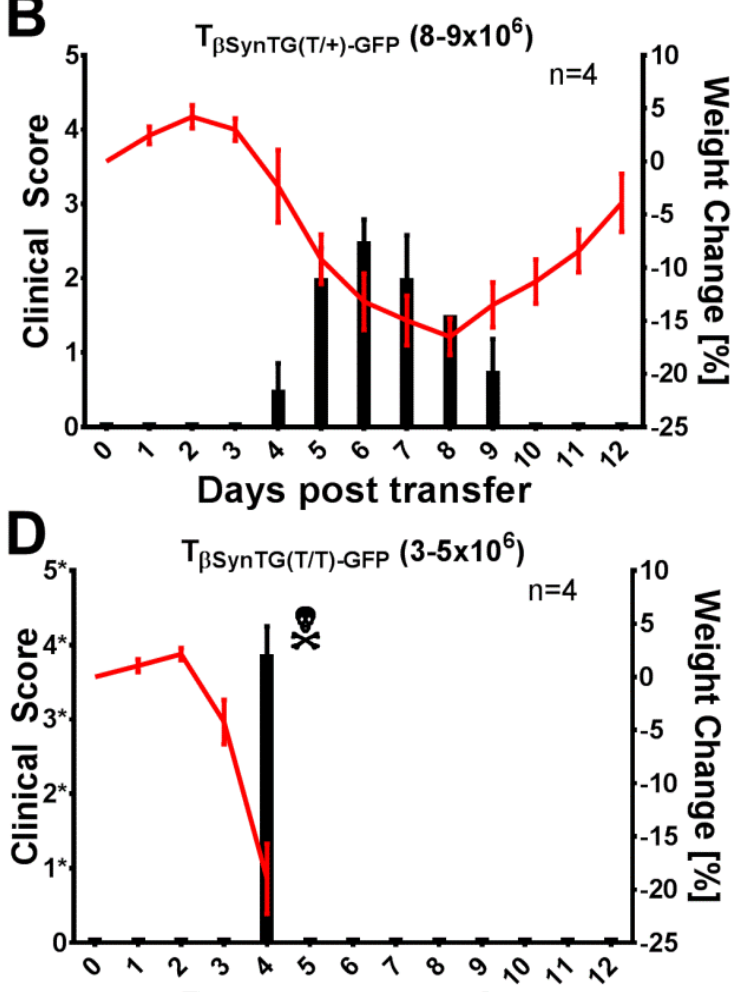

Days post transfer

$\mathbf{F}$

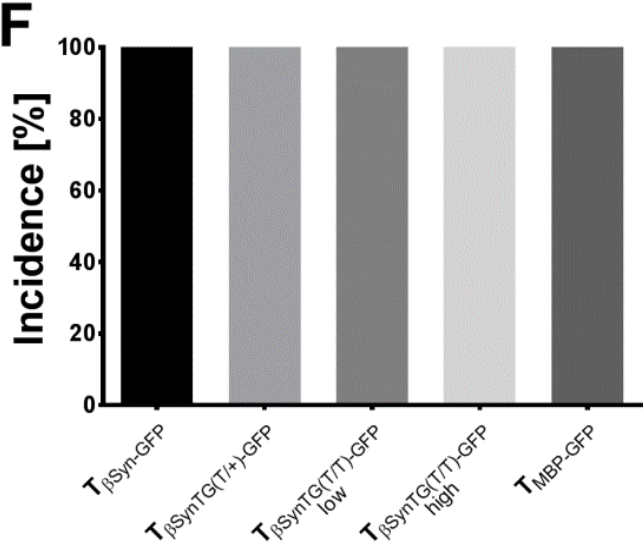

Figure 7: Passive transfer EAE induced by $\beta$ Syn-specific $T$ cell lines of different genetic origins.

Transfer of $\beta$ Syn-specific $T$ cells activated in vitro induces EAE in wild-type Lewis rats. (A) $\beta$ Syn-specific $T$ cells established from wild-type Lewis rats reliably induced an EAE course with classical ascending paralysis. (B) Cells of $\beta$ SynTG(T/+) origin induced EAE as seen in (A). (C) Transferred cells from a $\beta$ SynTG(T/T) background induced a pronounced EAE course, almost exclusively manifesting through atypical symptoms. (D) Transfer of $3-5 \times 10^{6} \mathrm{~T}$ cells of $\beta$ SynTG(T/T) origin induced a fatally potent EAE course. (E) MBP specific T cells from wild-type Lewis rat induced a classical EAE course. (F) ptEAE incidences. Data presented as mean $\pm S E M$, bars show clinical score, lines indicate weight change. Sample size indicated in graphs. (A-C) Representative graphs of 3 or more independent experiments are shown. (A+B) Scores: $0=$ No clinical symptoms; $0.5=$ Reduced tail tone or partial tail paralysis; $1=$ Tail paralysis; 2 = Gait disturbance/Ataxia; $3=$ Hind limb paralysis; 4 = Tetraparesis; 5 = Moribund. (C+D) Atypical Scores: $1^{*}=$ Ataxia, occasional twitches and scratching; $2^{*}=$ Frequent twitches and scratching, slight imbalance; $2.5^{*}=$ Pronounced imbalance; $3^{*}=$ Spastic paresis of hind limbs; $4^{*}=$ Tetraparesis; $5^{*}=$ Moribund. 


\section{IV.4. T-cell infiltration into the rat brain}

As described before, $T_{\beta S y n}$ cells were found to show a clear preference to infiltrate cortical grey matter (Schlosser, 2013). The brain cortex seemed to be one of the primary targets of infiltration, where a gradient could be seen starting from the meninges and declining towards the corpus callosum, where only very few cells were visible (Figure 8). Although grey matter areas, only few cells were found in the hippocampus and thalamus, advocating the hypothesis of the meninges as an entry route for encephalitogenic T cells (Schläger et al., 2016). Many cells could also be found around the ventricles, e.g. the third ventricle just above the thalamus. As expected, $\mathrm{T}_{\mathrm{MBP}}$ cells were only sporadically found in the brain parenchyma and localize mainly in the subpial cortex and thalamus, while they are rarely detectable in hippocampus or corpus callosum (Figure 9). Again, a number of GFP+ $\mathrm{T}_{\mathrm{MBP}}$ cells were visible around the lateral ventricles.
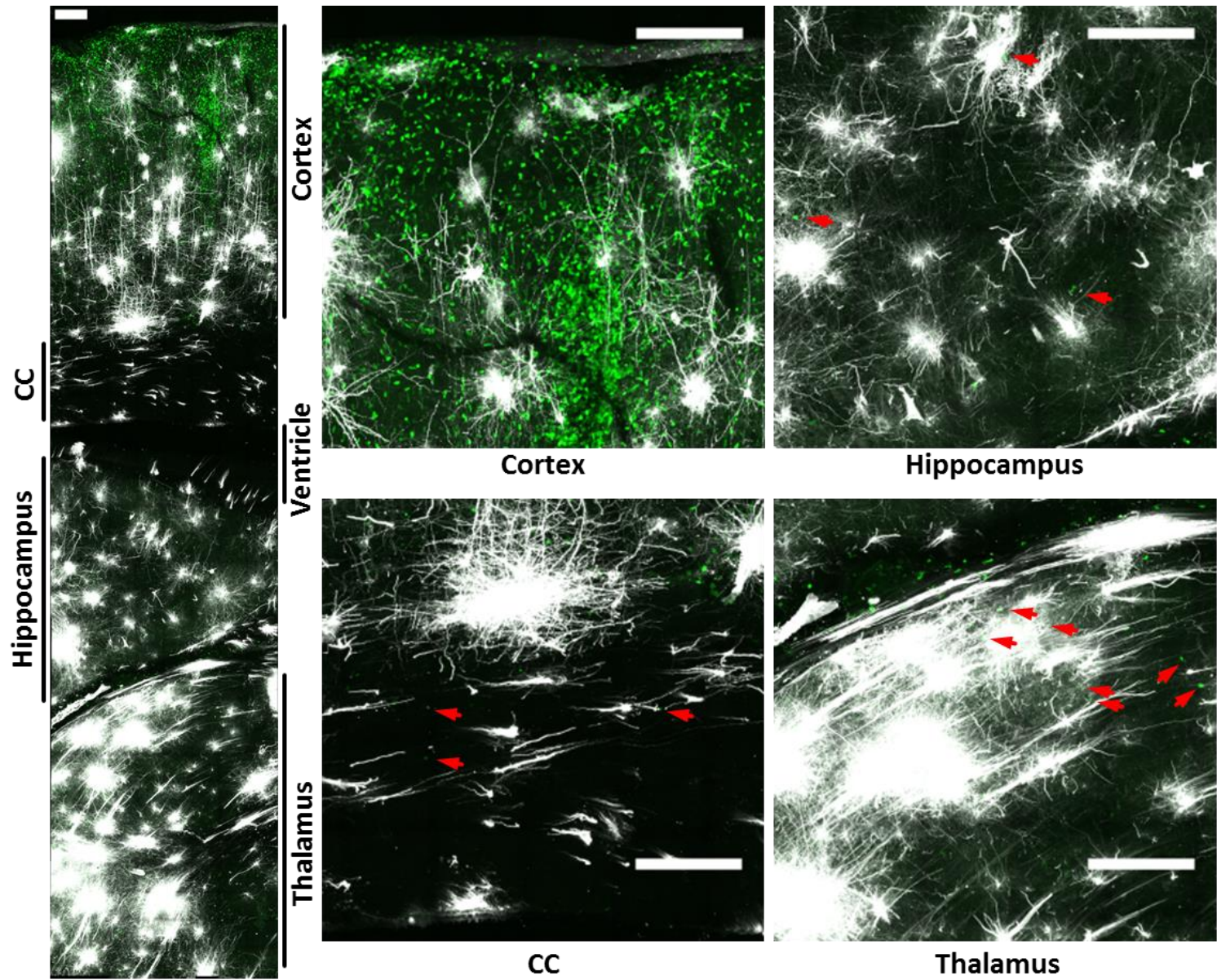

Hippocampus

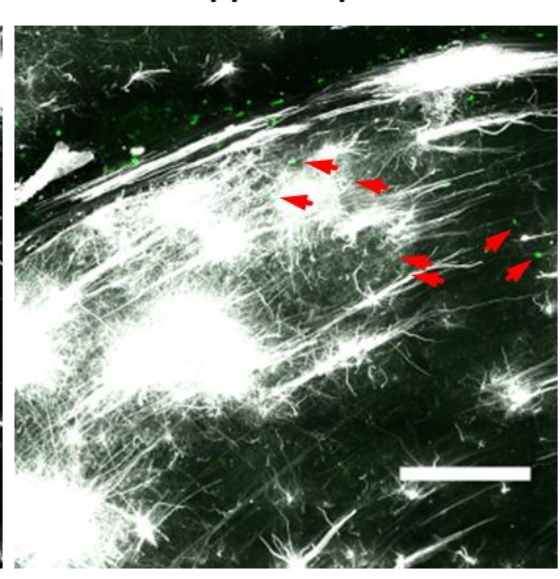

Thalamus

Figure 8: T $\beta S y n-G F P$ cells infiltrate the rat brain, where they are found mainly in the cortex.

Confocal image of TBSyn-GFP cells (green) and Dil+ neurons (white), showing massive infiltration in the cortex, while low numbers could be detected in hippocampus, corpus callosum (CC) and thalamus (red arrows); above the thalamus, a part of the lateral ventricle containing GFP+ cells can be seen; representative section $(300 \mu \mathrm{m}$ thick), taken from wild-type Lewis rat transferred with TßSyn-GFP cells, at peak of disease (d6 p.t., clinical score 3 ); scale bars $=200 \mu \mathrm{m}$. 

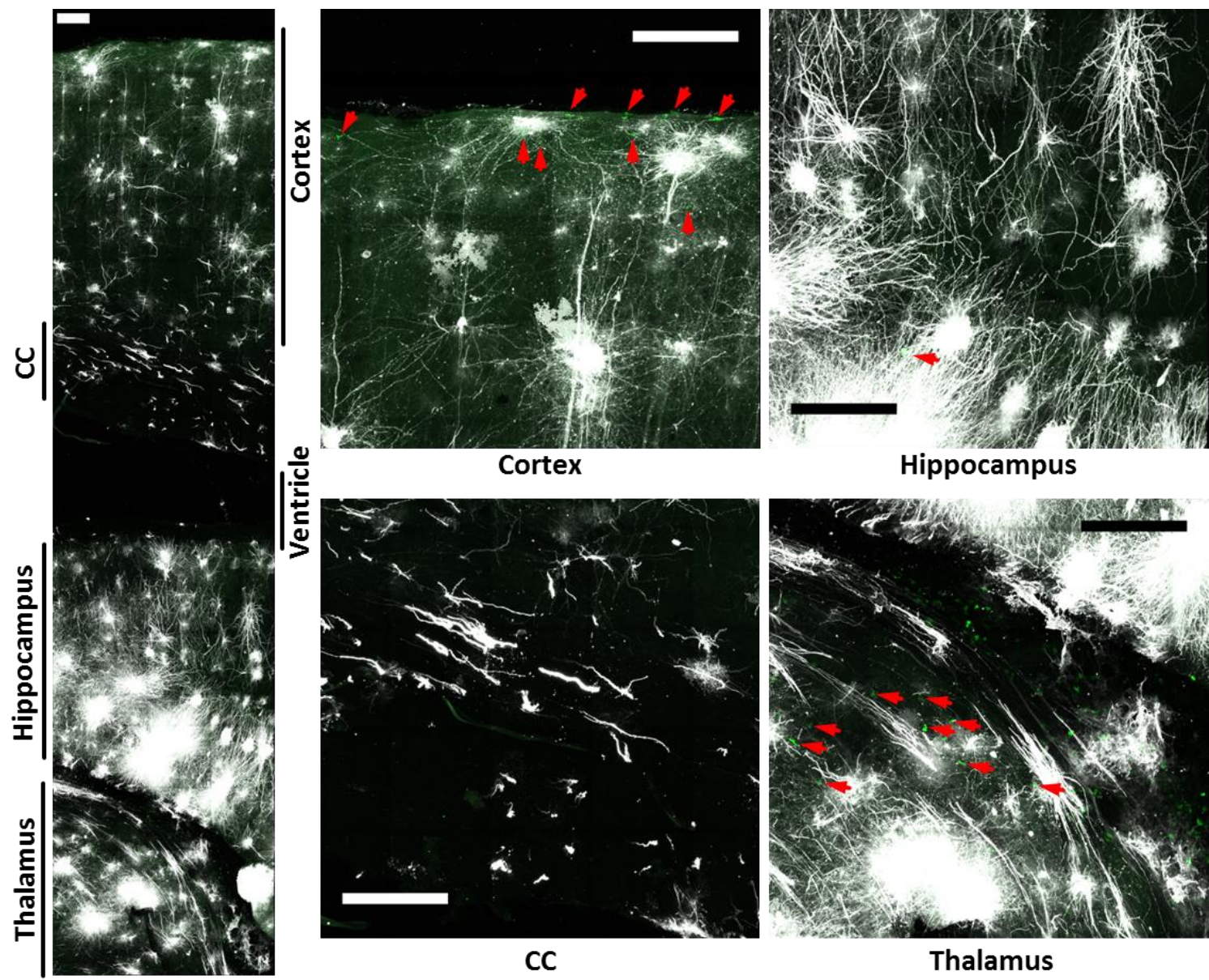

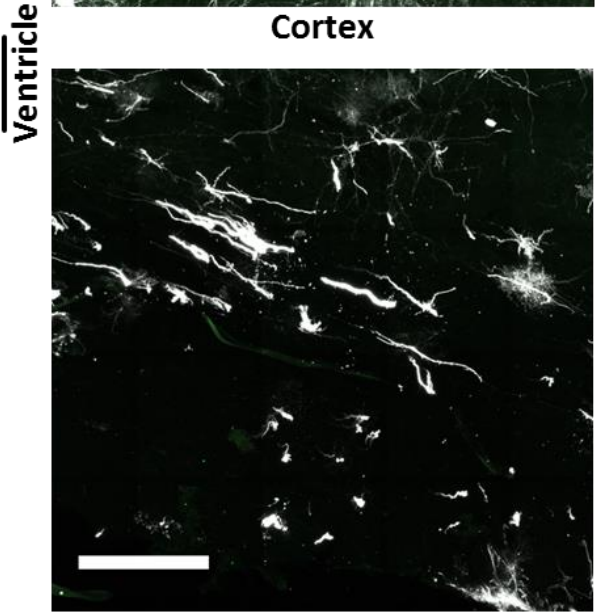

CC

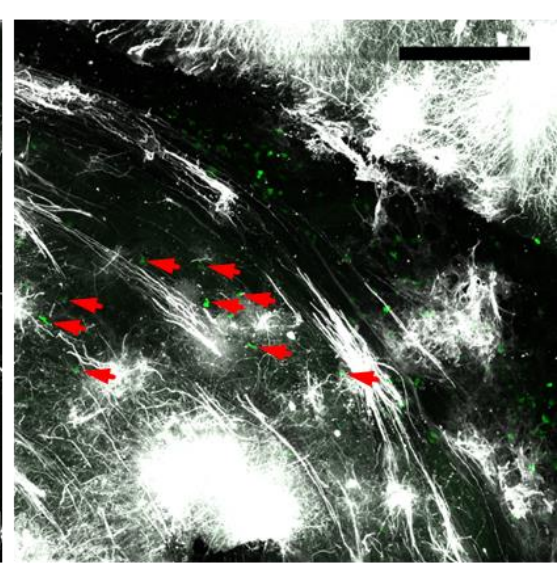

Thalamus

Figure 9: $T_{\text {MBP-GFP }}$ cells are found in low number in the subpial cortex and thalamus.

Confocal image of TMBP-GFP cells (green) and Dil+ neurons (white); infiltration of the brain was generally low, few cells could be detected in the subpial cortex and thalamus (red arrows); above the thalamus, a part of the lateral ventricle containing GFP+ cells can be seen; representative section $(300 \mu \mathrm{m})$, taken from wild-type Lewis rat transferred with TMBP-GFP cells, at peak of disease (d5 p.t., clinical score 3); scale bars $=200 \mu \mathrm{m}$.

\section{IV.5. TPLSM of T cells at the CNS vascular bed}

The histological findings were mirrored by observations in intravital two-photon laser scanning microscopy (TPLSM). Shortly before EAE onset, fluorescently labelled T cells were quantified on the surface of brain and SC, i.e. the subpial compartment of the brain and the leptomeninges of the SC. The number of cells found to be located inside the CNS vasculature was comparable between $T_{\beta S y n}$ and $T_{M B P}$ cells (Figure $10 \mathrm{~A}$; brain: $10.43 \pm 2.57 \mathrm{SEM}$ vs $9.50 \pm 2.09 S E M$; SC: $10.07 \pm 2.60$ SEM vs $4.18 \pm 0.69 S E M$; note that the number of intravascular $\mathrm{T}_{\mathrm{MBP}}$ cells was likely under-estimated caused by an overwhelming amount of perivascular cells). But while $\mathrm{T}_{\mathrm{MBP}}$ cells extravasated preferentially into the SC leptomeninges $(218.45 \pm 48.56 \mathrm{SEM})$ compared to brain subpial parenchyma (11.92 $\pm 1.91 \mathrm{SEM}), \mathrm{T}_{\beta S y n}$ cells 
showed elevated extravasation in both compartments (brain 62.07 $\pm 20.39 S E M$; SC 161.20 25.31 SEM). CNS ignorant T cells of OVA specificity were detectable in the vessels as well as on the surface of brain or SC in low numbers (brain: i.v. 1.79 \pm 0.50 SEM, e.v.

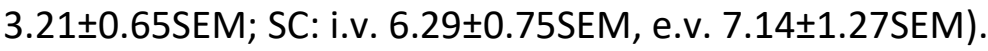

To elucidate whether T-cell locomotion within CNS vessels correlated with their extravasation profiles, intravascular motility behaviour was analysed via intravital TPLSM. One indicator for the status of the activation of the CNS milieu is the percentage to which T cells crawl (as opposed to roll) inside blood vessels (Bartholomäus et al., 2009). Indeed, TMBP cells crawled preferentially in the SC $(57.37 \% \pm 3.71$ SEM) compared to the brain (35.80\% $\pm 4.71 \mathrm{SEM})$. Tova cells on the other hand showed a low crawling percentage in SC $(40.51 \% \pm 4.08 \mathrm{SEM})$ that was even lower in the brain vessels $(24.15 \% \pm 4.47 \mathrm{SEM})$ (Figure $10 \mathrm{~B}$ ). $T_{\beta S y n}$ cells showed an elevated percentage of crawling cells that was almost identical between both compartments (brain $58.32 \% \pm 5.04$ SEM, SC 59.50\% \pm 5.70 SEM).

Further indication about the activation state of the CNS milieu can be drawn from motility parameters, e.g. T-cell velocity and the crawling duration (i.e. the time a single cell can be followed via TPLSM) (Bartholomäus et al., 2009). Generally, T cells moving in an inflamed milieu display a lower speed and a longer crawling time when comparing their movement in an un-inflamed milieu. As shown in Figure $10 \mathrm{C}$, the velocity did not differ between $\mathrm{T}_{\beta S y n}$ and $T_{M B P}$ cells, independent of the compartment. $T_{\beta S y n}$ cells showed an average velocity of $13.01 \mu \mathrm{m} / \mathrm{min} \pm 0.39 \mathrm{SEM}$ in the brain vasculature and $11.76 \mu \mathrm{m} / \mathrm{min} \pm 1.25 \mathrm{SEM}$ in the SC. TMBP cells moved with $11.01 \mu \mathrm{m} / \mathrm{min} \pm 0.77 \mathrm{SEM}$ through brain and with $11.42 \mu \mathrm{m} / \mathrm{min} \pm 1.01 \mathrm{SEM}$ through SC vessels. TovA cells were slightly faster with $14.66 \mu \mathrm{m} / \mathrm{min} \pm 1.41 \mathrm{SEM}$ in brain and $13.76 \mu \mathrm{m} / \mathrm{min} \pm 1.02 \mathrm{SEM}$ in SC, respectively. The parameter of track duration was little more illustrative in regard to the final T-cell distribution (Figure $10 \mathrm{D}$ ). The average track duration of $\mathrm{T}_{\beta \mathrm{Syn}}$ cells was $8.68 \mathrm{~min} \pm 0.90 \mathrm{SEM}$ in brain vessels and $10.88 \mathrm{~min} \pm 1.95 \mathrm{SEM}$ in the SC, while $T_{M B P}$ cells could be observed for $7.70 \mathrm{~min} \pm 0.24 \mathrm{SEM}$ in the brain and for $12.71 \mathrm{~min} \pm 1.40 \mathrm{SEM}$ in SC vasculature. The latter was indeed significantly different between compartments $(p=0.0079)$, but not in comparison to the other groups. This most likely reflected upon a higher inflammation of the SC parenchyma of $\mathrm{T}_{\mathrm{MBP}}$ recipient animals, as no significant differences could be detected between $T_{\beta S y n}$ and $T_{M B P}$ cells irrespectively of the examined compartment. Expectedly, Tova cells crawling at the CNS vascular bed could be observed for 
an only marginally shorter time with $5.87 \mathrm{~min} \pm 0.77 \mathrm{SEM}$ in the brain and $8.38 \mathrm{~min} \pm 0.89 \mathrm{SEM}$ in the SC. Here a significant difference could be detected for the crawling duration in the brain of $T_{\beta S y n}$ and Tova recipient animals $(p=0.0317)$, fitting the observation that Tova cells were rarely detected extravasated within the brain tissues. Taken together with the other data, the locomotion characteristics of the different effector $\mathrm{T}$ cells seems rather to be consequential of the general distribution of cells and the subsequent inflammation of the surrounding tissues than causative for the disparate distributions of neuron- or myelinspecific T cells throughout the CNS observed in histology and TPLSM.

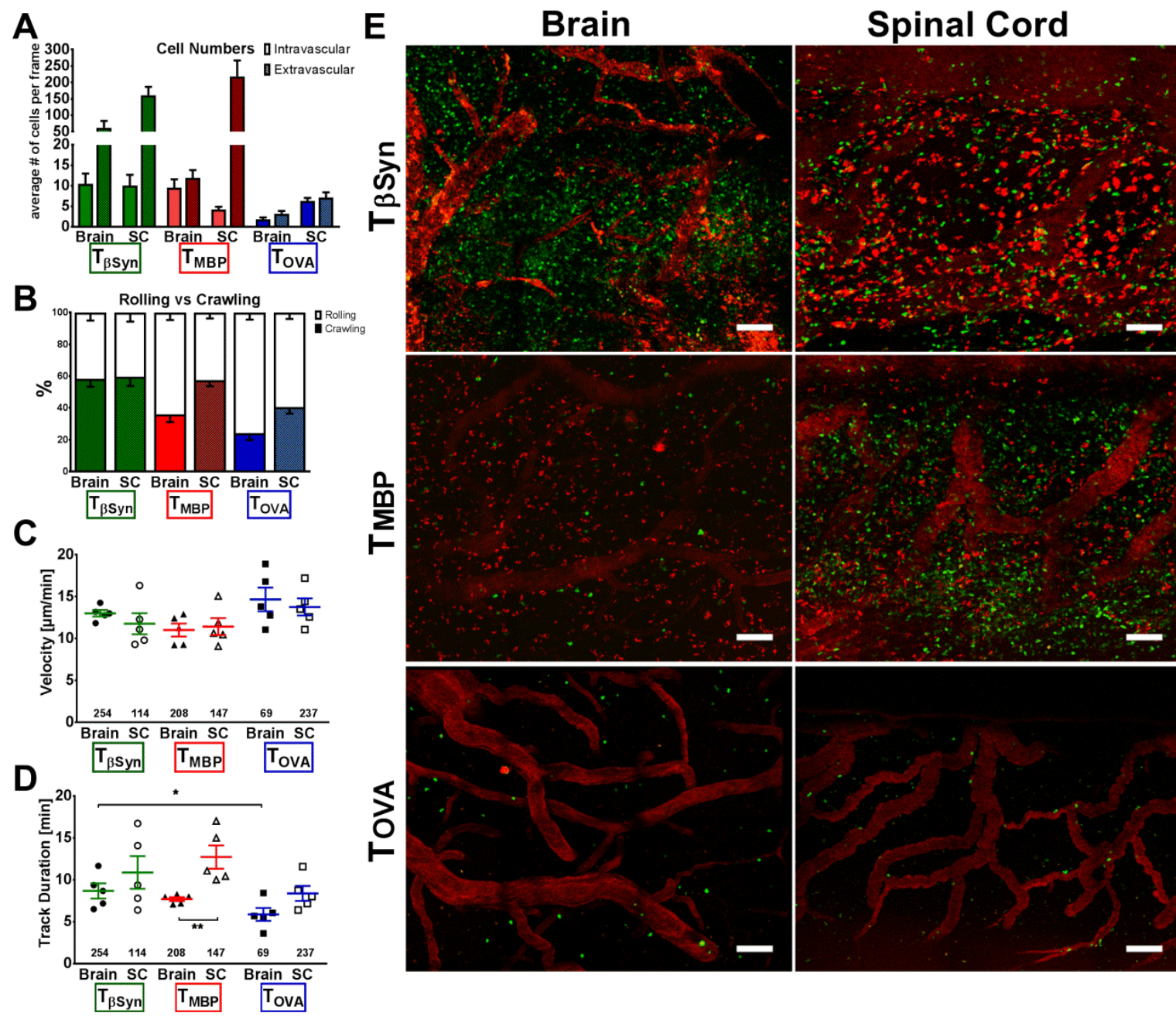

Figure 10: in vivo TPLSM in brain and SC of rats transferred with T cells of different antigen specificities. Fluorescently labelled $\beta$ Syn-, MBP or OVA-reactive $T$ cells ( $T_{\beta S y n}, T_{M B P}$ or Tova respectively) were observed shortly before EAE onset in brain and SC. (A) Quantification of T cells per frame, taken from the first frame of every 30' video. (B) Percentage of rolling versus crawling cells inside CNS vessels. (C) Velocity and (D) track duration of cells observed over a 30' period; number of analysed cells indicated in graph. (E) TPLSM tile scans from brain and SC of different T-cell recipient animals. Green: T cells. Red: blood vessels and (upper two rows) macrophages. Scale bars $=100 \mu \mathrm{m}$. All data originate from $n=5$ animals per group in independent experiments. In $C+D$ each point is representative of one animal where 4 videos were analysed per compartment. Statistical significance determined via Mann-Whitney test. All data presented as mean $\pm S E M$. 


\section{IV.6. Monitoring CD11 $\mathrm{b}^{+}$Monocytes at the CNS vascular bed reveals subtle differences in luminal crawling between brain and SC}

Looking at the Tova cell motility data it seemed probable that some fundamental difference exists between the vasculature on the surfaces of brain and spinal cord, independent of inflammation state, which could influence intraluminal motility behaviour. To test this hypothesis, naïve rats were injected with fluorescently labelled CD11b antibody in order to mark circulating monocytes. While the overall amount of monocytes detected in brain or SC

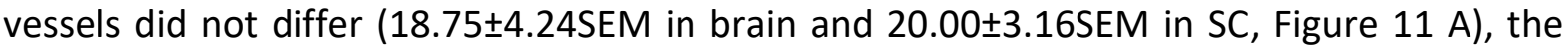
percentage to which these cells crawled was significantly lower in the brain (54.53\% $\pm 5.93 \mathrm{SEM})$ compared to the SC vessels (69.36\%2.50SEM, $p=0.0369$, Figure $11 \mathrm{~B})$. Velocity and average track duration on the other hand did not differ significantly from one another (Figure $11 C \& D$ ): the average velocity of $\mathrm{CD}_{11} \mathrm{~b}^{+}$monocytes was $9.72 \mu \mathrm{m} / \mathrm{min} \pm 1.31 \mathrm{SEM}$ in the brain and $11.09 \mu \mathrm{m} / \mathrm{min} \pm 0.77 \mathrm{SEM}$ in the SC $(p=0.4192)$. The average track duration with which these cells moved through brain vessels was also not altered compared to the SC $(9.38 \mathrm{~min} \pm 1.13 \mathrm{SEM}$ in brain vs $10.16 \pm 1.90$ in $\mathrm{SC}, \mathrm{p}=0.7407)$. It can thus be concluded that, while these cells can be observed in similar amounts in brain or SC and while their crawling parameters do not significantly differ, there nonetheless may exist some inherent minor difference between the CNS vascular compartments which influences the T cell adhesion properties to the vascular endothelium observable via TPLSM. These subtle differences however are very unlikely to justify profoundly distinct distribution

A

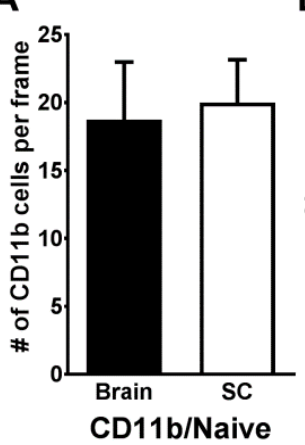

B

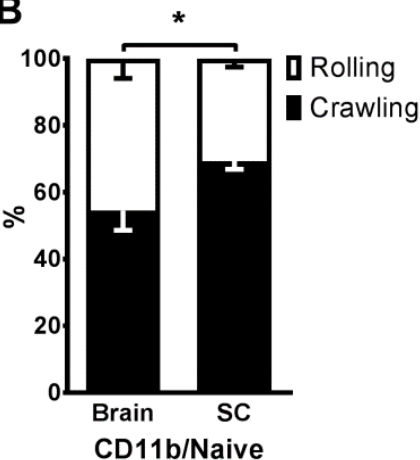

C

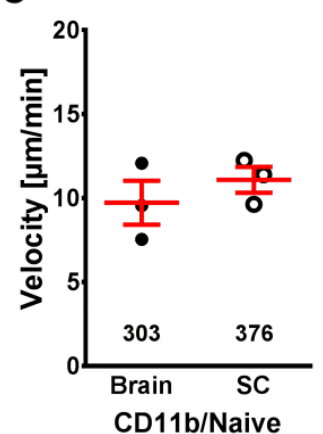

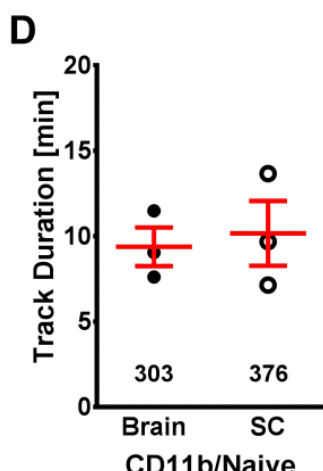

Figure 11: CD11b+ Monocytes at the vascular bed of naïve rats.

Fluorescently labelled CD11b+ monocytes were observed in brain and SC of naïve rats. (A) Quantification of T cells per frame, taken from the first frame of every 30' video. (B) Percentage of rolling versus crawling cells inside CNS vessels. (C) Velocity and (D) track duration of cells observed over a 30' period; number of analysed cells indicated in graph. (E) All data originate from the same $n=3$ animals in independent experiments. In $C+D$ each point is representative of one animal where 4 videos were analysed per compartment. Statistical significance determined via Student's t-test $(A+B)$ or Mann-Whitney test $(C+D)$, ${ }^{*} p \leq 0.05$. All data presented as mean \pm SEM. 
of $T_{\beta S y n}$ and $T_{M B P}$ cells in the CNS compartments.

\section{IV.7. Blocking integrin \& chemokine receptor signalling affects T-cell crawling and EAE development}

Transmigration of $\mathrm{T}_{\mathrm{MBP}}$ cells from vessels into the SC parenchyma has been shown to be dependent mainly on the alpha4/beta1 integrin VLA-4 and not on LFA-1 (alphaL/beta2; Bartholomäus et al., 2009; Schläger et al., 2016). Quantitative real-time PCR data revealed that $T_{\beta S y n}$ cells isolated from the blood express high levels of both VLA-4 and LFA-1, suggesting that $T_{\beta S y n}$ cell adhesion to the brain endothelium could be mediated by these molecular cues (Schlosser, 2013). To test this hypothesis, TPLSM was performed on the brains of rats transferred with $T_{\beta S y n}$ cells shortly before $E A E$ onset, when $T_{\beta S y n}$ cells were mainly located in the intravascular compartment. Compared to the studies on $\mathrm{T}_{\mathrm{MBP}}$ cells in the SC, the effect of $\alpha \mathrm{VLA}-4-m A b$ injection was even more pronounced on $\mathrm{T}_{\beta S y n}$ cells in brain vessels. Here, a single injection was sufficient to completely remove any detectable $\mathrm{T}$ cells within 30-40 minutes (Figure 12A \& F). As could be expected, FACS staining of T cells extracted from blood after this experiment showed complete blocking of the VLA-4 receptor (Figure $12 \mathrm{E}$ ). Preventive antibody-treatment consequently inhibited ptEAE development (Figure $12 \mathrm{~B}$ ): over the duration of the experiment no overt clinical signs were detectable in treated animals. Stagnation in weight gain was observed however during day 3 to 7 post transfer (p.t.) and subsequent FACS analysis revealed low amounts of infiltrating T cells in all CNS tissues on day 5 p.t. (Figure $12 \mathrm{C}$ ). The ratio of infiltration into the CNS was between 5 (brain) and 25 times (meninges SC) lower in treated animals compared to control (Figure 12 D), but the perseverance of cells explains the observed weight stagnation.

Upon the injection of $\alpha$ LFA-1 blocking antibody, a reduction in the number of observable T cells inside brain vessels by about $50 \%$ could be detected (Figure $13 \mathrm{~A} \& \mathrm{I}$ ). It is possible that this effect was slightly stronger in rolling and weakly adhering cells, indicated by the slightly increased percentage of crawling cells from $36.06 \% \pm 3.96$ SEM to $51.01 \% \pm 12.47$ SEM within one hour after injection (Figure $13 \mathrm{~B})$, this was however not significant $(p=0.5611)$. Furthermore, the LFA-1 antibody treatment did not seem to influence the motility characteristics of crawling cells, as neither track duration, nor velocity of the observed T 
cells changed within the observed time frame (Figure $13 C$ \& D). Again, blocking of the receptor was complete, as indicated by FACS staining (Figure $13 \mathrm{~F}$ ). According to these observations, it was little surprising that preventive treatment of $T_{\beta S y n}$-cell recipient animals with $\alpha$ LFA-1 blocking antibody had no influence on the clinical outcome compared to PBS treated controls (Figure $13 \mathrm{E}$ ). Accordingly, FACS analysis revealed no differences in the infiltration rate of $T_{\beta S y n-G F P}$ cells into the CNS compartments (Figure $13 G$ \& $H$ ): in brain, SC, SC meninges and blood, the ratio was around 1, indicating the same infiltration frequency. Interestingly, in one of three treated animals, an increased number of $T_{\beta S y n}$ cells in the brain meninges and spleen were detectable, elevating the infiltration ratio to 2.75 and 4, respectively.

Chemokines are supposed to play an important role in T-cell adhesion and transmigration. Blocking of the chemokine receptor CXCR3 has been shown to inhibit $\mathrm{T}_{\text {MBP-cell induced }}$ ptEAE development (Sporici \& Issekutz, 2010). In murine Th1/17 cells it is important for BBB transmigration and it is part of the molecular cluster which can be used to identify pathogenic Th1/17 cells in MS patients (Lee et al., 2012; Hu et al., 2017). Previous work has also identified a high expression of CXCR3 in $T_{\beta S y n}$ cells (Schlosser, 2013). However, for the intravascular crawling of these cells inside brain vessels it seemed of minor relevance. Injection of CXCR3-blocking antibody had no immediate effect on intraluminal $T_{\beta S y n}$ cells: within one hour after injection, no reduction in the number of crawling and rolling $T_{\beta S y n}$ cells within brain vessels could be detected (Figure 14A \& E). The values for crawling percentage as well as track duration remained stable during the entire observation period as well (Figure 14B \& C). Only T-cell velocity changed significantly in the $60-90$ minute time frame (Figure $14 \mathrm{D}$ ), increasing from a mean of $11.43 \mu \mathrm{m} / \mathrm{min} \pm 0.23 S E M$ to $12.58 \mu \mathrm{m} / \mathrm{min} \pm 0.29 S E M$. This hints to the possibility of a slowly acting mechanism that was not observable during the limited time frame of this experiment. Further, it cannot be excluded that the used antibody dosage was too low (it was chosen in relation to the experiments with VLA-4 and LFA-1), resulting in incomplete blockage, as in our hands no FACS staining could be established for the rat CXCR3. 
A Effect of $\alpha$ VLA4 injection on $T_{\beta s y n-G F P}$ cells

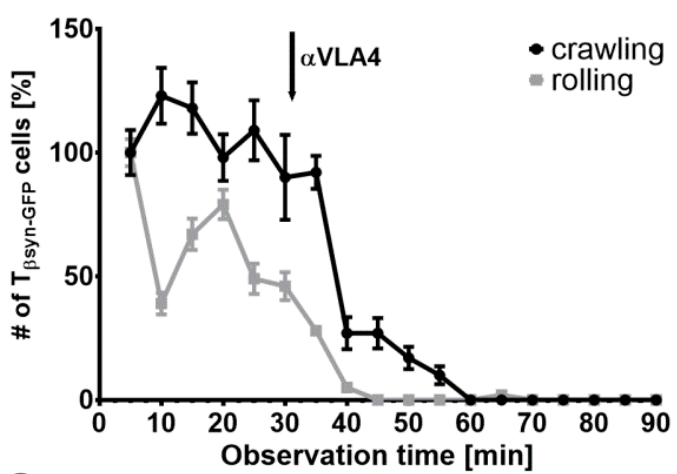

C

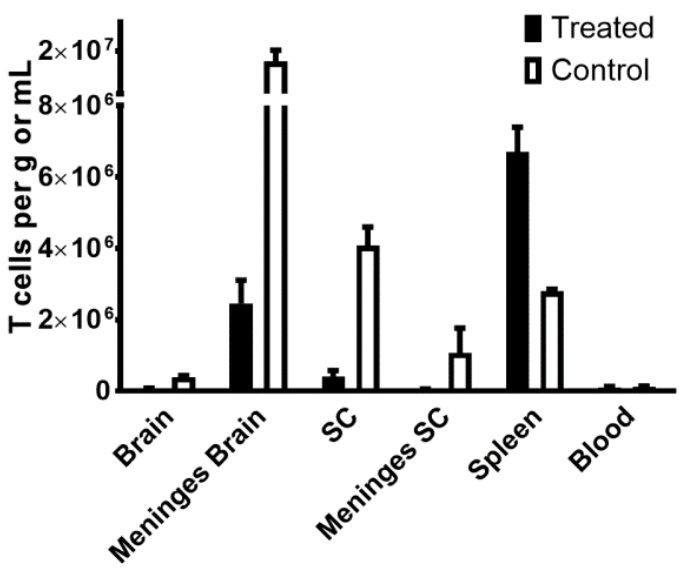

B

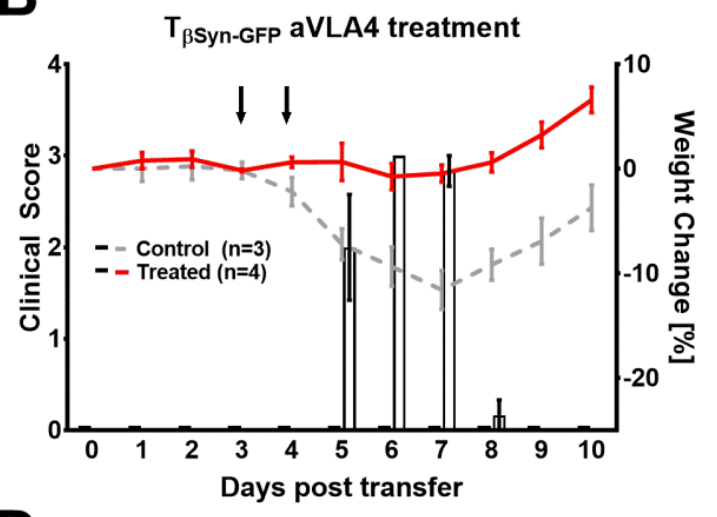

$\mathbf{D}$

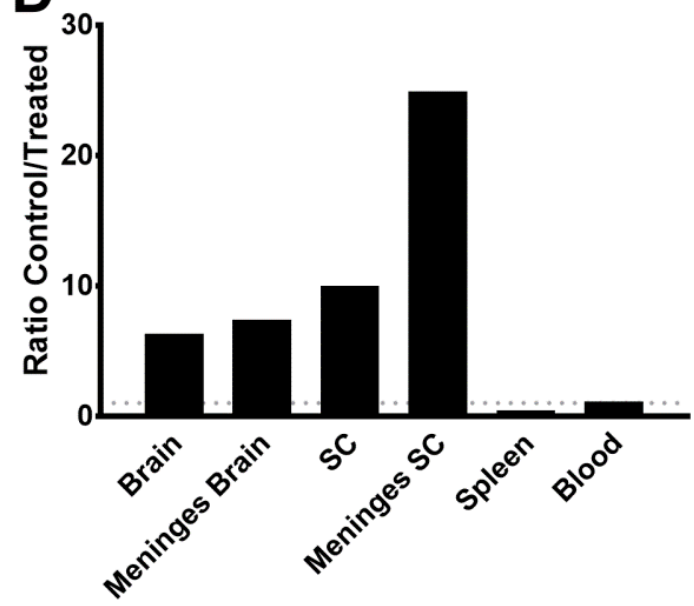

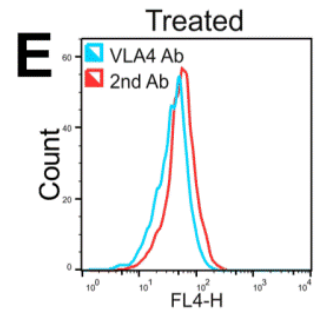
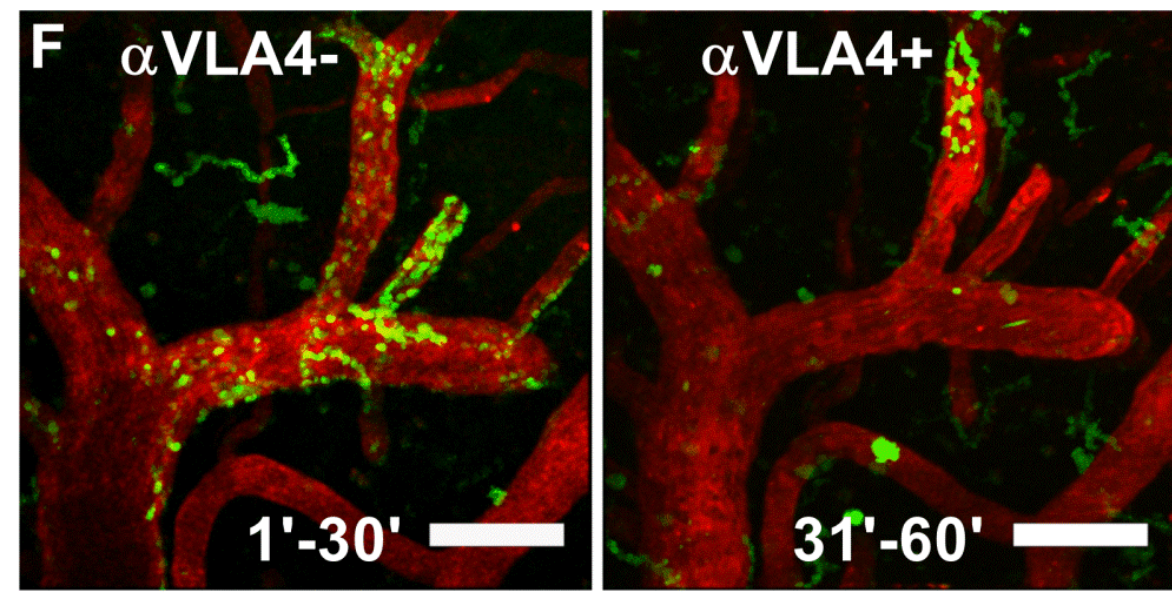

Figure 12: VLA-4 blocking washes T $\beta$ Syn cells from brain vasculature and impedes ptEAE development.

(A) Intravital TPLSM of rats transferred with TBSyn-GFP cells, day 3 after transfer. $\alpha$ VLA-4 mAb injected at 30 minutes time point. Cell numbers counted in 5-minute intervals. Black line shows crawling, grey line rolling cell percentage relative to 0 minutes time point. $n=3$, independent experiments (B) Clinical score (bars) and relative weight change (lines) of TßSyn recipient rats treated with $\alpha \mathrm{VLA}-4$ mAb on day 3 \& 4 p.t. (black bars/red line) or PBS-treated controls (white bars/grey line). Sample size indicated in graph. Scores: $0=$ No clinical symptoms; $0.5=$ Reduced tail tone or partial tail paralysis; $1=$ Tail paralysis; $2=$ Gait disturbance/Ataxia; 3 = Hind limb paralysis; 4 = Tetraparesis; 5 = Moribund. (C) FACS count of T $\beta$ Syn-GFP cells per gram or $\mathrm{mL}$ of tissue extracted, day 5 p.t. White bars show PBS control, black bars aVLA-4-treated group respectively. (D) Ratio of extracted cells in treated vs untreated group. (E) FACS staining of VLA-4

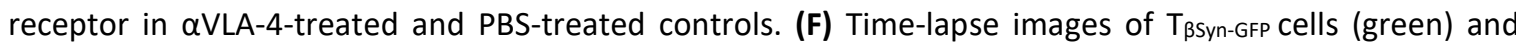
blood vessels (texas red labelled dextran, red) 30 minutes before (left) and after $\alpha \mathrm{VLA}-4$ Ab injection (right); Scale bar $=100 \mu \mathrm{m}$. Antigen concentration for all experiments: $1 \mathrm{mg} / \mathrm{kg}$. Data presented as mean \pm SEM. 
A Effect of $\alpha$ LFA1 injection on $T_{\text {psyn-GFP cells }}$

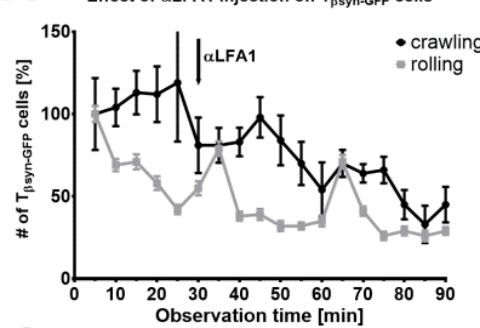

$c$

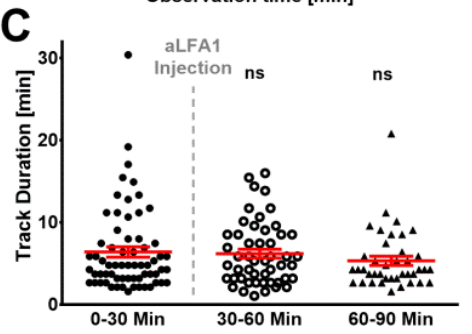

E

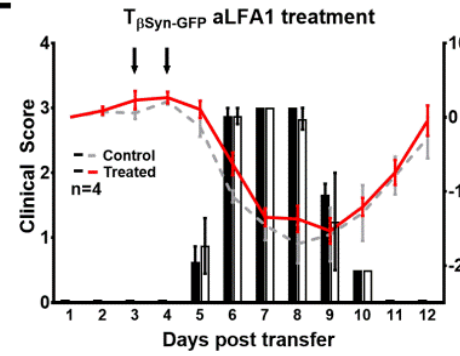

G
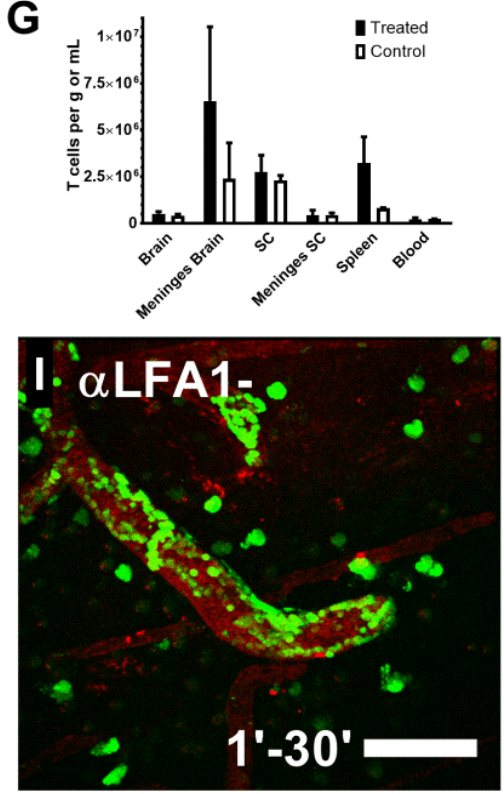

B

aLFA1 rolling vs crawling

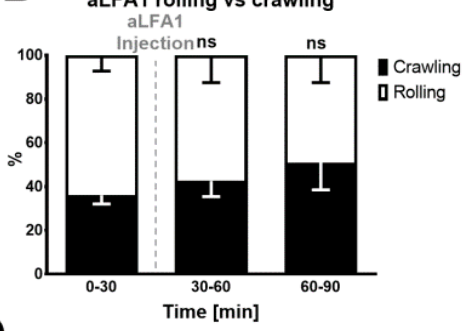

D

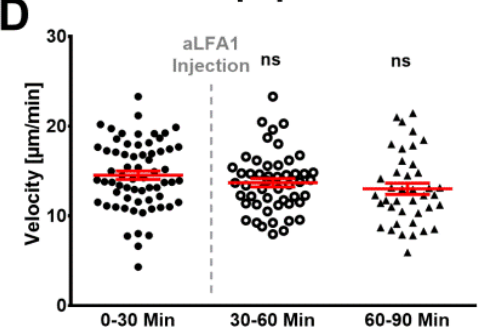

F

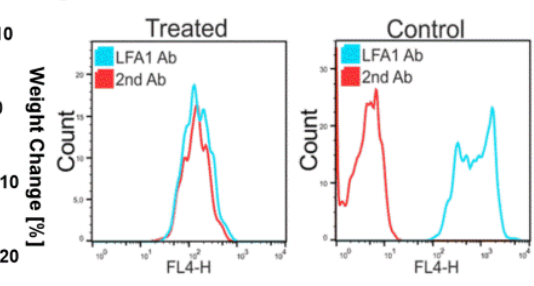

H
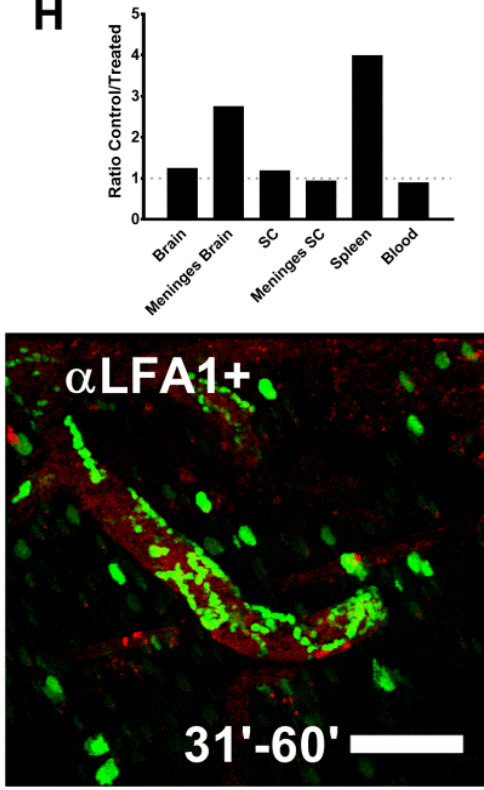

Figure 13: Blocking LFA-1 reduces TBSyn cell adhesion but does not influence crawling or ptEAE development.

(A) Intravital TPLSM of rats transferred with TBSyn-GFP cells, day 3 after transfer. $\alpha$ LFA-1 mAb injected at 30 minutes time point. Cell numbers counted in 5-minute intervals. Black line shows crawling, grey line rolling cell percentage relative to 0 minutes time point. (B) Percentage of rolling versus crawling cells inside brain vessels. (C) Track duration and (D) Velocity and of cells observed over 30 minute periods. (A-D) $n=3$, independent experiments. Antigen concentration for all experiments: $1 \mathrm{mg} / \mathrm{kg}$. Data presented as mean \pm SEM; Significance determined by Kruskal-Wallis one-way ANOVA with Dunn's Multiple Comparisons Test. ns = not significant. (E) Clinical score (bars) and relative weight change (lines) of TBSyn recipient rats treated with LFA-1 mAb on day 3 \& 4 p.t. (black bars/red line) or PBS-treated controls (white bars/grey line); $n=4$; Scores: $0=$ No clinical symptoms; $0.5=$ Reduced tail tone or partial tail paralysis; $1=$ Tail paralysis; 2 = Gait disturbance/Ataxia; 3 = Hind limb paralysis; 4 = Tetraparesis; 5 = Moribund. (F) FACS staining of LFA-1 receptor in $\alpha$ LFA-1-treated and PBS-treated controls. (G) FACS count of TBSyn-GFP cells per gram or $\mathrm{mL}$ of tissue extracted, day 5 p.t. White bars show PBS control, black bars $\alpha$ LFA-1-treated group respectively; $n=3$; Significance determined by two-way ANOVA with Bonferroni's Multiple Comparisons Test; no significant differences. (H) Ratio of extracted cells in treated vs untreated group. (I) Time-lapse images of T $\beta$ Syn-GFP cells (green) and blood vessels (texas red labelled dextran, red) 30 minutes before (left) and after (right) $\alpha$ LFA-1 Ab injection; Scale bar $=100 \mu \mathrm{m}$. 
A Effect of $\alpha$ CXCR3 injection on $T_{\beta \text { syn-GFP }}$ cells
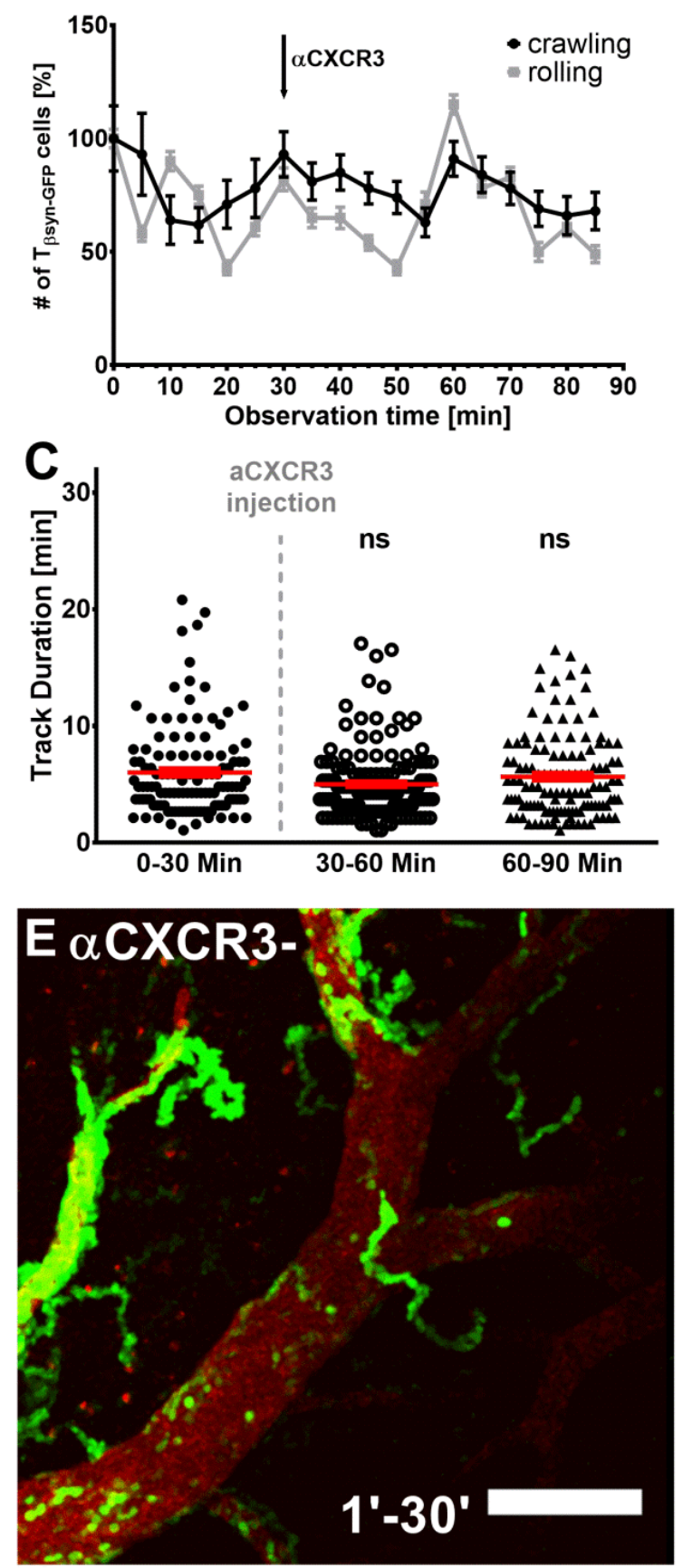

B
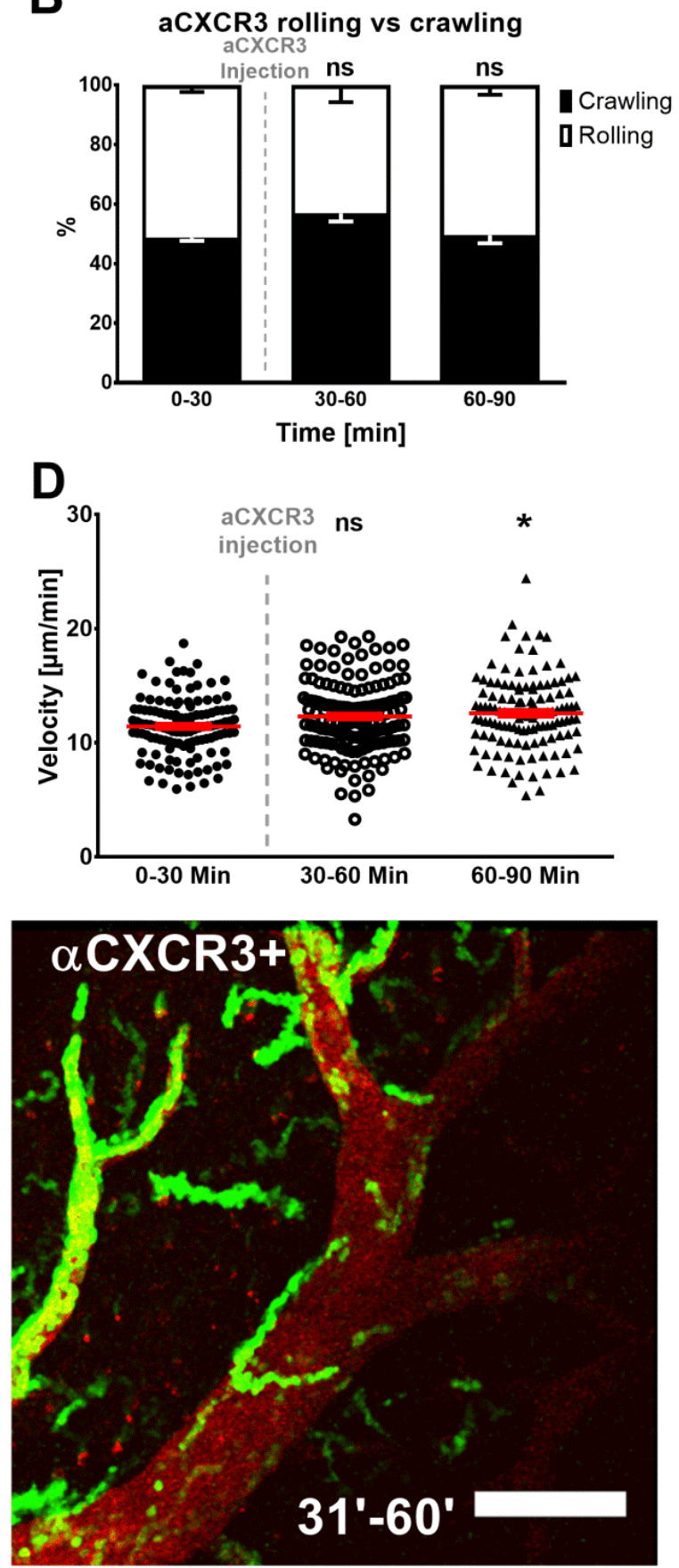

Figure 14: Effect of $\alpha$ CXCR3 mAb injection on T $\beta$ Syn cell motility.

(A) Intravital TPLSM of rats transferred with TBSyn-GFP cells, day 3 after transfer. $\alpha$ CXCR3 mAb injected at 30 minutes time point. Cell numbers counted in 5-minute intervals. Black line shows crawling, grey line rolling cell percentage relative to 0 minutes time point. (B) Percentage of rolling versus crawling cells inside brain vessels. (C) Track duration and (D) Velocity and of cells observed over 30 minute periods. (E) Time-lapse images of $T_{\beta S y n-G F p}$ cells (green) and blood vessels (texas red labelled dextran, red) 30 minutes before (left) and after (right) $\alpha$ CXCR3 Ab injection; Scale bar $=100 \mu m$. (A-D) $n=3$, independent experiments. All data originate from the same $n=3$ animals in independent experiments. Antigen concentration for all experiments: $1 \mathrm{mg} / \mathrm{kg}$. Data presented as mean \pm SEM. Significance determined by Kruskal-Wallis one-way ANOVA with Dunn's Multiple Comparisons Test. ns = not significant, * $p \leq 0.05$. 


\section{IV.8. Expression profiles of blood-derived $T$ cells are nearly identical between different antigen-specificities}

The similarity between $T$ cells of different specificities in the intravascular phase was underlined by their expression profiles discerned via next generation sequencing (NGS; Figure 15). T $T_{\beta S y n}$ cells were sorted from blood 3 days after transfer and their transcription profile was compared to sequencing data of $T_{M B P}$ cells previously obtained under the same conditions (Schläger et al., 2016). Comparing the expression of the most relevant genes for cytokine and chemokine receptors, cell adhesion, cell motility and transcription factors (a total of 145 genes), only one was found to be differentially regulated: Interleukin 2 receptor
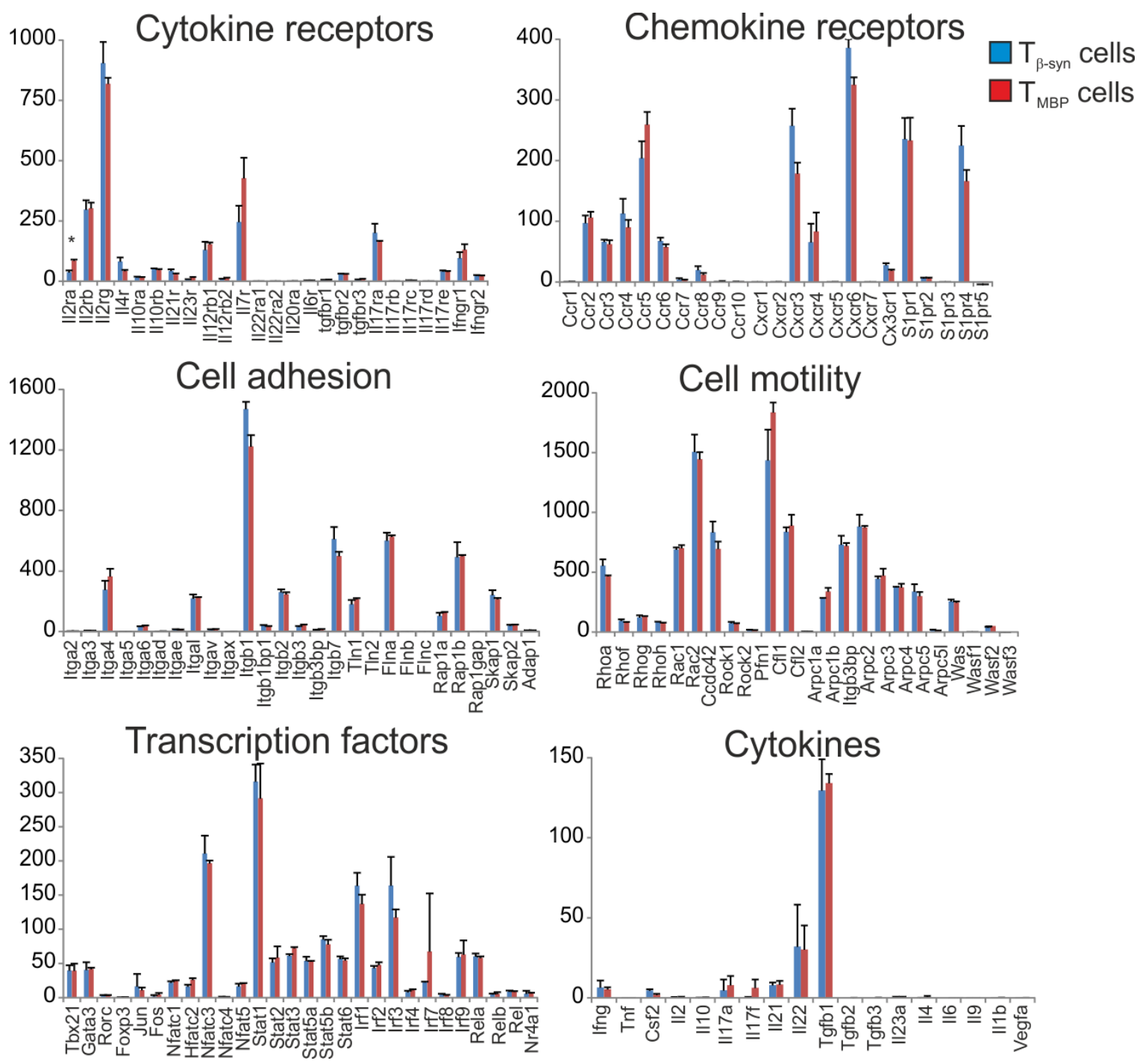

Figure 15: Next generation sequencing of T cells extracted from blood.

TßSyn cells were sorted from blood at $\mathrm{d} 3$ post transfer and their transcriptome compared to the one from TMBP cells isolated under the same conditions. Y-Axes show Reads Per Kilobase per Million mapped reads (RPKM). Statistical significance determined via Student's t-test, $* p \leq 0.05$. All data presented as mean \pm SD. TMBP sequencing data and list of relevant genes adapted with kind permission from Schläger et al., 2016. 
chain alpha (IL2ra, also known as CD25) was moderately less expressed in $\mathrm{T}_{\beta \text { Syn }}$ compared to $T_{\text {MBP }}$ cells. Together with the quantitative real-time PCR analysis (Schlosser, 2013), these data provide further strong evidence that there exist no major differences between $\mathrm{T}$ cells of different antigen-specificities before they enter the CNS.

\section{IV.9. Motility behaviour of $\mathrm{T}_{\beta S y n}$ cells in the brain grey matter}

After extravasation from the brain vessels, $T_{\beta S y n}$ cells rapidly accumulated in the subpial cortex, increasing their numbers within a few hours from $62.07 \pm 20.39$ SEM to 311.2 \pm 33.21 SEM cells per frame at EAE onset (Figure $16 \mathrm{~A}$ ). At disease peak, the number of extravasated cells seemed to increase further to around 500 cells per frame. During their patrolling of the extravascular space, T cells interact with local antigen presenting cells, where they can encounter their appropriate antigen and become re-activated. Due to these
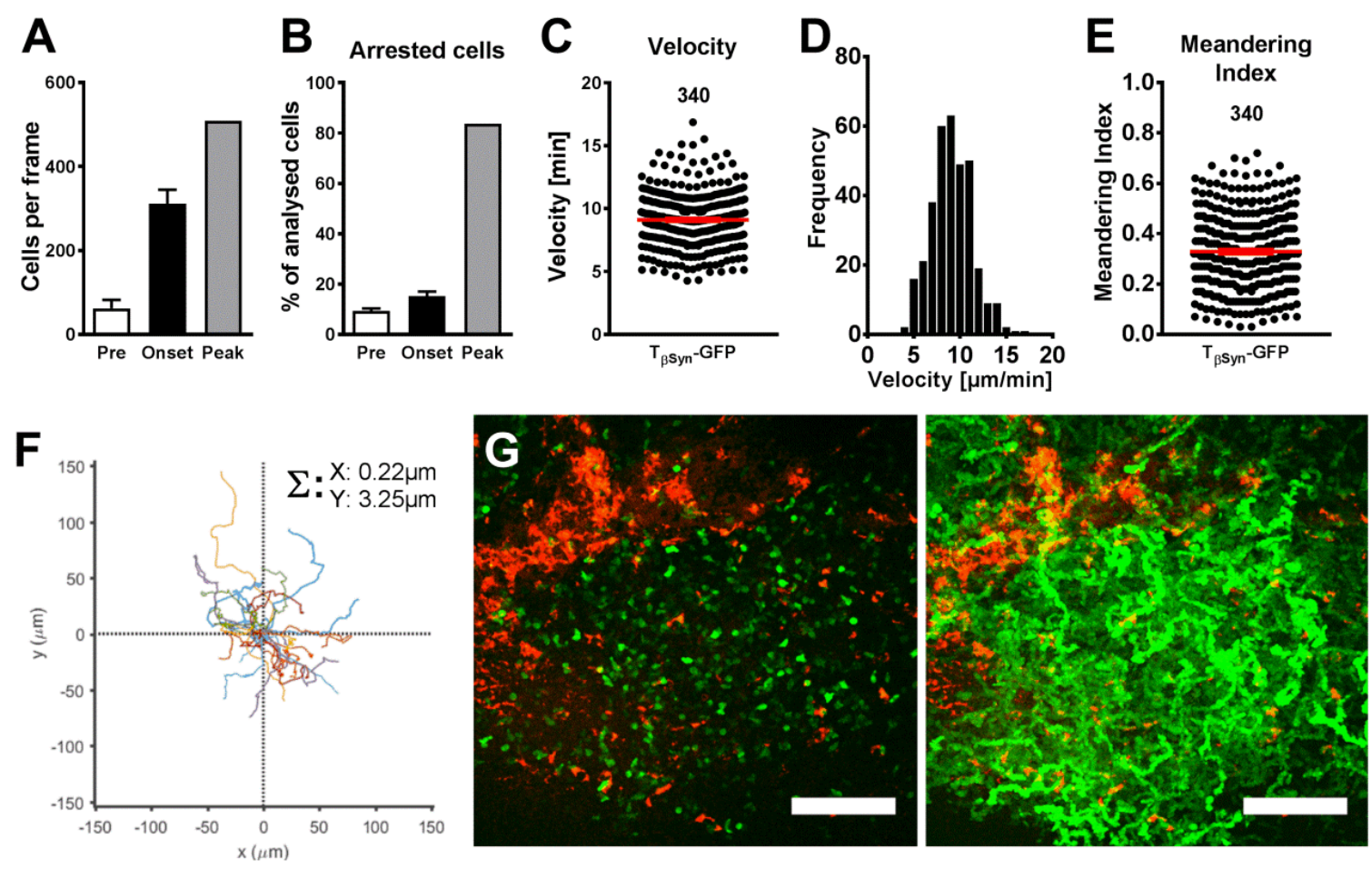

Figure 16: Analysis of TßSyn-GFP cell extravascular crawling via TPLSM.

Intra-vital TPLSM of TBSyn-GFP cells in the rat brain grey matter. (A) Quantification of T cells per frame, taken from the first frame of every 30' video (dataset for Pre adapted from Figure 10) \& (B) percentage of arrested TBSyn-GFP cells before onset (Pre), at onset and at peak of EAE. (C) Velocity \& (D) velocity frequency of T $\beta S y n-G F P$ cells during a 30' observation period at EAE onset. (E) Meandering index of T $\beta S y n-$ GFP cells observed over a 30' period. (F) Representative graph of superimposed trajectories of T $\beta$ Syn cells in one video ( $n=30$ cells, each line representing one cell); $\Sigma$ : sum of trajectory vectors divided by the number of cells. (G) Representative image of TßSyn-GFP cells (green) and blood vessels/APCs (red) at the first frame (left) and as a 30' time-projection (right); Scale bar $=100 \mu m$. Pre $n=4$; Onset $n=3$; Peak $n=1$. All data presented as mean \pm SEM. 
interactions, T-cell velocity is slowed down and the percentage of arrested cells is increased (Bartholomäus et al., 2009; Lodygin et al., 2013). In vivo TPLSM of $\mathrm{T}_{\beta S y n}$ cells in the grey matter of the brain revealed a similar pattern with an increase in arrested cell percentage from $9.32 \% \pm 1.06 \mathrm{SEM}$ in the pre-clinical phase to $15.27 \% \pm 1.80 \mathrm{SEM}$ at EAE onset (Figure 16 B), suggesting an increased T-cell-APC-interaction at this time point. Several hours later, at EAE peak, more than $80 \%$ of cells ceased movement and appeared rounded (not shown), indicative of initiated apoptosis and presumably the beginning of disease remission (Gold et al., 1997). Following these observations, further analysis of motile $T_{\beta S y n}$ cells inside brain grey matter parenchyma at EAE onset was performed. Trajectory analysis revealed that $\mathrm{T}_{\beta S y n}$ cells moved with an average velocity of $9.11 \mu \mathrm{m} / \mathrm{min} \pm 0.12 \mathrm{SEM}$ and, while the majority of cells $(65 \%)$ moved with $8-11 \mu \mathrm{m} / \mathrm{min}$, the maximum velocity reached was $16.86 \mu \mathrm{m} / \mathrm{min}$ (Figure 16 C \& D). No directed motion was detectable (Figure 16 F). Interestingly, in a 30minute observation time $T_{\beta \text { Syn }}$ cells scanned the entire target tissue freely and thoroughly, despite the presumable density of the grey matter parenchyma (Figure $16 \mathrm{G}$ ). The meandering index however, might give some indication of the laboriousness of navigating grey matter parenchyma compared to the meninges. While a meandering index of 1 would describe a perfectly straight line, a value approaching 0 describes a highly skewed movement path. $T_{\beta S y n}$ cells in the grey matter parenchyma showed a meandering index of 0.33 (Figure $16 \mathrm{E}$ ). In literature, a slightly higher meandering index of roughly 0.4 was described for $\mathrm{T}_{\mathrm{MBP}}$ cells navigating the SC meninges (Schläger et al., 2016).

\section{IV.10. Comparison of expression profiles between blood- and brain-derived $\mathrm{T}_{\beta S y n}$ cells indicates re-activation in situ}

It has been shown that an essential step for EAE development is the local re-activation of $\mathrm{T}_{\mathrm{MBP}}$ cells in the SC (Lodygin et al., 2013). We therefore investigated if the same process occurred for $T_{\beta S y n}$ cells in the brain. Such a local re-activation of T cells in their target tissue should be reflected by their expression profile. Therefore, at EAE onset (day 4), $T_{\beta S y n}$ cells were isolated from blood and brain and their expression profiles analysed via NGS (Figure 17). Of note, gene expression of blood-resident $T_{\beta S y n}$ cells did not change between day 3 (see chapter IV.8) and day 4 post transfer and only 7 genes were found to be differentially 


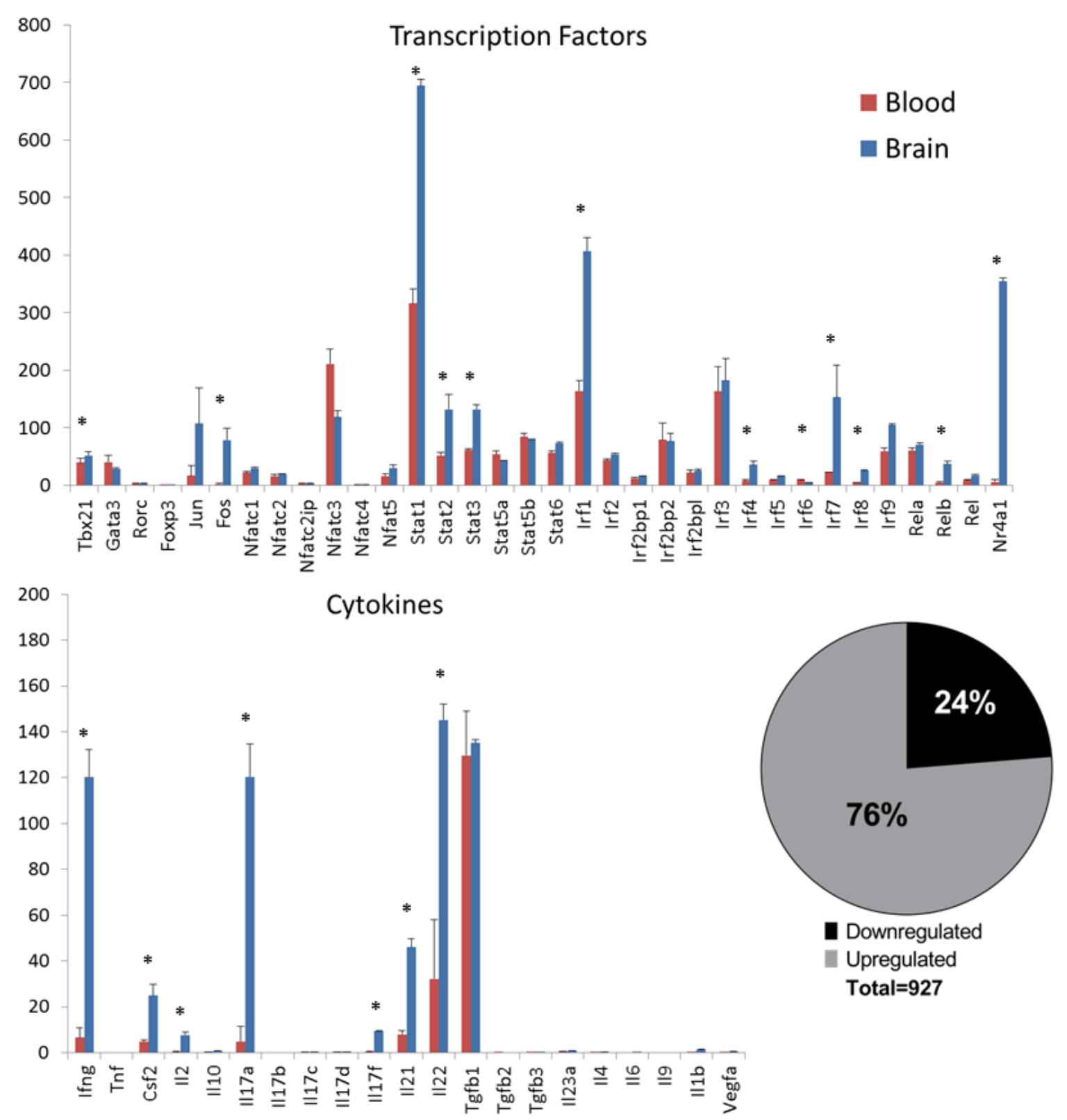

Figure 17: Comparison of the expression profiles of TßSyn cells derived from blood and brain.

$T_{\beta S y n}$ cells were sorted from blood and brain at $d 4$ post transfer and analysed for differential gene expression. In total, 927 genes were differentially regulated (76\% up-/24\% downregulated in T $\beta$ Syn cells isolated from brain compared to blood). Y-Axes show Reads Per Kilobase per Million mapped reads (RPKM). Statistical significance determined via Student's t-test, ${ }^{*} p \leq 0.05$. All data presented as mean $\pm S D$.

regulated between those cells (not shown, max. change was $-1.08 \log 2$-fold). Signifying pronounced expressional changes, of 927 differentially regulated genes, 707 ( 76\%) were found to be up-regulated in brain-derived $T_{\beta S y n}$ cells compared to the blood (Figure 17). Importantly, the up-regulation of many of the most relevant transcription factors (12 of 34 genes) and cytokines (7 of 21 genes; see also chapter IV.8) in brain-derived $T_{\beta S y n}$ cells clearly demonstrated an elevated activation state of $\mathrm{T}_{\beta \mathrm{Syn}}$ cells in the target tissue. In particular, several transcription factors related to T-cell activation were significantly regulated (e.g. 
tbx21 and the IFN $\mathrm{Y}$-responsive STAT1). Among the cytokines a significant up-regulation of IFNY, III7A and F, IL-2 and IL-21 was observed.

\section{IV.11. AAV-mediated antigen-availability influences T-cell recruitment and motility}

In order to confirm the role of antigen availability in determining T-cell infiltration (Kawakami et al., 2004), we aimed to foster specific antigen presentation in the brain by cranially injecting new-born pups with an adeno-associated virus either expressing human $\beta$-Synuclein and GFP (AAV- $\beta$ Syn-GFP) or as control the fluorescent reporter GFP (AAV-GFP) under a neuronal promoter (Kügler et al., 2003). Of note, the human $\beta$-Synuclein shares $98 \%$ homology with the rat protein and the sequence of the peptide 93-111, which is used to establish the $T_{\beta S y n}$ cell lines, is identical (Altschul et al., 1990; Lavedan et al., 1998). At the age of 6-8 weeks, ptEAE was induced by injection of $\left(5 \times 10^{6}\right) T_{\beta S y n-m C h e r r y}$ cells. Due to limited availability of animals, the clinical course was only followed until day 5 post transfer, where no significant change between the two groups could be observed, but a trend can be surmised (Figure $18 \mathrm{~A}$ ). It is also possible that a locally restricted overexpression did not suffice to evoke disease aggravation. Intravital TPLSM of the parietal cortex revealed $T_{\beta S y n-m C h e r r y}$ cells in close proximity to fluorescently marked neurons at EAE onset (day 4 post transfer, Figure 18B \& C). Comparative analysis revealed that, while EAE symptoms were comparable, three-fold more $T_{\beta S y n-m \text { cherry }}$ cells invaded the cortex of AAV- $\beta$ Syn-GFP animals relative to the AAV-GFP group (560.2 \pm 77.31 SEM vs $181.2 \pm 31.86 S E M, p=0.0043$, Figure $18 \mathrm{D}$ ). In line with this finding, the histological analyses revealed increased infiltration of $\mathrm{T}$ cells into AAV- $\beta S y n-G F P$ brains, compared to AAV-GFP controls. Local expression of AAV- $\beta S y n-$ GFP even seemed to lead to heightened recruitment to areas that were otherwise only sparsely infiltrated, like the hippocampus (Figure 18G \& H). Analysis of in situ motility data showed that $T_{\beta S y n-m \text { cherry }}$ cells in AAV- $\beta$ Syn-GFP animals moved with notably reduced velocity compared to their counterparts in AAV-GFP brains $(9.40 \mu \mathrm{m} / \mathrm{min} \pm 0.14$ SEM vs $11.23 \mu \mathrm{m} / \mathrm{min} \pm 0.20 \mathrm{SEM}, \mathrm{p}<0.0001$, Figure $18 \mathrm{E})$. No difference could be detected in the meandering index between both groups (Figure $18 \mathrm{~F}$ ). Overall, these data indicate increased recruitment and of $T_{\beta S y n}$ cells in response to increased antigen availability. To conclusively confirm the local reactivation of $T_{\beta s y n}$ cells, further experiments will be necessary; they will be addressed in the discussion. 

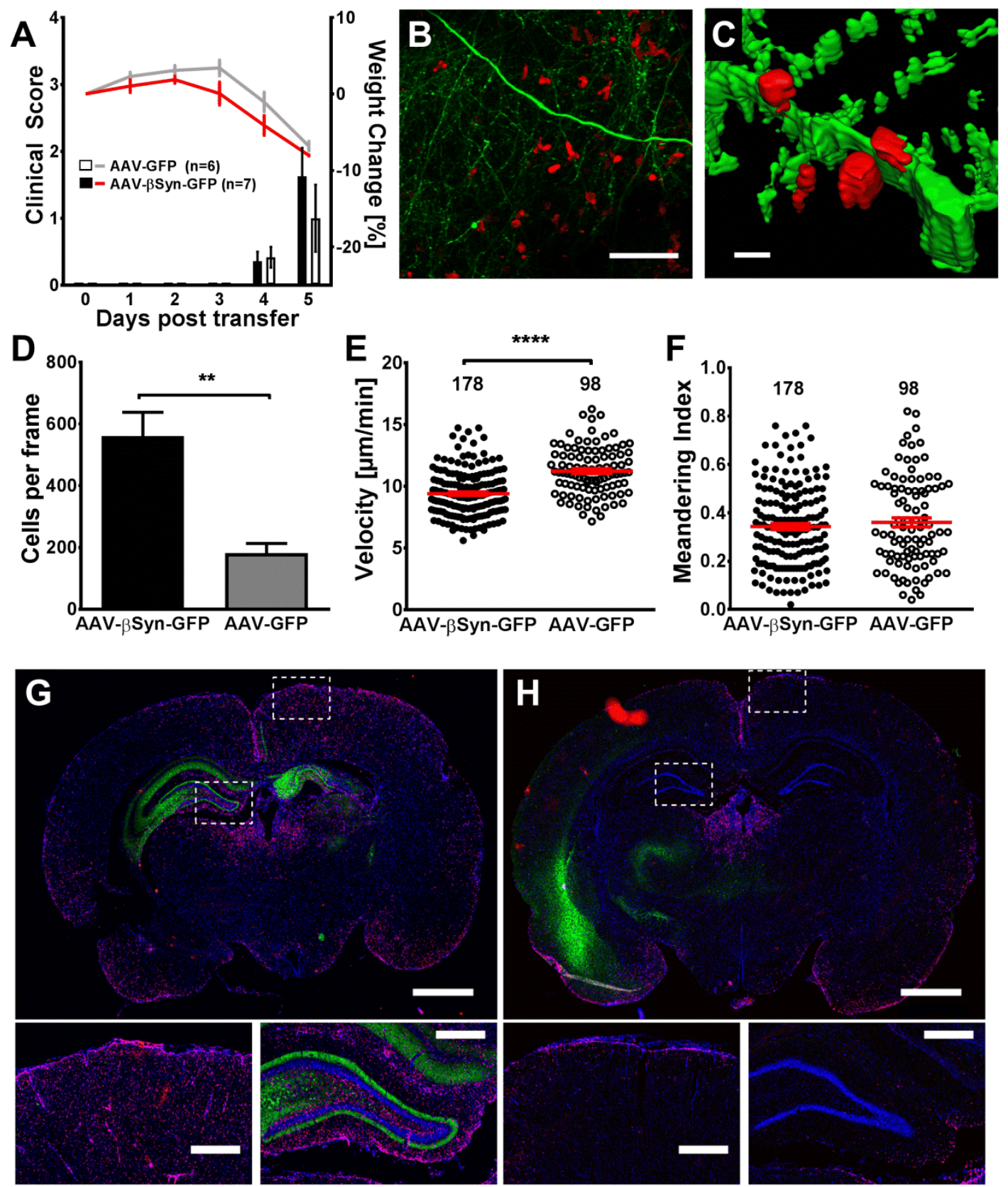

Figure 18: Increasing local $\beta$-Synuclein availability via AAV transduction elevates T $\beta$ Syn cell infiltration in the brain.

Rats were neonatally transduced with an AAV expressing GFP or $\beta$ Syn-GFP under a neuronal promoter and received TBSyn-mCherry transfer $\left(5 \times 10^{6}\right.$ per animal). Of note, for a more sensitive readout, a reduced number of $T$ cells were transferred compared to other experiments. (A) Clinical score (bars) and relative weight change (lines) of AAV- $\beta$ Syn-GFP rats (black bars/red line) or AAV-GFP controls (white bars/grey line) transferred with TBSyn-mCherry cells; $n=7$; Scores: $0=$ No clinical symptoms; $0.5=$ Reduced tail tone or partial tail paralysis; 1 = Tail paralysis; 2 = Gait disturbance/Ataxia; 3 = Hind limb paralysis; 4 = Tetraparesis; 5 = Moribund. (B) In vivo TPLSM of an AAV-GFP rat brain day 4 p.t.; neurons (green) and TBSyn-mCherry cells (red); scale bar $=50 \mu \mathrm{m}$. (C) 3D-reconstruction of TBSyn-mCherry cells (red) in close proximity to AAVGFP neurons (green); scale bar $=10 \mu \mathrm{m}$. (D) Quantification of extravascular T cells per frame, taken from the first frame of every 30' video. (E) Velocity and (F) meandering index and of TßSyn-mCherry cells observed over 30 minute periods. $n=2$, in two independent experiments 178 (AAV- $\beta S y n-G F P$ ) and 98 (AAVGFP) T cells were observed. (G) Brain slices from AAV- $\beta$ Syn-GFP \& (H) AAV-GFP control rats, d4 p.t., score 1; AAV expression (green), TBSyn-mCherry cells (red) and DAPI-stained nuclei (blue), scale bars $=2 \mathrm{~mm}$; cut-outs show cortex \& hippocampus, scale bars $=500 \mu \mathrm{m}$. Statistical significance determined via MannWhitney test, ${ }^{* *} \mathrm{p} \leq 0.01, * * * * \mathrm{p} \leq 0.0001$. All data presented as mean $\pm \mathrm{SEM}$. 


\section{IV.12. Spine density is reduced in $\mathrm{T}_{\beta S y n-}$ but not $\mathrm{T}_{\mathrm{MBP}}$-cell mediated ptEAE}

Given the presence of inflammatory infiltrates in the brain cortex, the neuronal integrity was examined. Indeed, as shown before (Figure 8), $T_{\beta S y n}$ cells were frequently found in direct proximity to cortical neurons, some of them seemed to directly interact with dendritic spines (Figure 18B \& C, Figure $19 \mathrm{D}-\mathrm{F}$ ). We therefore wondered if there were any detectable consequences on the cortical neurons themselves. In order to gain insight into possible changes within the cortex of EAE-affected rats, spine density analyses of the apical dendrites of cortical layer $2 / 3$ neurons were performed at EAE peak. This method allows for the detection of morphological changes underlying synaptic transmission on a microscopic level that have also been implicated in MS pathology (Fiala et al., 2002; Magliozzi et al., 2010; Ksiazek-Winiarek et al., 2015). Changes in the density of dendritic spines occur very rapidly (Lendvai et al., 2000; Trachtenberg et al., 2002), therefore each experimental group (2-3 repeated experiments per group) was accompanied with its individual set of healthy littermate controls. Interestingly, while spine density remained unchanged $(p=0.9327)$ in rats at the peak of ptEAE induced by transfer of $\mathrm{T}_{\mathrm{MBP}}$ cells $(2.30 \pm 0.10 \mathrm{SEM}$ spines/ $\mu \mathrm{m})$ versus control $(2.26 \pm 0.08 \mathrm{SEM}$ spines $/ \mu \mathrm{m})$, the reduction of spine density in $T_{\beta S y n}$ cell ptEAE $(1.42 \pm 0.05 \mathrm{SEM}$ spines $/ \mu \mathrm{m})$ compared to control $(1.95 \pm 0.07 \mathrm{SEM}$ spines/ $\mu \mathrm{m})$ was highly significant $(p<0.0001$, Figure 19A \& B). In an attempt to show a direct comparison of spine density in $T_{\beta S y n}$ and $T_{M B P}$ ptEAE, Figure $19 \mathrm{C}$ shows all values transformed to be expressed as a percentage of the corresponding naïve littermate control. Spine density was reduced to $74.60 \% \pm 3.35 S E M$ in $T_{\beta S y n}$ ptEAE ( $\left.p=0.0210\right)$. In comparison, no change was detectable in $T_{M B P}$ ptEAE with $101.38 \% \pm 3.20$ SEM change $(p=0.8955)$. Notably, the observed effect did not persist after the acute EAE bout. In fact, spine density approaches control values with diminishing disease score (recovery) and can be assumed to completely normalize with disappearance of EAE pathology (data not shown). 
A Spine Density ( $\beta$ Syn ptEAE)

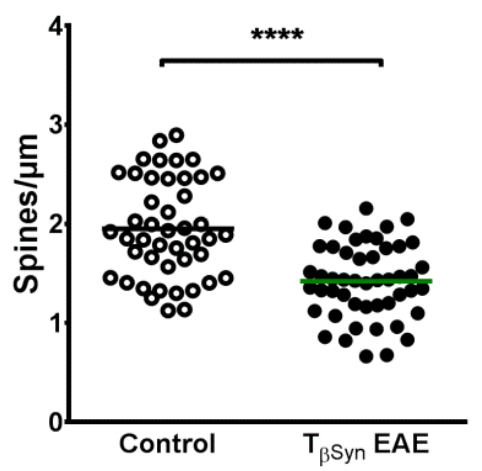

B Spine Density (MBP ptEAE)

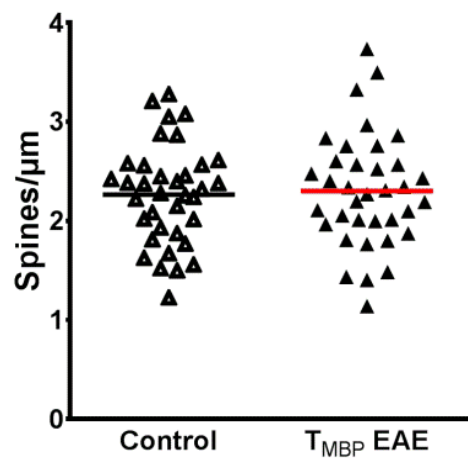

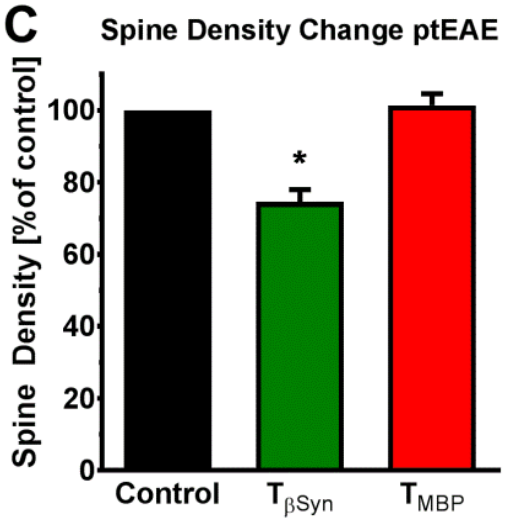
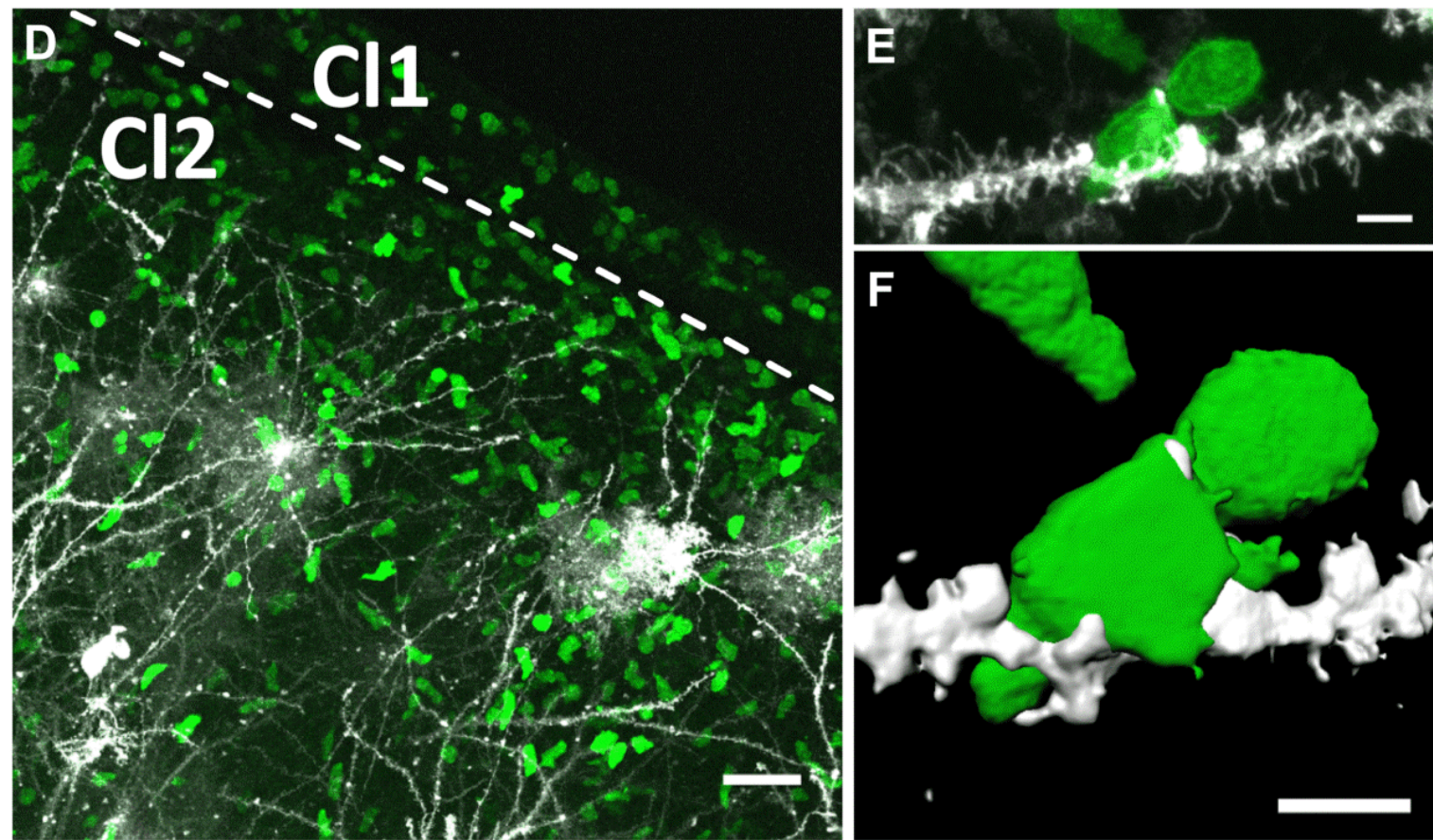

Figure 19: Dendritic spines are reduced during peak TBSyn ptEAE, but not during TMBP ptEAE.

Spine density on apical dendrites of cortical layer $2 / 3$ neurons was (A) reduced in T $\beta$ Syn ptEAE vs naïve littermate controls (1.42 $\pm 0.05 \mathrm{SEM}$ vs $1.95 \pm 0.07 \mathrm{SEM}$ spines/ $\mu \mathrm{m}, \mathrm{p}<0.0001) ; \mathrm{n}=7,3$ individual experiments). (B) Spine density remained unchanged in TMBP ptEAE $(2.30 \pm 0.10 \mathrm{SEM}$ vs $2.26 \pm 0.08 \mathrm{SEM}$ spines/ $\mu \mathrm{m}$, $p=0.9327) ; n=6,2$ individual experiments. (C) Shows the same data as relative percentages of the corresponding control (reduction to $74.60 \% \pm 3.35$ SEM in TBSyn ptEAE, $p=0.0210$; no change in TMBP ptEAE with $101.38 \% \pm 3.20$ SEM, $p=0.8955)$. Apical dendrites of $6-8$ cortical layer $2 / 3$ neurons were analysed for each sample. Statistical significance determined via Mann-Whitney test. Data presented as mean \pm SEM. (D) Massive infiltration of TßSyn-GFP cells (green) around cortical layer 2 (Cl2) Dil-stained neurons (white); scale bar $=30 \mu \mathrm{m}$. (E) Detail image of TBSyn-GFP cells around $\mathrm{Cl} 2$ dendrite. (F) 3D-reconstruction of $(E)$ to highlight the extreme proximity of dendrite and T cell. (E\&F) scale bars $=10 \mu \mathrm{m}$. 


\section{IV.13. MRI as a tool for investigating EAE over time}

Longitudinal MRI was chosen as a method of observing the impact of neuronal EAE on brain and BBB. Both active and passive transfer EAE were investigated. The following parameters were evaluated:

(1) Ventricular enlargement (Figure $20 \mathrm{~A}$ ). It was described as an early indicator of EAE in mice (Lepore et al., 2013) and its occurrence has been linked to cortical atrophy in rat EAE (Tambalo et al., 2015).

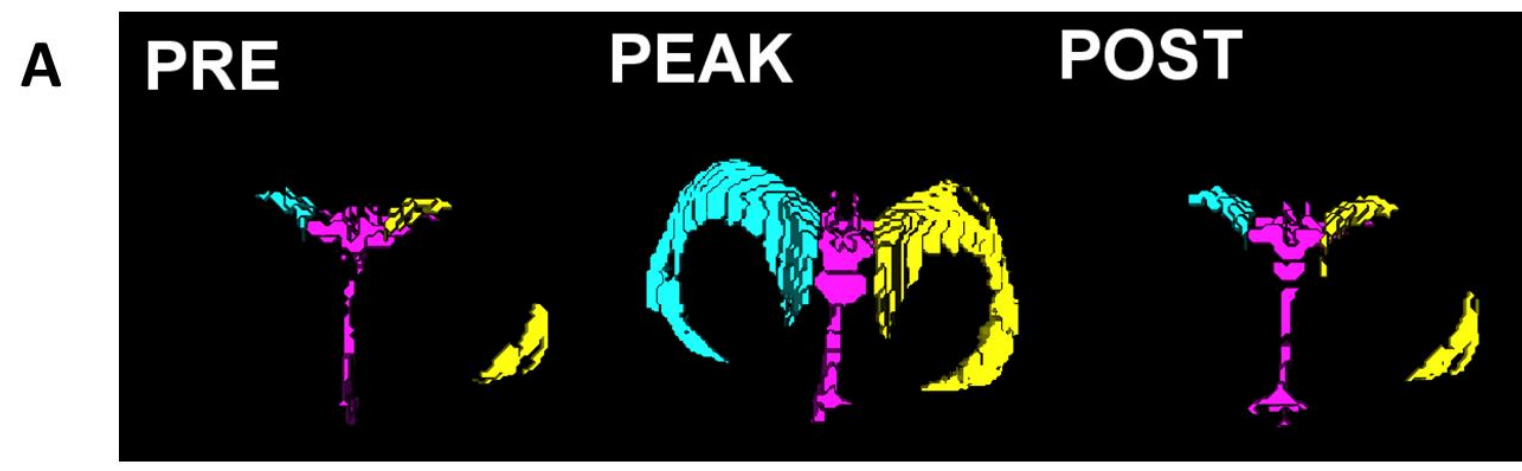

B

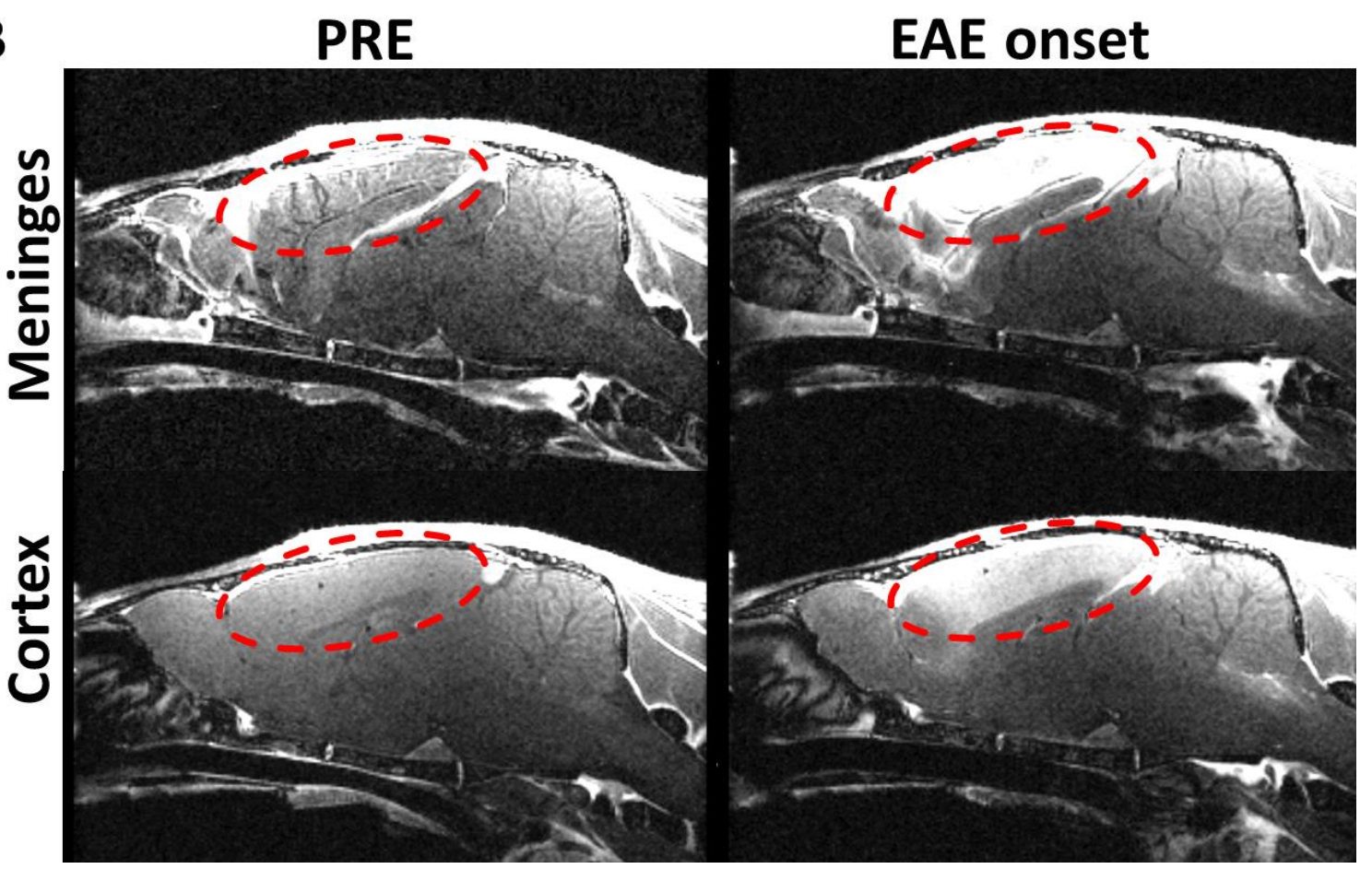

Figure 20: MRI analysis of ventricular enlargement and gadolinium enhancement.

Representative images of a $\beta$ SynTG(T/+) rat acquired during aEAE. (A) 3D reconstruction (frontal view) of the third (magenta) and lateral (turquoise/yellow) ventricles, before (PRE), during (PEAK) and after the course of EAE (POST). (B) Sagittal view of gadolinium enhancement in cortical meninges (upper panel, midsagittal) and cortex (lower panel, $\sim 0.5 \mathrm{~mm}$ from mid-sagittal) before EAE induction and at disease onset; image acquired by Dr. Takashi Watanabe (Biomedizinische NMR Forschungs GmbH, MPI for biophysical Chemistry). 
(2) Cortical thickness. Loss of brain volume is strongly associated with cognitive impairment in MS patients (reviewed by Vollmer et al., 2015).

(3) Leakage of the BBB, measured by Gadolinium (Gad) enhancement (Figure $20 \mathrm{~B}$ ). It has been shown to be linked to leukocyte infiltration and macrophage activation into the brain (Hawkins et al., 1990; Morrissey et al., 1996).

Moreover, imaging of the eyes was included in this analysis, as inflammation was frequently detected here (not shown; Mor et al., 2003).

\section{IV.13.1. MRI in passive transfer EAE}

Animals were examined before induction, at the onset, at the peak of EAE, and 3-5 days after recovery. Intra-group analysis revealed a transient ventricular enlargement during the onset of EAE in $T_{\beta S y n}$ recipient rats $(p=0.0154)$. This was, however, not significantly different from $T_{M B P}$ recipients $(p=0.7765)$, who showed no significant overall changes (Figure $21 A$ ). Cortical thickness remained unchanged in both groups over the entire observation period (Figure 21 B). Regarding the Gad enhancement caused by BBB leakage, the only site with a significant difference between the ptEAE groups were the meninges, where a substantial increase in signal intensity was found in $T_{\beta S y n}$ recipient rats at EAE onset ( $p=0.0046$; Figure $21 \mathrm{C})$. At this time point the intra-group analysis also revealed a highly significant, transient Gad enhancement within the $T_{\beta S y n}$ group $(p=0.0002)$. Similarly, significantly increased Gad signals were detected at disease onset for both groups in the brainstem surrounding the area postrema and in the adjacent choroid plexus, a network of cells with a reduced tightness of the blood-CSF barrier, which was discussed as a possible entry site for T cells into the CNS (reviewed in Ransohoff and Engelhardt, 2012). In the white matter (corpus callosum) no changes could be detected in either group. 

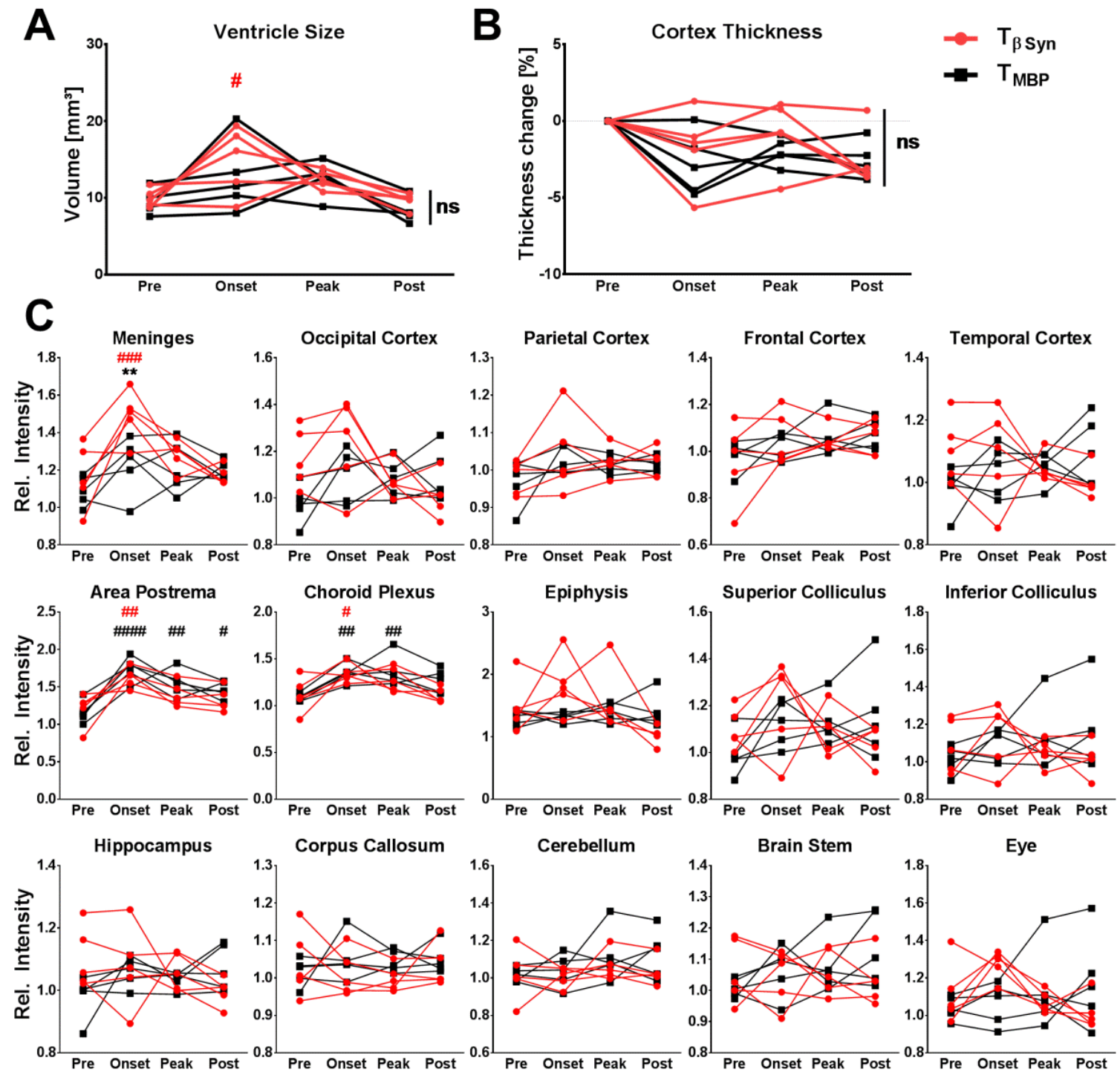

Figure 21: Longitudinal MRI in neuronal and classical passive transfer EAE.

Rats transferred with $T_{\beta S y n}$ (red) or $T_{M B P}$ (black) cells were examined before induction, at EAE onset, at peak, and 4-7 days after recovery. (A) Combined volume of lateral and third ventricles. (B) Change in cortical thickness. (C) Relative signal intensity of different brain areas and eye in Gad-enhanced T1weighted MRI. $n=5$; Statistical significance determined via repeated measures two-way ANOVA with Bonferroni's multiple comparisons test for inter-group comparison ( $\left.{ }^{*} p \leq 0.01\right)$ and Dunnett's multiple comparisons test for intra-group analysis (\#p $\leq 0.05, \# \# p \leq 0.01, \# \# \# \leq 0.001, \# \# \# p \leq 0.0001$ ); hash mark colour indicates the group analysed (red $\mathrm{T}_{\beta S y n}$, black $\mathrm{T}_{\mathrm{MBP}}$ ).

\section{IV.13.2. $\quad$ MRI in active EAE}

Active EAE was induced in $\beta$ SynTG ${ }^{(\mathrm{T} /+)}$ rats by immunization against $\beta$ Syn and in $\mathrm{MBPTG}^{(\mathrm{T} /+)}$ rats using MBP (see IV.1). MRI was performed before induction, during EAE and 4-7 days after recovery. In many regards, the effects observed in ptEAE of $\beta$ Syn-specific $T$ cells appeared amplified in active EAE of $\beta S y n \mathrm{G}^{(\mathrm{T} /+)}$ rats. The increase in ventricular volume, 

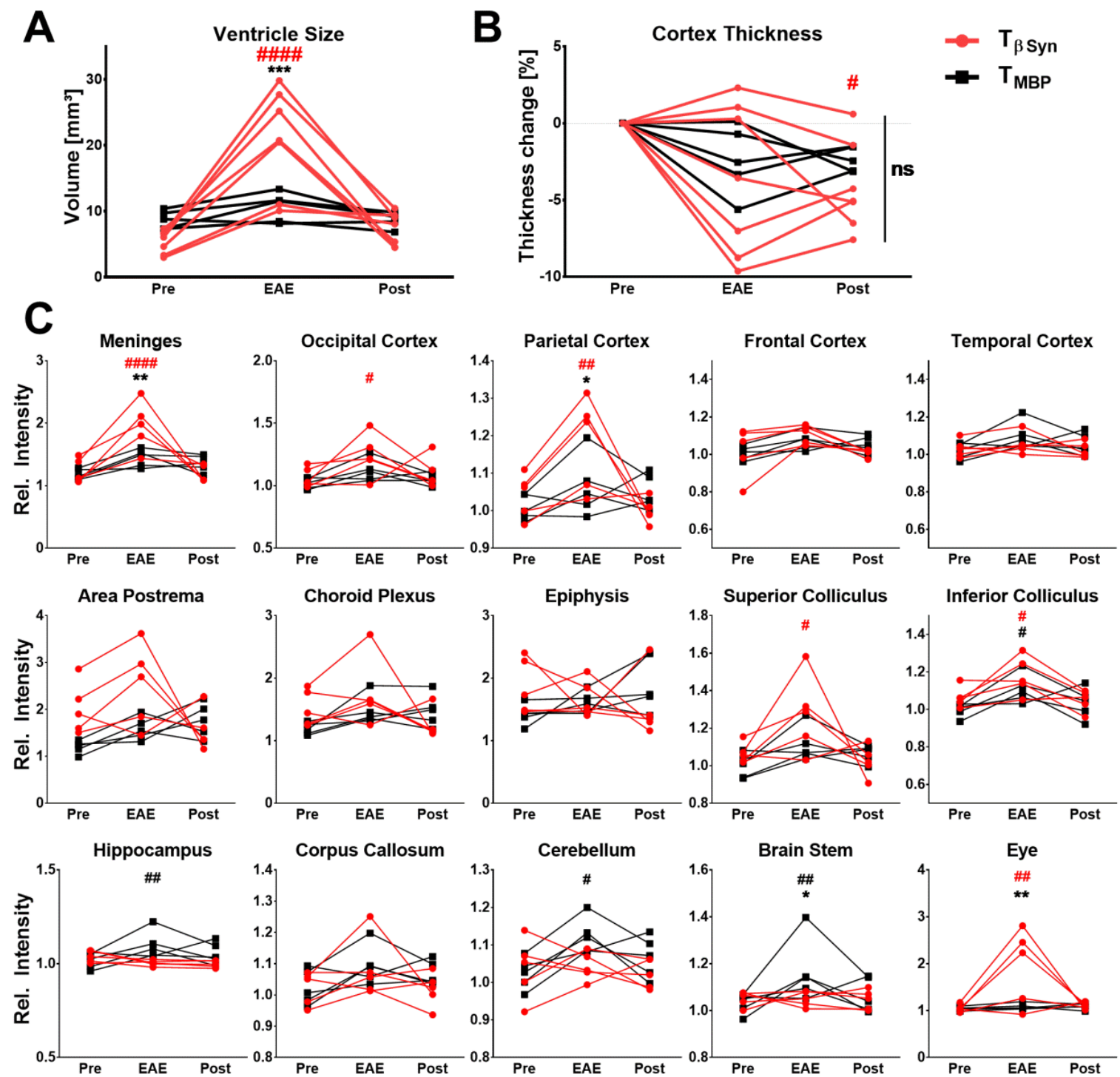

Figure 22: Longitudinal MRI in $\beta$ Syn-mediated active EAE in $\beta$ SynTG(T/+) rats reveals transient ventricular enlargement and BBB disruption, as well as cortical atrophy.

Rats actively immunized with $\beta$ Syn ( $\beta$ SynTG(T/+) genotype, red, $n=7$ ) or MBP (MBPTG(T/+) genotype, black, $n=5$ ) were examined before induction, during EAE, and 4-7 days after recovery. (A) Combined volume of lateral and third ventricles. (B) Change in cortical thickness. (C) Relative signal intensity of different brain areas and eye in Gad-enhanced T1-weighted MRI. Statistical significance determined via repeated measures two-way ANOVA with Bonferroni's multiple comparisons test for inter-group comparison $\left({ }^{*} p \leq 0.05,{ }^{* *} p \leq 0.01,{ }^{* * *} p \leq 0.001\right)$ and Dunnett's multiple comparisons test for intra-group analysis (\#p $\leq 0.05, \# \# p \leq 0.01, \# \# \# p \leq 0.0001$ ); hash mark colour indicates the group analysed (red $\beta$ Syn, black MBP).

while again transient, was more than three-fold in some animals. Meanwhile, no increase was detectable in $\mathrm{MBPTG}^{(\mathrm{T} /+)}$ animals $(p=0.0003$, Figure $22 \mathrm{~A})$. Indications of atrophy were found after recovery, where a significant decrease in cortical thickness was detectable by intra-group analysis in $\beta$ SynTG ${ }^{(T /+)}$ rats $(p=0.0451)$. However, this reduction was not significant by inter-group comparison (Figure $22 \mathrm{~B}$ ). 
A transient breakdown of the BBB (i.e. Gad enhancement) was evident not just in the meninges $(p=0.0015)$, but also in the parietal cortex $(p=0.0441)$ during EAE in $\beta S y n T G^{(T /+)}$ but not $\mathrm{MBPTG}^{(\mathrm{T} /+)}$ animals (Figure $22 \mathrm{C}$ ). As in ptEAE, no significant change was detected in the corpus callosum. $\mathrm{MBPTG}^{(\mathrm{T} /+)}$ rats further showed $\mathrm{Gad}$ enhancement in brain stem, cerebellum and also the hippocampus. In inter-group analyses, these values were only significant in the brain stem $(p=0.0448)$.

Interestingly, the eyes were also strongly affected in aEAE of $\beta S y n T G^{(T /+)}$ rats. Strong Gad enhancement, indicative of uveitis, was detected in the eyes of most rats ( $p=0.0015$; Figure $22 \mathrm{C})$. Virtually no $\beta$ SynTG ${ }^{(\mathrm{T} /+)}$ rat examined by MRI was free of morphological changes in the eye, while in $\mathrm{MBPTG}^{(\mathrm{T} /+)}$ rats the eyes were not affected (not shown).

\section{IV.14. Repeated inflammatory bouts aggravate EAE-induced changes in the brain}

So far, MRI and histological data indicated that a single inflammatory attack induces transitory neuronal damage. In MS, a strong connection was drawn between meningeal inflammation, neuronal pathology and disability (Magliozzi et al., 2010). Interestingly, we discovered that heterozygous receptor-transgenic $\beta S y n \mathrm{TG}^{(\mathrm{T} /+)}$ rats can be repeatedly transferred with $T_{\beta S y n T(T / T)}$ cells, each time resulting in EAE development. This provides a singular opportunity for studying the consequence of repeated CNS grey matter inflammations solely incited by encephalitogenic T-cell transfer. Drawing parallels to MS, the effects of repeated inflammatory bouts on the CNS tissue were examined. Therefore, $\beta$ SynTG ${ }^{(T /+)}$ rats were transferred with either $T_{\beta S y n T G(T / T)}(E A E)$ or TovA (control) cells, for four times every 15 days. $\beta$ SynTG ${ }^{(T /+)}$ rats responded with a severe bout of atypical EAE to every transfer of $T_{\beta S y n T G(T / T)}$ cells, followed by apparent complete remission of clinical symptoms; TOVA-GFP recipients remained healthy (Figure 23 A). There was no significant difference between EAE and control after the first EAE bout ( $p=0.0751)$, whereas a highly significant reduction in cortical thickness was detected four days $(p<0.0001)$ and even 18 days after recovery from the last EAE ( $p=0.0003$, Figure $23 \mathrm{~B})$. No such change was detected at any point in the corpus callosum (Figure $23 \mathrm{C}$ ), underlining the cortical grey matter as the actual target of the observed effects. MRI examination revealed prominent ventricular enlargement in EAE animals during the first disease episode $(p<0.0001)$, receding within 3 
days post recovery. After the fourth bout of EAE, this enlargement was again detected $(p=0.0097)$, but it did not recede completely after four $(p=0.0001)$ and even 18 days post recovery $(p=0.0077)$, indicative of an irreversible change in brain structure (Figure $23 D)$. We subsequently measured rotarod performance in rats which had suffered multiple episodes of $E A E$, but found no evidence of motor deficits (Figure $23 \mathrm{E}$ ). Additionally, no changes in dendritic spine density were found six weeks after the last EAE bout (Figure $23 \mathrm{~F}$ ), indicating compensatory or regenerative mechanisms in the remaining neurons.

Analysis of Gadolinium enhancement during the first and fourth EAE episode revealed a highly significant BBB disruption in the cortical meninges, all examined cortical areas (occipital, parietal, frontal and temporal), as well as the superior and inferior colliculi (Figure $23 \mathrm{G})$. The choroid plexus and the epiphysis were also affected, but not the area postrema, hippocampus, nor the corpus callosum, cerebellum, brainstem or eyes. This correlated well with the observed infiltration pattern of $T_{\beta S y n}$ cells (Figure 8). Interestingly, Gadolinium enhancement trended to decline with repeated EAE incidences, hinting at potential compensatory mechanisms which strengthened BBB integrity after multiple inflammatory events. 
A

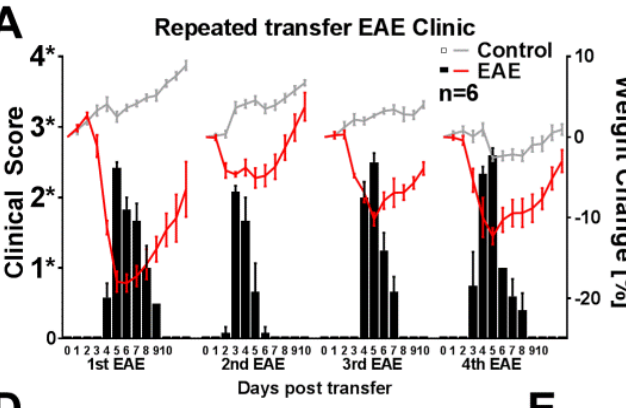

B cortex Thickness C

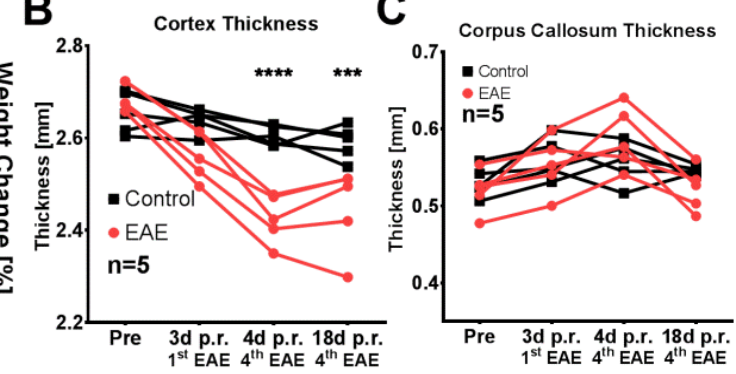

D

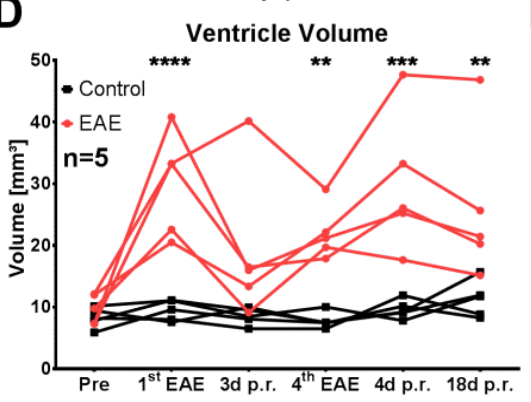

E

D.

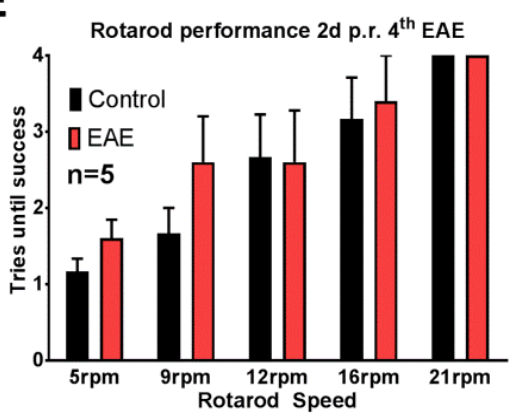

F Spine Density
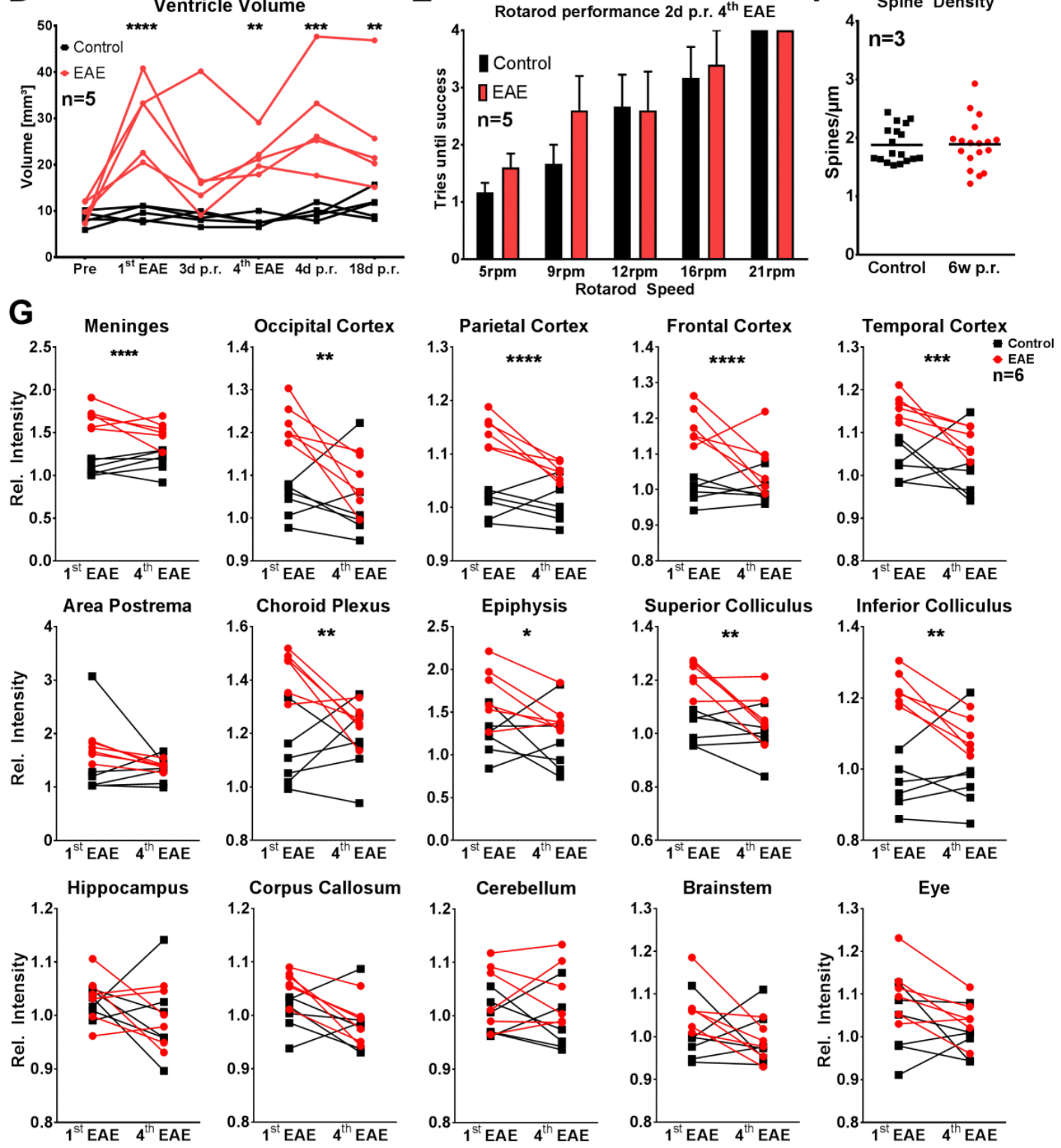

Figure 23: Repeated inflammation aggravates EAE-associated changes in the brain.

$\beta$ SynTG $(T /+)$ rats transferred four times with $T_{\beta S y n T G(T / T)}$ (red) or Tova (black) cells were examined over the course of multiple EAE bouts. (A) Clinical score (bars) and weight change (lines) presented as mean \pm SEM. Scores: $1^{*}=$ Ataxia, occasional twitches and scratching; $2^{*}=$ Frequent twitches and scratching, slight imbalance; $2.5^{*}=$ Pronounced imbalance; $3^{*}=$ Spastic paresis of hind limbs; $4^{*}=$ Tetraparesis; $5^{*}=$ Moribund. (B) Change in cortical thickness, (C) change of corpus callosum thickness before first EAE, 3d post recovery of first EAE and $4 \mathrm{~d}$ as well as $18 \mathrm{~d}$ post recovery of fourth EAE. (D) Combined volume of lateral and third ventricles before, during and after the first as well as fourth EAE. (E) Rotarod performance $2 \mathrm{~d}$ after recovery from the fourth $E A E$, presented as mean \pm SEM. (F) Spine density on apical dendrites of neurons in cortical layer 2/3, 6 weeks after recovery from the fourth EAE. (G) Relative signal intensity of different brain areas and eye in Gad-enhanced T1-weighted MRI. Sample sizes indicated in graphs. Statistical significance determined via repeated measures two-way ANOVA with Bonferroni's multiple comparisons test $\left({ }^{*} \mathrm{p} \leq 0.05,{ }^{* *} \mathrm{p} \leq 0.01,{ }^{* * *} \mathrm{p} \leq 0.001,{ }^{* * * *} \mathrm{p} \leq 0.0001\right)$. 


\section{Discussion}

\section{V.1. Invasion of neuron-specific $\mathrm{T}$ cells into the grey matter}

The goal of this thesis was to characterize a grey matter EAE model using $\beta S y n$ as the primary trigger of immunological action. While the use of $\beta$ Syn as antigen to induce EAE is not novel, all published studies rely either on transferring a significantly higher number of T cells (Mor et al., 2003) or pre-treating recipients by irradiation or injecting immunized rats with cyclophosphamide or PTX (Mor \& Cohen, 2006; Kela-Madar et al., 2009). More importantly, these studies focused on the infiltration of $T_{\beta S y n}$ cells in spinal cord and/or uvea. Although an infiltration of mononuclear cells into the cerebral cortex was described and speculations about cortical involvement were made (Mor et al., 2003; Mor \& Cohen, 2006), $T_{\beta S y n}$-cell infiltration into the brain was never specifically addressed. In none of these previous studies the pathogenic T cells were tracked. Finally, from a clinical point of view, the occurrence of atypical symptoms was not observed. It should be mentioned that these atypical clinical signs were more frequently observed in ptEAE induced by $T_{\beta S y n T G}$ cells from T-cell receptor-transgenic rats. In the wild-type rats the classical EAE disease type dominated.

This thesis demonstrates that 1 ) pathogenic $T_{\beta S y n}$ cells can be reliably generated and used for inducing transfer EAE and 2) active EAE can be reproducibly induced in receptortransgenic rats. In both cases, no additional treatment with pertussis toxin or cyclophosphamide was required. Taking advantage of our transfer model using GFP-tagged cells, we could further track and functionally characterize the encephalitogenic $T_{\beta S y n}$ cells on their way into the cortex and finally describe the consequences of grey matter infiltration by neuron-specific T cells.

One of the most intriguing findings in this project was the discovery of the occurrence of atypical symptoms in many of the $T_{\beta S y n T G(T /+)}$ and all of the $T_{\beta S y n T G(T / T)}$ recipients. While immunization with $\beta$ Syn constantly led to the development of the classical EAE symptoms of ascending paralysis, transfer with in vitro activated $T_{\beta S y n}$ cells of wild-type origin resulted in only a moderate fraction of atypical cases. Furthermore, these cases manifested themselves in front limb paralysis or hemiparesis (Schlosser, 2013). While still only poorly characterized, the symptoms observed here seemed to rather affect the rats' sense of balance, fine-motor 
control in all four limbs as well as sensory or sensorimotor pathways resulting in scratching behaviour and twitching or jerking movements. Upon $\mathrm{T}_{\beta S y n T G(T / T)}$ cell transfer, these symptoms became so pronounced they were reminiscent of some of the symptoms described in rodent epilepsy models (Curia et al., 2008).

While the induction of active EAE is always dependent on boosting the innate immune system (e.g. by the use of CFA, reviewed by Libbey \& Fujinami, 2011), it is crucial to be able to forgo further interference with the immune system or BBB, especially when changes in BBB permeability are investigated in response to CNS inflammation. PTX strongly affects the immune system and has been shown to transiently increase BBB permeability in rodents and human cultured endothelial cells (Brabb et al., 1997; Kerfoot et al., 2004; Kügler et al., 2007). It further blocks chemokine receptors such as CXCR4 and CCR5, activates the TCR signalling cascade and subsequently inhibits CXCL12-mediated chemotaxis (Witvliet et al., 1992; Schneider et al., 2009). Cyclophosphamide was shown to deplete $C D 4^{+} C D 25^{+}$ regulatory T cells (Ghiringhelli et al., 2004) and, although with contradicting results, has been used in the treatment of MS (Awad \& Stüve, 2009). Immunization of $\beta$ SynTG ${ }^{(T /+)}$ rats with the $\beta S_{y n_{93-111}}$ peptide and CFA does not require any further steps to reliably induce active EAE (Figure 5). As this induction is stable up to an age of 6 months and probably well beyond (Figure 6), this model might be an interesting candidate for the research into autoimmunity in aged rats, an approach that has been argued to increase translatability of rodent data to humans (Jackson et al., 2017). Why active neuronal EAE can only be induced in heterozygous $\beta$ SynTG rats remains unclear. As $T$ cells from draining lymph nodes of immunized animals could be isolated and used in the generation of pathogenic cell lines, the priming phase of these T cells did not seem to be affected. Possibly, a strict control of selftolerance against neuronal antigens in these animals prevented EAE development. To test this hypothesis, cyclophosphamide could be used to pre-treat these animals before EAE induction, in analogy to the approach used by Kela-Madar and colleagues (Kela-Madar et al., 2009).

Apart from the accelerated disease course of EAE induced via passive transfer compared to active immunization (Figure 7), another obvious advantage of this approach is that by using retroviral transduction, antigen-specific $T$ cells can be modified to express genes for fluorescent proteins and traced on their way to and through the CNS (Flügel et al., 1999, 
2007). Amongst others, this approach allowed the first visualization of the in vivo entry of $\mathrm{T}_{\mathrm{MBP}}$ cells into the SC and their infiltration into the CSF via the leptomeninges (Bartholomäus et al., 2009; Schläger et al., 2016). Utilising this method and building on the work of Mor and colleagues (Mor et al., 2003), who discovered the encephalitogenic potential of $\mathrm{T}_{\beta S y n}$ cells, it could be shown that these cells preferentially invade the grey matter of the brain, an area in which $T_{M B P}$ cells are rarely found (Figure 8 \& 9; Schlosser, 2013). To investigate if intrinsic properties of $\mathrm{T}$ cells in the pre-clinical phase would justify their different homing, three experimental approaches were chosen: (1) TPLSM of T cells at the CNS vascular bed, (2) signalling-blockage of selected integrins and chemokines and (3) transcriptome analysis via next generation sequencing.

(1) For the first approach, the intraluminal crawling behaviour of $T_{\beta S y n}, T_{M B P}$ as well as CNSignorant Tova cells was examined in pial vessels of brain and SC just before EAE onset (Figure 10). Overall, no qualitative differences seemed to exist between T cells of different antigenspecificities, as they displayed the same rolling and crawling phenotypes. However, a quantitative difference was detected, most evident in the percentage to which cells crawled inside the CNS vessels. Correlating with the amount of $\mathrm{T}$ cell infiltration and the inflammation state of the surrounding tissue, $T_{M B P}$ cells, which almost exclusively infiltrated the SC, preferentially crawled in SC vessels. In the brain, were only small numbers of $\mathrm{T}_{\mathrm{MBP}}$ cells were detected, they were mainly found to be rolling. On the other hand, $T_{\beta S y n}$ cells preferentially crawled in both compartments, matching their infiltration profile in both brain and SC. This is in line with the observation of Bartholomäus and colleagues, who artificially introduced OVA as an antigen into the CNS and found a subsequent inflammation caused by local re-activation of usually CNS-ignorant Tova cells. This inflammation in turn had a marked effect on the intraluminal crawling behaviour of Tova cells (Bartholomäus et al., 2009). Interestingly, we found Tova cells crawling in a reduced numbers in brain vessels compared to the SC. As these $\mathrm{T}$ cell recognize an irrelevant antigen, this finding came as a surprise. However, as the same discrepancy was observed for $C D 11 b^{+}$monocytes in naïve rats, we hypothesized that differences between brain and SC endothelium or blood flow (e.g. Nyström \& Norlén, 1983; Wilhelm et al., 2016) might influence the crawling behaviour of patrolling cells, but that this effect was leveraged under inflammatory conditions. 
(2) The expression of integrins and chemokine receptors is highly similar between $T_{M B P}$ and $\mathrm{T}_{\beta S y n}$ cells (Figure 15), as are their in vitro responses to chemoattractants (Schlosser, 2013). In Lewis rat EAE, capture, adhesion, crawling and the subsequent transmigration of $\mathrm{T}_{\mathrm{MBP}}$ cells at the SC vasculature can be inhibited by treatment with VLA-4-blocking antibody, while no effect of blocking LFA-1 is observed. Subsequently, preventive treatment with $\alpha \mathrm{VLA}-4$, but not $\alpha \mathrm{LFA}-1$ antibodies diminishes $\mathrm{T}_{\mathrm{MBP}}$ cell mediated EAE development (Bartholomäus et al., 2009). The effects of blocking these integrins in $T_{\beta S y n}$ cells in the brain vasculature were comparable: $\alpha \mathrm{VLA}-4$ treatment was effective in blocking $\mathrm{T}_{\beta \text { Syn }}$ cell adhesion and crawling, as well as EAE development and strongly reduced CNS infiltration (Figure 12). Blocking of LFA-1 only mildly interfered with $\mathrm{T}_{\beta S y n}$ cell adhesion, but had no further apparent effect; neither did it prevent EAE development (Figure 13). Of note, in other EAE models LFA-1 was shown to be essential for adhesion and subsequent transmigration (Vajkoczy et al., 2001). However, in MS patients, blockage of VLA-4 (by the drug Natalizumab), but not of LFA-1, was shown efficacious (Lublin \& the Hu23F2G MS Study Group, 1999; Goldenberg, 2012).

Chemokine receptor CXCR3 is highly expressed in $T_{\beta S y n}$ cells and seems important for BBB transmigration as well as pathogenicity of Th1/17 cells (Lee et al., 2012; Schlosser, 2013; Hu et al., 2017). Its influence on intraluminal crawling of $T_{\beta S y n}$ cells in the brain, however, was negligible (Figure 14). CNS infiltration was not addressed here, but it remains plausible to assume that blocking CXCR3 could impair EAE development by inhibiting BBB transmigration, as it was demonstrated in murine $T_{M B P}$ cell ptEAE (Sporici \& Issekutz, 2010). Overall, the findings described here seem parallel to observations made for $T_{M B P}$ cells, further underlining functional similarity between $\mathrm{T}$ cell lines of different antigen-specificities.

(3) Perhaps the most direct confirmation for the similarity between circulating $T_{\beta S y n}$ and $T_{M B P}$ cells came from our transcriptome analyses. TMBP cells isolated from blood showed little to no signs of activation (Schläger et al., 2016). Compared to these, virtually no differences were found in $\mathrm{T}_{\beta \mathrm{Syn}}$ cells taken from blood regarding chief cytokines, chemokine and cytokine receptors, cell adhesion and motility molecules as well as transcription factors. Merely the expression of IL2ra was found moderately reduced in $\mathrm{T}_{\beta S y n}$ cells. IL2ra (also known as CD25) is an important growth-factor for T cells, and IL-2 signalling restricts Th17 development and the main target of the MS drug Daclizumab (Morgan et al., 1976; 
Laurence et al., 2007; Zhang et al., 2014). Thus, the relative down-regulation of IL2ra might have some functional relevance, but the NGS analysis overall underlined the similarities between neuron- and myelin-specific T cells preceding re-activation inside the CNS. It has been hypothesized that signalling-molecule expression profiles guide effector T-cells' infiltration into different CNS compartments. While Th17 cells were suggested to enter the brain via the CCR6-CCL20 axis, Th1 cells would enter the SC via the meninges in a CXCR3and VLA-4-mediated fashion (Stromnes et al., 2008; Reboldi et al., 2009; Rothhammer et al., 2016). In our model, this could be reasonably excluded, as expression profiles as well as the response to receptor-blockage did not meaningfully differ between $T_{\beta S y n}$ and $T_{M B P}$ cells and no specific enrichment of either Th1 or Th17 phenotype in the target tissue was detected (Figure 16).

Our data demonstrate that antigen-specificities or expression profiles cannot explain $\mathrm{T}$ cell homing into different target tissues. Based on this insight, we hypothesized that $\mathrm{T}$ cells which routinely patrol the CNS (Figure 10; Bartholomäus et al., 2009; Reboldi et al., 2009; Odoardi et al., 2012) become re-activated in situ (Kawakami et al., 2004; Lodygin et al., 2013) and initiate a self-perpetuating process: local re-activation leads to the production of proinflammatory cytokines, leading in turn to the recruitment of more T cells, monocytes and microglia activation, in turn causing more inflammation and recruitment, finally resulting in EAE development. Again, three sets of data were acquired to support this hypothesis: (1) observation of $T_{\beta S y n}$ cell motility in the brain parenchyma, (2) NGS sequencing and (3) an AAV-mediated increase in local antigen availability.

(1) The motility characteristics of $T_{\beta S y n}$ cells argued for the occurrence of local re-activation (Figure 16). TPLSM revealed that $T_{\beta S y n}$ cells scanned the brain parenchyma freely and thoroughly. An increase in arrested T-cell number, in comparison with the number detected in the pre-clinical phase, indicated a heightened frequency of T-cell-APC-interactions. TMBP cells show very similar motility patterns while being re-activated by interacting with APCs in the SC leptomeninges (Lodygin et al., 2013) and it seems in turn reasonable to assume an identical process to take place for $T_{\beta S y n}$ cells within the brain parenchyma.

(2) NGS transcriptome analysis of brain-derived $T_{\beta S y n}$ cells (Figure 17) revealed an upregulation of the IFN $Y$ and IL-17 signalling pathways. These increases were likely caused by 
local re-activation, as they were not observable in blood-derived cells. This is in line with the previously described up-regulation of CD25 and OX40 detected via intracellular staining for ex vivo, brain-derived $T_{\beta S y n}$ cells (Schlosser, 2013). $T_{M B P}$ cells extracted from the SC show a highly similar expression profile (Bartholomäus et al., 2009; Schläger et al., 2016) and have been demonstrated to undergo local re-activation in the SC leptomeninges and parenchyma (Lodygin et al., 2013).

(3) We argued that increased antigen availability should lead to more frequent APCmediated antigen-encounters, consequently speeding up the EAE-induction cycle. Indeed, locally increased antigen availability had a marked effect on the infiltration and motility of $T_{\beta S y n}$ cells (Figure 18). A 3-fold increase in the number of $T_{\beta \text { Syn }}$ cells was detected in the brains of AAV- $\beta$ Syn-GFP rats, animals where a subpopulation of neurons over-expressed $\beta$ Syn. Supportive of our hypothesis, local overexpression seemed to even recruit $T_{\beta S y n}$ cells to areas that are otherwise only sparsely infiltrated, like the hippocampus. This is again similar to the observations of Bartholomäus and colleagues, where Tova cells have been shown to infiltrate the CNS and initiate inflammation when their antigen was made artificially available (Bartholomäus et al., 2009). Additionally, the velocity of $T_{\beta S y n}$ cells was drastically reduced in AAV-BSyn-GFP rats, indicative of an increased occurrence of antigenrecognition (Flügel et al., 2007; Odoardi et al., 2007).

Altogether, these observations are supportive of our hypothesis. However, in order to provide conclusive proof that $T_{\beta S y n}$ cells are locally re-activated, leading in turn to an increase in T-cell recruitment, further experiments will be necessary. One strategy currently pursued is the creation of $\beta$ Syn-specific T-cell lines expressing fluorescently tagged NFAT. As it has been demonstrated for $\mathrm{T}_{\mathrm{MBP}}$ cells in the SC, these cells would allow the visualization of $\mathrm{T}_{\beta S y n-c e l l}$ re-activation in situ (Lodygin et al., 2013), exploiting the relocation of NFAT to the nucleus in response to antigen-stimulation, in turn regulating gene expression for T-cell activation (Shaw et al., 1988). Furthermore, rats could be treated with FK506 just before EAE onset, as FK506 leads to a re-localization of NFAT into the cytosol, inhibiting T-cell (re-)activation (Schreiber \& Crabtree, 1992). Alternatively, Ox6 antibodies could be used to block the interaction of T cells and MHC-II molecules within the brain (McMaster \& Williams, 1979). 


\section{V.2. The brain as a target of autoimmune attack: linking MS and EAE grey matter pathology}

Grey matter lesions are frequent, often occur already early in the MS course and are strongly linked to disability (Peterson et al., 2001; Hulst \& Geurts, 2011; Geurts et al., 2012; Calabrese et al., 2013; Schlaeger et al., 2014; Calabrese, Reynolds, et al., 2015). Furthermore, grey matter lesions have been shown to contain activated microglia and infiltrated immune cells, suggesting the involvement of these cells as mediators of neurodegeneration (Lucchinetti et al., 2011). Meningeal inflammation was further associated with neuronal loss and cortical grey matter lesions. These have, in turn, been correlated with the progression of clinical decline in (both secondary and primary) progressive MS patients (Howell et al., 2011; Choi et al., 2012). Diffuse inflammatory patterns, independent of focal lesions, have also been postulated to induce neuronal pathology (Magliozzi et al., 2010; Calabrese, Magliozzi, et al., 2015). This implies an immune cell-mediated, inflammation-driven cortical neurodegeneration in MS, which is at least to a certain extent independent of demyelination. In a post-mortem MS study, dendritic spines of cortical neurons have been found to be significantly reduced, independent of lesion-location (Jürgens et al., 2016). As dendritic spines are of central importance for synaptic transmission, it is likely that this loss contributes to the cognitive impairment seen in MS patients (Chiaravalloti \& DeLuca, 2008; Grienberger et al., 2015). This so called synaptopathy is today considered a pivotal element in MS pathology (Centonze et al., 2010; Mandolesi et al., 2015). In chronic-progressive EAE models, a reduction in dendritic spine density was found in the striatum of mice (Centonze et al., 2009) and cortical layer 4 neurons of Dark Agouty rats, accompanied by grey matter atrophy (Tambalo et al., 2015). Here, we demonstrate that a reduction in cortical (layer 2 \& 3) spine density can be acutely induced by the transfer of neuron-, but not myelin-specific $T$ cells (Figure 19). This provides a direct link between local inflammation and spine-density reduction. Furthermore, it underlines the relevance of inflammation for the generation of grey matter pathology; supporting the notion that neurodegeneration could be independent of the location of cortical demyelinating lesions and rather dependent on inflammation. Both IFN $\gamma$ and TNF $\alpha$ have been shown to mediate inflammation-dependent dendritic spine loss, identifying Th1 cells and activated microglia as potential candidates for (preventive) treatment approaches (Centonze et al., 2009; Kreutzfeldt et al., 2013; Yang et 
al., 2013). Macrophage/microglia activation and T-cell infiltration also correlate with BBB breakdown in SC, brainstem and cerebellum in the classical myelin EAE model in mice and is revealed by Gadolinium enhancement (Hawkins et al., 1990; Morrissey et al., 1996; Nessler et al., 2007). The use of Gadolinium as a contrast agent in studying MS lesions has long been established (Grossman et al., 1986). Exploiting this approach, we found Gadolinium to be selectively enhanced in the cortical meninges of $T_{\beta S y n}$-cell induced, but not $T_{M B P}$-cell mediated passive transfer EAE (Figure 21). In $\beta S y n$ active EAE, Gadolinium enhancement was even more pronounced, extending into the parietal cortex (Figure 21). These findings are in line with the observed massive infiltration of $T_{\beta S y n}$ cells into meninges and cortex (Figure 8) and the reduction in spine density in the superficial layers (Figure 19). Our observation that ventricular volume transiently increases during EAE could be caused by an inflammation-dependent surge in CSF production by the choroid plexus (Karimy et al., 2017), indicative of inflammatory damage and cortical atrophy (Lepore et al., 2013; Tambalo et al., 2015), or both. Cortical atrophy is considered a hallmark of MS and strongly associated with clinical disability (De Stefano et al., 2003; Calabrese et al., 2009; Calabrese, Rinaldi, et al., 2010; Calabrese, Rocca, et al., 2010; Vollmer, Huynh, et al., 2015; Vollmer, Signorovitch, et al., 2015). While in ptEAE no change was apparent, we observed a significant reduction in cortical thickness in the wake of $\beta$ Syn active EAE (Figure 22), further recommending the $\beta S y n$ neuronal EAE model for the investigation of grey matter pathology.

Another exceptional aspect of our model is the possibility of inducing multiple independent bouts of inflammation via the repeated transfer of $\mathrm{T}_{\beta S y n T(\mathrm{~T} / \mathrm{T})}$ cells to $\beta$ SynTG ${ }^{(\mathrm{T} /+)}$ recipients (Figure 23). Tambalo and colleagues describe long-term cortical atrophy and synaptopathy in Dark Agouty rat EAE after immunization with CNS homogenate, but these animals never show full remission of clinical symptoms, suggestive of chronic inflammation (Tambalo et al., 2015). Attempts to induce lasting grey matter lesions by repeated, discrete inflammatory episodes have so far been unsuccessful: repeated cortical injection of a combination of TNF $\alpha$ and IFN $\gamma$ only leads to transient lesion formation and is leveraged by the regenerative capacity of oligodendroglia precursor cells (Merkler, Ernsting, et al., 2006; Rodriguez et al., 2014). Another approach combines $T_{M B P}$-cell transfer and anti-MOG antibody-injection, resulting in demyelinating lesions which persist for at least 60 days in the SC white matter, however no grey matter pathology is observed (Linington et al., 1992). Similarly, the 
combination of two inflammatory stimuli might lead to a persisting susceptibility to $E A E$ in our model: while Linington and colleagues combined activated T cells with antibodies, a possible low level of persisting inflammation caused by the presence of auto-reactive, $\beta$ Synspecific T cells or self-antibodies in combination with the transfer of fresh, activated cells might be the mediator in our model. The observation of lasting ventricular enlargement and severe, persistent, cortical atrophy found after multiple inflammatory bouts reinforces the connection between meningeal inflammation and neuronal degeneration and argues against the hypothesis that neurodegeneration and inflammation can be considered separate processes (e.g. Hutchinson, 2015; Louapre \& Lubetzki, 2015).

It will be interesting to see what more sensitive readouts will unveil about atrophy and higher brain function in our model (e.g. using the 5-choice serial reaction time task; Robbins, 2002). Finally, an on-going morphological analysis revealed strong signs of degeneration in cortical neurons (not shown). In face of the absence of dendritic spine reduction, this observation might suggest intact regenerative capacities in the persisting neurons. Taking this into consideration, our model could help to better understand which pathways critically contribute to the neuronal degeneration underlying MS pathology and to investigate potential neuroprotective approaches (Friese et al., 2014).

As discussed in the introduction, other rodent EAE models exist that evoke some aspects of grey matter pathology, but they either target myelin or astrocytes, but not neuronal antigens (Kojima et al., 1994; Storch et al., 2006), or target neuronal antigens without eliciting clear grey matter pathology in the brain (Huizinga et al., 2007, 2008). Taken together, the $\beta$ Syn neuronal EAE model examined here combines three major hallmarks of grey matter MS pathology, i.e. meningeal inflammation, synaptopathy and cortical atrophy, by targeting a single neuronal antigen. To my knowledge, it is the only rodent model to do so and will provide a useful tool for studying the underlying mechanisms and determining potential treatment routes. 


\section{Summary}

In the present thesis I demonstrated that pathogenic $T_{\beta S y n}$ cells of wild-type and receptortransgenic origins could be reliably generated and used for inducing passive transfer EAE; active EAE could be reproducibly induced in receptor-transgenic rats. Both inductions were possible without pre-treatment of recipient animals with pertussis toxin or cyclophosphamide. I additionally described the possibility to induce multiple independent bouts of inflammation and EAE by repeated transfer of $T_{\beta S y n T G(T / T)}$ cells into $\beta$ SynTG ${ }^{(T /+)}$ recipients.

Additionally, I presented evidence supporting the hypothesis that local re-activation, not cell-intrinsic properties, determined T-cell homing into the target CNS tissue. Motility and gene-expression were highly similar between $T_{\beta S y n}$ and $T_{M B P}$ cells prior to CNS infiltration. Intravascular crawling of $T_{\beta S y n}$ cells was found to be dependent on VLA-4, but not LFA-1 or CXCR3, as it has been previously described for $\mathrm{T}_{\mathrm{MBP}}$-cell mediated EAE in the Lewis rat. Subsequently, the motility parameters and gene expression of $\mathrm{T}_{\beta \mathrm{Syn}}$ cells in the brain suggested an activated state of these cells and resembled the parameters described for locally re-activated $\mathrm{T}_{\mathrm{MBP}}$ cells located inside the SC. Local overexpression of the $\beta$ Syn antigen led to an increased recruitment of $T_{\beta S y n}$ cells into the cortex, further emphasizing the importance of antigen-recognition for T-cell homing.

Addressing the consequence of T-cell mediated inflammation in the brain, I demonstrated that transfer of $T_{\beta S y n}$ cells, but not of $T_{M B P}$ cells, mediated a transient reduction in synaptic spine density on cortical neurons, thereby providing a direct link between local inflammation and alterations in neuronal connectivity. Finally, I showed that active EAE as well as the repeated transfer of $\mathrm{T}_{\beta S y n T G(T / T)}$ cells induced neurodegeneration in $\beta$ SynTG ${ }^{(T /+)}$ rats, indicated by cortical atrophy.

Taken together, several hallmarks of MS could be reproduced here by targeting the neuronal antigen $\beta$ Syn, namely meningeal inflammation, synaptopathy and cortical atrophy. These observations recommend the $\beta$ Syn neuronal EAE model as a suitable model for immune cell-mediated, inflammation-driven cortical neurodegeneration in MS and further underline the importance of researching the neuronal and grey matter aspects of the disease. 


\section{References}

't Hart, B.A., Dunham, J., Faber, B.W., Laman, J.D., van Horssen, J., Bauer, J., \& Kap, Y.S. (2017) A B cell-driven autoimmune pathway leading to pathological hallmarks of progressive multiple sclerosis in the marmoset experimental autoimmune encephalomyelitis model. Front. Immunol., 8, 1-14.

't Hart, B.A., Hintzen, R.Q., \& Laman, J.D. (2008) Preclinical Assessment of Therapeutic Antibodies against Human CD40 and Human Interleukin-12/23p40 in a Nonhuman Primate Model of Multiple Sclerosis. Neurodegener. Dis., 5, 38-52.

't Hart, B.A., Hintzen, R.Q., \& Laman, J.D. (2009) Multiple sclerosis - a response-to-damage model. Trends Mol. Med., 15, 235-244.

Altschul, S.F., Gish, W., Miller, W., Myers, E.W., \& Lipman, D.J. (1990) Basic local alignment search tool. J. Mol. Biol., 215, 403-410.

Awad, A. \& Stüve, O. (2009) Cyclophosphamide in multiple sclerosis: scientific rationale, history and novel treatment paradigms. Ther. Adv. Neurol. Disord., 2, 50-61.

Barkhof, F., Calabresi, P.A., Miller, D.H., \& Reingold, S.C. (2009) Imaging outcomes for neuroprotection and repair in multiple sclerosis trials. Nat. Rev. Neurol., 5, 256-266.

Bartholomäus, I., Kawakami, N., Odoardi, F., Schläger, C., Miljkovic, D., Ellwart, J.W., Klinkert, W.E.F., Flügel-Koch, C., Issekutz, T.B., Wekerle, H., \& Flügel, A. (2009) Effector T cell interactions with meningeal vascular structures in nascent autoimmune CNS lesions. Nature, 462, 94-98.

Ben-Nun, A., Wekerle, H., \& Cohen, I.R. (1981) The rapid isolation of clonable antigenspecific T lymphocyte lines capable of mediating autoimmune encephalomyelitis. Eur. J. Immunol., 11, 195-199.

Bjartmar, C., Kidd, G., Mörk, S., Rudick, R., \& Trapp, B.D. (2000) Neurological disability correlates with spinal cord axonal loss and reduced $\mathrm{N}$-acetyl aspartate in chronic multiple sclerosis patients. Ann. Neurol., 48, 893-901.

Bjartmar, C., Wujek, J.R., \& Trapp, B.D. (2003) Axonal loss in the pathology of MS: Consequences for understanding the progressive phase of the disease. J. Neurol. Sci., 206, 165-171.

Brabb, T., Goldrath, A.W., von Dassow, P., Paez, A., Liggitt, H.D., \& Goverman, J. (1997) Triggers of autoimmune disease in a murine TCR-transgenic model for multiple sclerosis. J. Immunol., 159, 497-507.

Brauer, L. (1898) Muskelatrophie bei multipler Sklerose. Neurol Cent., 17:635. 
Brown, J.W.P., Buell, A.K., Michaels, T.C.T., Meisl, G., Carozza, J., Flagmeier, P., Vendruscolo, M., Knowles, T.P.J., Dobson, C.M., \& Galvagnion, C. (2016) $\beta$-Synuclein suppresses both the initiation and amplification steps of $\alpha$-synuclein aggregation via competitive binding to surfaces. Sci. Rep., 6, 36010.

Calabrese, M., Agosta, F., Rinaldi, F., Mattisi, I., Grossi, P., Favaretto, A., Atzori, M., Bernardi, V., Barachino, L., Rinaldi, L., Perini, P., Gallo, P., \& Filippi, M. (2009) Cortical Lesions and Atrophy Associated With Cognitive Impairment in Relapsing-Remitting Multiple Sclerosis. Arch. Neurol., 66.

Calabrese, M., Magliozzi, R., Ciccarelli, O., Geurts, J.J.G., Reynolds, R., \& Martin, R. (2015) Exploring the origins of grey matter damage in multiple sclerosis. Nat. Rev. Neurosci., 16, 147-158.

Calabrese, M., Reynolds, R., Magliozzi, R., Castellaro, M., Morra, A., Scalfari, A., Farina, G., Romualdi, C., Gajofatto, A., Pitteri, M., Benedetti, M.D., \& Monaco, S. (2015) Regional distribution and evolution of gray matter damage in different populations of multiple sclerosis patients. PLoS One, 10, 1-12.

Calabrese, M., Rinaldi, F., Mattisi, I., Grossi, P., Favaretto, A., Atzori, M., Bernardi, V., Barachino, L., Romualdi, C., Rinaldi, L., Perini, P., \& Gallo, P. (2010) Widespread cortical thinning characterizes patients with MS with mild cognitive impairment. Neurology, 74, 321-328.

Calabrese, M., Rocca, M.A., Atzori, M., Mattisi, I., Favaretto, A., Perini, P., Gallo, P., \& Filippi, M. (2010) A three-year MRI study of cortical lesions in relapse-onset multiple sclerosis. Ann. Neurol., NA-NA.

Calabrese, M., Romualdi, C., Poretto, V., Favaretto, A., Morra, A., Rinaldi, F., Perini, P., \& Gallo, P. (2013) The changing clinical course of multiple sclerosis: A matter of gray matter. Ann. Neurol., 74, 76-83.

Centonze, D., Muzio, L., Rossi, S., Cavasinni, F., De Chiara, V., Bergami, A., Musella, A., D’Amelio, M., Cavallucci, V., Martorana, A., Bergamaschi, A., Cencioni, M.T., Diamantini, A., Butti, E., Comi, G., Bernardi, G., Cecconi, F., Battistini, L., Furlan, R., \& Martino, G. (2009) Inflammation Triggers Synaptic Alteration and Degeneration in Experimental Autoimmune Encephalomyelitis. J. Neurosci., 29, 3442-3452.

Centonze, D., Muzio, L., Rossi, S., Furlan, R., Bernardi, G., \& Martino, G. (2010) The link between inflammation, synaptic transmission and neurodegeneration in multiple sclerosis. Cell Death Differ., 17, 1083-1091.

Chard, D.T., Griffin, C.M., Parker, G.J.M., Kapoor, R., Thompson, a J., \& Miller, D.H. (2002) Brain atrophy in clinically early relapsing-remitting multiple sclerosis. Brain, 125, 327337. 
Chiaravalloti, N.D. \& DeLuca, J. (2008) Cognitive impairment in multiple sclerosis. Lancet Neurol., 7, 1139-1151.

Choi, S.R., Howell, O.W., Carassiti, D., Magliozzi, R., Gveric, D., Muraro, P.A., Nicholas, R., Roncaroli, F., \& Reynolds, R. (2012) Meningeal inflammation plays a role in the pathology of primary progressive multiple sclerosis. Brain, 135, 2925-2937.

Compston, A. (1988) The 150th anniversary of the first depiction of the lesions of multiple sclerosis. J. Neurol. Neurosurg. Psychiatry, 51, 1249-1252.

Compston, A. \& Coles, A. (2008) Multiple sclerosis. Lancet, 372, 1502-1517.

Curia, G., Longo, D., Biagini, G., Jones, R.S.G., \& Avoli, M. (2008) The pilocarpine model of temporal lobe epilepsy. J. Neurosci. Methods, 172, 143-157.

De Stefano, N., Matthews, P.M., Filippi, M., Agosta, F., De Luca, M., Bartolozzi, M.L., Guidi, L., Ghezzi, A., Montanari, E., Cifelli, A., Federico, A., \& Smith, S.M. (2003) Evidence of early cortical atrophy in MS: Relevance to white matter changes and disability. Neurology, 60, 1157-1162.

Dejerine, J. (1884) Etude sur la sclérose en plaques cérébrospinale à forme de sclérose latérale amyotrophique. Rev Med, 4:193.

Derfuss, T., Parikh, K., Velhin, S., Braun, M., Mathey, E., Krumbholz, M., Kumpfel, T., Moldenhauer, A., Rader, C., Sonderegger, P., Pollmann, W., Tiefenthaller, C., Bauer, J., Lassmann, H., Wekerle, H., Karagogeos, D., Hohlfeld, R., Linington, C., \& Meinl, E. (2009) Contactin-2/TAG-1-directed autoimmunity is identified in multiple sclerosis patients and mediates gray matter pathology in animals. Proc. Natl. Acad. Sci., 106, 8302-8307.

Fiala, J.C., Spacek, J., \& Harris, K.M. (2002) Dendritic Spine Pathology: Cause or Consequence of Neurological Disorders? Brain Res. Rev., 39, 29-54.

Flügel, A., Berkowicz, T., Ritter, T., Labeur, M., Jenne, D.E., Li, Z., Ellwart, J.W., Willem, M., Lassmann, H., \& Wekerle, H. (2001) Migratory Activity and Functional Changes of Green Fluorescent Effector Cells before and during Experimental Autoimmune Encephalomyelitis. Immunity, 14, 547-560.

Flügel, A., Odoardi, F., Nosov, M., \& Kawakami, N. (2007) Autoaggressive effector T cells in the course of experimental autoimmune encephalomyelitis visualized in the light of two-photon microscopy. J. Neuroimmunol., 191, 86-97.

Flügel, A., Willem, M., Berkowicz, T., \& Wekerle, H. (1999) Gene transfer into CD4+ T lymphocytes: green fluorescent protein-engineered, encephalitogenic $\mathrm{T}$ cells illuminate brain autoimmune responses. Nat. Med., 5, 843-847.

Friese, M.A., Schattling, B., \& Fugger, L. (2014) Mechanisms of neurodegeneration and 
axonal dysfunction in multiple sclerosis. Nat. Rev. Neurol., 10, 225-238.

Galvin, J.E., Schuck, T.M., Lee, V.M.-Y., \& Trojanowski, J.Q. (2001) Differential Expression and Distribution of $\alpha-, \beta-$, and $\gamma^{-S y n u c l e i n}$ in the Developing Human Substantia Nigra. Exp. Neurol., 168, 347-355.

George, J.M. (2002) The synucleins. Genome Biol., 3, REVIEWS3002.

Geurts, J.J.G., Calabrese, M., Fisher, E., \& Rudick, R.A. (2012) Measurement and clinical effect of grey matter pathology in multiple sclerosis. Lancet Neurol., 11, 1082-1092.

Ghiringhelli, F., Larmonier, N., Schmitt, E., Parcellier, A., Cathelin, D., Garrido, C., Chauffert, B., Solary, E., Bonnotte, B., \& Martin, F. (2004) CD4+CD25+ regulatory T cells suppress tumor immunity but are sensitive to cyclophosphamide which allows immunotherapy of established tumors to be curative. Eur. J. Immunol., 34, 336-344.

Giasson, B.I., Duda, J.E., Forman, M.S., Lee, V.M.-Y., \& Trojanowski, J.Q. (2001) Prominent perikaryal expression of alpha- and beta-synuclein in neurons of dorsal root ganglion and in medullary neurons. Exp. Neurol., 172, 354-362.

Gold, R., Hartung, H.-P., \& Lassmann, H. (1997) T-cell apoptosis in autoimmune diseases: termination of inflammation in the nervous system and other sites with specialized immune-defense mechanisms. Trends Neurosci., 20, 399-404.

Goldenberg, M.M. (2012) Multiple sclerosis review. P T, 37, 175-184.

Grienberger, C., Chen, X., \& Konnerth, A. (2015) Dendritic function in vivo. Trends Neurosci., $38,45-54$.

Grossman, R.I., Gonzalez-Scarano, F., Atlas, S.W., Galetta, S., \& Silberberg, D.H. (1986) Multiple sclerosis: gadolinium enhancement in MR imaging. Radiology, 161, 721-725.

Hawkins, C.P., Munro, P.M.G., Mackenzie, F., Kesselring, J., Tofts, P.S., Boulay, E.P.G.H.D., Landon, D.N., \& Mcdonald, W.I. (1990) Duration and selectivity of blood-brain barrier breakdown in chronic relapsing experimental allergic encephalomyelitis studied by gadolinium-dtpa and protein markers. Brain, 113, 365-378.

Hohlfeld, R. \& Wekerle, H. (2004) Autoimmune concepts of multiple sclerosis as a basis for selective immunotherapy: From pipe dreams to (therapeutic) pipelines. Proc. Natl. Acad. Sci., 101, 14599-14606.

Howell, O.W., Reeves, C.A., Nicholas, R., Carassiti, D., Radotra, B., Gentleman, S.M., Serafini, B., Aloisi, F., Roncaroli, F., Magliozzi, R., \& Reynolds, R. (2011) Meningeal inflammation is widespread and linked to cortical pathology in multiple sclerosis. Brain, 134, 27552771. 
Hu, D., Notarbartolo, S., Croonenborghs, T., Patel, B., Cialic, R., Yang, T.-H., Aschenbrenner, D., Andersson, K.M., Gattorno, M., Pham, M., Kivisakk, P., Pierre, I. V., Lee, Y., Kiani, K., Bokarewa, M., Tjon, E., Pochet, N., Sallusto, F., Kuchroo, V.K., \& Weiner, H.L. (2017) Transcriptional signature of human pro-inflammatory TH17 cells identifies reduced IL10 gene expression in multiple sclerosis. Nat. Commun., 8, 1600.

Huizinga, R., Gerritsen, W., Heijmans, N., \& Amor, S. (2008) Axonal loss and gray matter pathology as a direct result of autoimmunity to neurofilaments. Neurobiol. Dis., 32, 461-470.

Huizinga, R., Heijmans, N., Schubert, P., Gschmeissner, S., Hart, B.A.F., Herrmann, H., \& Amor, S. (2007) Immunization With Neurofilament Light Protein Induces Spastic Paresis and Axonal Degeneration in Biozzi ABH Mice. Neuropathol. Exp. Neurol., 66, 295-304.

Hulst, H.E. \& Geurts, J.J.G. (2011) Gray matter imaging in multiple sclerosis: what have we learned? BMC Neurol., 11, 153.

Hutchinson, M. (2015) Neurodegeneration in multiple sclerosis is a process separate from inflammation: No. Mult. Scler. J., 21, 1628-1631.

International Multiple Sclerosis Genetics Consortium, Hafler, D.A., Compston, A., Sawcer, S., Lander, E.S., Daly, M.J., De Jager, P.L., de Bakker, P.I.W., Gabriel, S.B., Mirel, D.B., Ivinson, A.J., Pericak-Vance, M.A., Gregory, S.G., Rioux, J.D., McCauley, J.L., Haines, J.L., Barcellos, L.F., Cree, B., Oksenberg, J.R., \& Hauser, S.L. (2007) Risk alleles for multiple sclerosis identified by a genomewide study. N. Engl. J. Med., 357, 851-862.

International Multiple Sclerosis Genetics Consortium, Wellcome Trust Case Control Consortium 2, Sawcer, S., Hellenthal, G., Pirinen, M., Spencer, C.C.A., Patsopoulos, N.A., Moutsianas, L., Dilthey, A., Su, Z., Freeman, C., Hunt, S.E., Edkins, S., Gray, E., Booth, D.R., Potter, S.C., Goris, A., Band, G., Oturai, A.B., Strange, A., Saarela, J., Bellenguez, C., Fontaine, B., Gillman, M., Hemmer, B., Gwilliam, R., Zipp, F., Jayakumar, A., Martin, R., Leslie, S., Hawkins, S., Giannoulatou, E., D’alfonso, S., Blackburn, H., Martinelli Boneschi, F., Liddle, J., Harbo, H.F., Perez, M.L., Spurkland, A., Waller, M.J., Mycko, M.P., Ricketts, M., Comabella, M., Hammond, N., Kockum, I., McCann, O.T., Ban, M., Whittaker, P., Kemppinen, A., Weston, P., Hawkins, C., Widaa, S., Zajicek, J., Dronov, S., Robertson, N., Bumpstead, S.J., Barcellos, L.F., Ravindrarajah, R., Abraham, R., Alfredsson, L., Ardlie, K., Aubin, C., Baker, A., Baker, K., Baranzini, S.E., Bergamaschi, L., Bergamaschi, R., Bernstein, A., Berthele, A., Boggild, M., Bradfield, J.P., Brassat, D., Broadley, S.A., Buck, D., Butzkueven, H., Capra, R., Carroll, W.M., Cavalla, P., Celius, E.G., Cepok, S., Chiavacci, R., Clerget-Darpoux, F., Clysters, K., Comi, G., Cossburn, M., Cournu-Rebeix, I., Cox, M.B., Cozen, W., Cree, B.A.C., Cross, A.H., Cusi, D., Daly, M.J., Davis, E., de Bakker, P.I.W., Debouverie, M., D’hooghe, M.B., Dixon, K., Dobosi, R., Dubois, B., Ellinghaus, D., Elovaara, I., Esposito, F., Fontenille, C., Foote, S., Franke, A., Galimberti, D., Ghezzi, A., 
Glessner, J., Gomez, R., Gout, O., Graham, C., Grant, S.F.A., Guerini, F.R., Hakonarson, H., Hall, P., Hamsten, A., Hartung, H.-P., Heard, R.N., Heath, S., Hobart, J., Hoshi, M., Infante-Duarte, C., Ingram, G., Ingram, W., Islam, T., Jagodic, M., Kabesch, M., Kermode, A.G., Kilpatrick, T.J., Kim, C., Klopp, N., Koivisto, K., Larsson, M., Lathrop, M., LechnerScott, J.S., Leone, M.A., Leppä, V., Liljedahl, U., Bomfim, I.L., Lincoln, R.R., Link, J., Liu, J., Lorentzen, A.R., Lupoli, S., Macciardi, F., Mack, T., Marriott, M., Martinelli, V., Mason, D., McCauley, J.L., Mentch, F., Mero, I.-L., Mihalova, T., Montalban, X., Mottershead, J., Myhr, K.-M., Naldi, P., Ollier, W., Page, A., Palotie, A., Pelletier, J., Piccio, L., Pickersgill, T., Piehl, F., Pobywajlo, S., Quach, H.L., Ramsay, P.P., Reunanen, M., Reynolds, R., Rioux, J.D., Rodegher, M., Roesner, S., Rubio, J.P., Rückert, I.-M., Salvetti, M., Salvi, E., Santaniello, A., Schaefer, C.A., Schreiber, S., Schulze, C., Scott, R.J., Sellebjerg, F., Selmaj, K.W., Sexton, D., Shen, L., Simms-Acuna, B., Skidmore, S., Sleiman, P.M.A., Smestad, C., Sørensen, P.S., Søndergaard, H.B., Stankovich, J., Strange, R.C., Sulonen, A.-M., Sundqvist, E., Syvänen, A.-C., Taddeo, F., Taylor, B., Blackwell, J.M., Tienari, P., Bramon, E., Tourbah, A., Brown, M.A., Tronczynska, E., Casas, J.P., Tubridy, N., Corvin, A., Vickery, J., Jankowski, J., Villoslada, P., Markus, H.S., Wang, K., Mathew, C.G., Wason, J., Palmer, C.N.A., Wichmann, H.-E., Plomin, R., Willoughby, E., Rautanen, A., Winkelmann, J., Wittig, M., Trembath, R.C., Yaouanq, J., Viswanathan, A.C., Zhang, H., Wood, N.W., Zuvich, R., Deloukas, P., Langford, C., Duncanson, A., Oksenberg, J.R., Pericak-Vance, M.A., Haines, J.L., Olsson, T., Hillert, J., Ivinson, A.J., De Jager, P.L., Peltonen, L., Stewart, G.J., Hafler, D.A., Hauser, S.L., McVean, G., Donnelly, P., \& Compston, A. (2011) Genetic risk and a primary role for cell-mediated immune mechanisms in multiple sclerosis. Nature, 476, 214-219.

Iwai, A., Yoshimoto, M., Masliah, E., \& Saitoh, T. (1995) Non-A.beta. Component of Alzheimer's Disease Amyloid (NAC) is Amyloidogenic. Biochemistry, 34, 10139-10145.

Jackson, S.J., Andrews, N., Ball, D., Bellantuono, I., Gray, J., Hachoumi, L., Holmes, A., Latcham, J., Petrie, A., Potter, P., Rice, A., Ritchie, A., Stewart, M., Strepka, C., Yeoman, M., \& Chapman, K. (2017) Does age matter? The impact of rodent age on study outcomes. Lab. Anim., 51, 160-169.

Jakes, R., Spillantini, M.G., \& Goedert, M. (1994) Identification of 2 Distinct Synucleins From Human Brain. Febs Lett., 345, 27-32.

Jürgens, T., Jafari, M., Kreutzfeldt, M., Bahn, E., Brück, W., Kerschensteiner, M., \& Merkler, D. (2016) Reconstruction of single cortical projection neurons reveals primary spine loss in multiple sclerosis. Brain, 139, 39-46.

Karimy, J.K., Zhang, J., Kurland, D.B., Theriault, B.C., Duran, D., Stokum, J.A., Furey, C.G., Zhou, X., Mansuri, M.S., Montejo, J., Vera, A., Diluna, M.L., Delpire, E., Alper, S.L., Gunel, M., Gerzanich, V., Medzhitov, R., Simard, J.M., \& Kahle, K.T. (2017) Inflammation-dependent cerebrospinal fluid hypersecretion by the choroid plexus 
epithelium in posthemorrhagic hydrocephalus. Nat. Med.,.

Kawakami, N., Lassmann, S., Li, Z., Odoardi, F., Ritter, T., Ziemssen, T., Klinkert, W.E.F., Ellwart, J.W., Bradl, M., Krivacic, K., Lassmann, H., Ransohoff, R.M., Volk, H.-D., Wekerle, H., Linington, C., \& Flügel, A. (2004) The Activation Status of Neuroantigen-specific T Cells in the Target Organ Determines the Clinical Outcome of Autoimmune Encephalomyelitis. J. Exp. Med., 199, 185-197.

Kela-Madar, N., de Rosbo, N.K., Ronen, A., Mor, F., \& Ben-Nun, A. (2009) Autoimmune spread to myelin is associated with experimental autoimmune encephalomyelitis induced by a neuronal protein, beta-Synuclein. J. Neuroimmunol., 208, 19-29.

Kerfoot, S.M., Long, E.M., Hickey, M.J., Andonegui, G., Lapointe, B.M., Zanardo, R.C.O., Bonder, C., James, W.G., Robbins, S.M., \& Kubes, P. (2004) TLR4 Contributes to DiseaseInducing Mechanisms Resulting in Central Nervous System Autoimmune Disease. J. Immunol., 173, 7070-7077.

Kidd, D., Barkhof, F., McConnell, R., Algra, P., R., Allen, I., V., \& Revesz, T. (1999) Cortical lesions in multiple sclerosis. Brain, 122, 17-26.

Kitz, A. (2013) Generation and analysis of T cell receptor transgenic rats to model CNS autoimmunity.

Kojima, K., Berger, T., Lassmann, H., Hinze-Selch, D., Zhang, Y., Gehrmann, J., Reske, K., Wekerle, H., \& Linington, C. (1994) Experimental autoimmune panencephalitis and uveoretinitis transferred to the Lewis rat by T lymphocytes specific for the S100 beta molecule, a calcium binding protein of astroglia. J. Exp. Med., 180, 817-829.

Kreutzfeldt, M., Bergthaler, A., Fernandez, M., Brück, W., Steinbach, K., Vorm, M., Coras, R., Blümcke, I., Bonilla, W. V., Fleige, A., Forman, R., Müller, W., Becher, B., Misgeld, T., Kerschensteiner, M., Pinschewer, D.D., \& Merkler, D. (2013) Neuroprotective intervention by interferon- $\nu$ blockade prevents CD8+ T cell-mediated dendrite and synapse loss. J. Exp. Med., 210, 2087-2103.

Ksiazek-Winiarek, D.J., Szpakowski, P., \& Glabinski, A. (2015) Neural Plasticity in Multiple Sclerosis: The Functional and Molecular Background. Neural Plast., 2015.

Kügler, S., Böcker, K., Heusipp, G., Greune, L., Kim, K.S., \& Schmidt, M.A. (2007) Pertussis toxin transiently affects barrier integrity, organelle organization and transmigration of monocytes in a human brain microvascular endothelial cell barrier model. Cell. Microbiol., 9, 619-632.

Kügler, S., Kilic, E., \& Bähr, M. (2003) Human synapsin 1 gene promoter confers highly neuron-specific long-term transgene expression from an adenoviral vector in the adult rat brain depending on the transduced area. Gene Ther., 10, 337-347. 
Kutschenko, A., Manig, A., Reinert, M.-C., Mönnich, A., \& Liebetanz, D. (2016) In-vivo comparison of the neurotoxic potencies of incobotulinumtoxinA, onabotulinumtoxinA, and abobotulinumtoxinA. Neurosci. Lett., 627, 216-221.

Kutzelnigg, A., Lucchinetti, C.F., Stadelmann, C., Brück, W., Rauschka, H., Bergmann, M., Schmidbauer, M., Parisi, J.E., \& Lassmann, H. (2005) Cortical demyelination and diffuse white matter injury in multiple sclerosis. Brain, 128, 2705-2712.

Laurence, A., Tato, C.M., Davidson, T.S., Kanno, Y., Chen, Z., Yao, Z., Blank, R.B.B., Meylan, F., Siegel, R., Hennighausen, L., Shevach, E.M., \& O'Shea, J.J.J. (2007) Interleukin-2 Signaling via STAT5 Constrains T Helper 17 Cell Generation. Immunity, 26, 371-381.

Lavedan, C., Leroy, E., Torres, R., Dehejia, A., Dutra, A., Buchholtz, S., Nussbaum, R.L., \& Polymeropoulos, M.H. (1998) Genomic Organization and Expression of the Human $\beta$ Synuclein Gene (SNCB). Genomics, 54, 173-175.

Lee, Y., Awasthi, A., Yosef, N., Quintana, F.J., Xiao, S., Peters, A., Wu, C., Kleinewietfeld, M., Kunder, S., Hafler, D.A., Sobel, R.A., Regev, A., \& Kuchroo, V.K. (2012) Induction and molecular signature of pathogenic TH17 cells. Nat. Immunol., 13, 991-999.

Lendvai, B., Stern, E.A., Chen, B., \& Svoboda, K. (2000) Experience-dependent plasticity of dendritic spines in the developing rat barrel cortex in vivo. Nature, 404, 876-881.

Lepore, S., Waiczies, H., Hentschel, J., Ji, Y., Skodowski, J., Pohlmann, A., Millward, J.M., Paul, F., Wuerfel, J., Niendorf, T., \& Waiczies, S. (2013) Enlargement of Cerebral Ventricles as an Early Indicator of Encephalomyelitis. PLoS One, 8, 1-10.

Ley, K., Laudanna, C., Cybulsky, M.I., \& Nourshargh, S. (2007) Getting to the site of inflammation: the leukocyte adhesion cascade updated. Nat. Rev. Immunol., 7, 678689.

Libbey, J.E. \& Fujinami, R.S. (2011) Experimental autoimmune encephalomyelitis as a testing paradigm for adjuvants and vaccines. Vaccine, 29, 3356-3362.

Linington, C., Engelhardt, B., Kapocs, G., \& Lassmann, H. (1992) Induction of persistently demyelinated lesions in the rat following the repeated adoptive transfer of encephalitogenic T cells and demyelinating antibody. J. Neuroimmunol., 40, 219-224.

Lodygin, D., Odoardi, F., Schläger, C., Körner, H., Kitz, A., Nosov, M., van den Brandt, J., Reichardt, H.M., Haberl, M., \& Flügel, A. (2013) A combination of fluorescent NFAT and $\mathrm{H} 2 \mathrm{~B}$ sensors uncovers dynamics of $\mathrm{T}$ cell activation in real time during CNS autoimmunity. Nat. Med., 19, 784-790.

Louapre, C. \& Lubetzki, C. (2015) Neurodegeneration in multiple sclerosis is a process separate from inflammation: Yes. Mult. Scler. J., 21, 1626-1628. 
Lublin, F. \& the Hu23F2G MS Study Group (1999) A phase II trial of anti-CD11/CD18 monoclonal antibody in acute exacerbations of multiple sclerosis. Neurology, 52.6.

Lublin, F.D., Reingold, S.C., Cohen, J. a, Cutter, G.R., Thompson, A.J., Wolinsky, J.S., Fox, R.J., Freedman, M.S., Goodman, A.D., \& Lubetzki, C. (2014) Defining the clinical course of multiple sclerosis: The 2013 revisions Defining the clinical course of multiple sclerosis The 2013 revisions $1-10$.

Lucchinetti, C.F., Brück, W., Parisi, J., Scheithauer, B., Rodriguez, M., \& Lassmann, H. (2000) Heterogeneity of multiple sclerosis lesions: Implications for the pathogenesis of demyelination. Ann. Neurol., 47, 707-717.

Lucchinetti, C.F., Popescu, B.F.G., Bunyan, R.F., Moll, N.M., Roemer, S.F., Lassmann, H., Brück, W., Parisi, J.E., Scheithauer, B.W., Giannini, C., Weigand, S.D., Mandrekar, J., \& Ransohoff, R.M. (2011) Inflammatory Cortical Demyelination in Early Multiple Sclerosis. N. Engl. J. Med., 365, 2188-2197.

Magliozzi, R., Howell, O.W., Reeves, C., Roncaroli, F., Nicholas, R., Serafini, B., Aloisi, F., \& Reynolds, R. (2010) A Gradient of neuronal loss and meningeal inflammation in multiple sclerosis. Ann. Neurol., 68, 477-493.

Mandolesi, G., Gentile, A., Musella, A., Fresegna, D., De Vito, F., Bullitta, S., Sepman, H., Marfia, G.A., \& Centonze, D. (2015) Synaptopathy connects inflammation and neurodegeneration in multiple sclerosis. Nat. Rev. Neurol., 11, 711-724.

Marrie, R.A. (2004) Environmental risk factors in multiple sclerosis aetiology. Lancet Neurol., 3, 709-718.

Martin, R., McFarland, H.F., \& McFarlin, D.E. (1992) Immunological Aspects of Demyelinating Diseases. Annu. Rev. Immunol., 10, 153-187.

McMaster, W.R. \& Williams, A.F. (1979) Identification of la glycoproteins in rat thymus and purification from rat spleen. Eur. J. Immunol., 9, 426-433.

Merkler, D., Boscke, R., Schmelting, B., Czeh, B., Fuchs, E., Bruck, W., \& Stadelmann, C. (2006) Differential Macrophage/Microglia Activation in Neocortical EAE Lesions in the Marmoset Monkey. Brain Pathol., 16, 117-123.

Merkler, D., Ernsting, T., Kerschensteiner, M., Brück, W., \& Stadelmann, C. (2006) A new focal EAE model of cortical demyelination: Multiple sclerosis-like lesions with rapid resolution of inflammation and extensive remyelination. Brain, 129, 1972-1983.

Middleton, E.R. \& Rhoades, E. (2010) Effects of Curvature and Composition on $\alpha$-Synuclein Binding to Lipid Vesicles. Biophys. J., 99, 2279-2288.

Miller, D., Barkhof, F., Montalban, X., Thompson, A., \& Filippi, M. (2005) Clinically isolated 
syndromes suggestive of multiple sclerosis, part I: natural history, pathogenesis, diagnosis, and prognosis. Lancet Neurol., 4, 281-288.

Montgomery, S., Hiyoshi, A., Burkill, S., Alfredsson, L., Bahmanyar, S., \& Olsson, T. (2017) Concussion in adolescence and risk of multiple sclerosis. Ann. Neurol., 82, 554-561.

Mor, F. \& Cohen, I.R. (2006) How special is a pathogenic CNS autoantigen? Immunization to many CNS self-antigens does not induce autoimmune disease. J. Neuroimmunol., 174, 3-11.

Mor, F., Quintana, F., Mimran, A., \& Cohen, I.R. (2003) Autoimmune encephalomyelitis and uveitis induced by $T$ cell immunity to self beta-synuclein. J Immunol, 170, 628-634.

Morgan, D.A., Ruscetti, F.W., \& Gallo, R. (1976) Selective in vitro growth of T lymphocytes from normal human bone marrows. Science, 193, 1007-1008.

Morrissey, S.P., Stodal, H., Zettl, U., Simonis, C., Jung, S., Kiefer, R., Lassmann, H., Hartung, H.-P., Haase, A., \& Toyka, K. V. (1996) In vivo MRI and its histological correlates in acute adoptive transfer experimental allergic encephalomyelitis. Brain, 119, 239-248.

Mouradian, M.M. (2002) Recent advances in the genetics and pathogenesis of Parkinson disease. Neurology, 58, 179-185.

Mullins, L.J. \& Mullins, J.J. (1996) Transgenesis in the rat and larger mammals. J. Clin. Invest., 97, 1557-1560.

Murphy, D.D., Rueter, S.M., Trojanowski, J.Q., \& Lee, V.M. (2000) Synucleins are developmentally expressed, and alpha-synuclein regulates the size of the presynaptic vesicular pool in primary hippocampal neurons. J. Neurosci., 20, 3214-3220.

Nessler, S., Boretius, S., Stadelmann, C., Bittner, A., Merkler, D., Hartung, H.-P., Michaelis, T., Bruck, W., Frahm, J., Sommer, N., \& Hemmer, B. (2007) Early MRI changes in a mouse model of multiple sclerosis are predictive of severe inflammatory tissue damage. Brain, 130, 2186-2198.

Nyström, B. \& Norlén, K. (1983) Regional Spinal Cord and Brain Blood Flows in the Rat. Neurol. Res., 5, 91-101.

O'Connor, K.C., Bar-Or, A., \& Hafler, D.A. (2001) The Neuroimmunology of Multiple Sclerosis: Possible Roles of T and B Lymphocytes in Immunopathogenesis. J. Clin. Immunol., 21, 81-92.

Odoardi, F., Kawakami, N., Li, Z., Cordiglieri, C., Streyl, K., Nosov, M., Klinkert, W.E.F., Ellwart, J.W., Bauer, J., Lassmann, H., Wekerle, H., \& Flügel, A. (2007) Instant effect of soluble antigen on effector $\mathrm{T}$ cells in peripheral immune organs during immunotherapy of autoimmune encephalomyelitis. Proc. Natl. Acad. Sci. U. S. A., 104, 920-925. 
Odoardi, F., Sie, C., Streyl, K., Ulaganathan, V.K., Schläger, C., Lodygin, D., Heckelsmiller, K., Nietfeld, W., Ellwart, J., Klinkert, W.E.F., Lottaz, C., Nosov, M., Brinkmann, V., Spang, R., Lehrach, H., Vingron, M., Wekerle, H., Flügel-Koch, C., \& Flügel, A. (2012) T cells become licensed in the lung to enter the central nervous system. Nature, 488, 675-679.

Ollion, J., Cochennec, J., Loll, F., Escudé, C., \& Boudier, T. (2013) TANGO: a generic tool for high-throughput 3D image analysis for studying nuclear organization. Bioinformatics, 29, 1840-1841.

Paterson, P.Y. (1960) Transfer of allergic encephalomyelitis in rats by means of lymph node cells. J. Exp. Med., 111, 119-136.

Peterson, J.W., Bö, L., Mörk, S., Chang, A., \& Trapp, B.D. (2001) Transected neurites, apoptotic neurons, and reduced inflammation in cortical multiple sclerosis lesions. Ann. Neurol., 50, 389-400.

Pomeroy, I.M., Matthews, P.M., Frank, J.A., Jordan, E.K., \& Esiri, M.M. (2005) Demyelinated neocortical lesions in marmoset autoimmune encephalomyelitis mimic those in multiple sclerosis. Brain, 128, 2713-2721.

Ransohoff, R.M. \& Engelhardt, B. (2012) The anatomical and cellular basis of immune surveillance in the central nervous system. Nat. Rev. Immunol., 12, 623-635.

Ransohoff, R.M., Hafler, D.A., \& Lucchinetti, C.F. (2015) Multiple Sclerosis - a quiet revolution. Nat Rev Neurol, 11, 134-142.

Rauskolb, S., Zagrebelsky, M., Dreznjak, A., Deogracias, R., Matsumoto, T., Wiese, S., Erne, B., Sendtner, M., Schaeren-Wiemers, N., Korte, M., \& Barde, Y.-A. (2010) Global Deprivation of Brain-Derived Neurotrophic Factor in the CNS Reveals an Area-Specific Requirement for Dendritic Growth. J. Neurosci., 30, 1739-1749.

Reboldi, A., Coisne, C., Baumjohann, D., Benvenuto, F., Bottinelli, D., Lira, S., Uccelli, A., Lanzavecchia, A., Engelhardt, B., \& Sallusto, F. (2009) C-C chemokine receptor 6regulated entry of $\mathrm{TH}-17$ cells into the CNS through the choroid plexus is required for the initiation of EAE. Nat. Immunol., 10, 514-523.

Rivers, T.M., Sprunt, D.H., \& Berry, G.P. (1933) Observations on Attempts To Produce Acute Disseminated Encephalomyelitis in Monkeys. J. Exp. Med., 58, 39-53.

Robbins, T. (2002) The 5-choice serial reaction time task: behavioural pharmacology and functional neurochemistry. Psychopharmacology (Berl)., 163, 362-380.

Rodriguez, E.G., Wegner, C., Kreutzfeldt, M., Neid, K., Thal, D.R., Jürgens, T., Brück, W., Stadelmann, C., \& Merkler, D. (2014) Oligodendroglia in cortical multiple sclerosis lesions decrease with disease progression, but regenerate after repeated experimental demyelination. Acta Neuropathol., 128, 231-246. 
Rothhammer, V., Mascanfroni, I.D., Bunse, L., Takenaka, M.C., Kenison, J.E., Mayo, L., Chao, C.-C., Patel, B., Yan, R., Blain, M., Alvarez, J.I., Kébir, H., Anandasabapathy, N., Izquierdo, G., Jung, S., Obholzer, N., Pochet, N., Clish, C.B., Prinz, M., Prat, A., Antel, J., \& Quintana, F.J. (2016) Type I interferons and microbial metabolites of tryptophan modulate astrocyte activity and central nervous system inflammation via the aryl hydrocarbon receptor. Nat. Med., 22, 586-597.

Schindelin, J., Arganda-Carreras, I., Frise, E., Kaynig, V., Longair, M., Pietzsch, T., Preibisch, S., Rueden, C., Saalfeld, S., Schmid, B., Tinevez, J.-Y., White, D.J., Hartenstein, V., Eliceiri, K., Tomancak, P., \& Cardona, A. (2012) Fiji: an open-source platform for biological-image analysis. Nat. Methods, 9, 676-682.

Schlaeger, R., Papinutto, N., Panara, V., Bevan, C., Lobach, I. V., Bucci, M., Caverzasi, E., Gelfand, J.M., Green, A.J., Jordan, K.M., Stern, W.A., Von Büdingen, H.C., Waubant, E., Zhu, A.H., Goodin, D.S., Cree, B.A.C., Hauser, S.L., \& Henry, R.G. (2014) Spinal cord gray matter atrophy correlates with multiple sclerosis disability. Ann. Neurol., 76, 568-580.

Schläger, C., Körner, H., Krueger, M., Vidoli, S., Haberl, M., Mielke, D., Brylla, E., Issekutz, T., Cabañas, C., Nelson, P.J., Ziemssen, T., Rohde, V., Bechmann, I., Lodygin, D., Odoardi, F., \& Flügel, A. (2016) Effector T-cell trafficking between the leptomeninges and the cerebrospinal fluid. Nature, 530, 349-353.

Schlosser, C. (2013) Live imaging of autoimmune responses in distinct milieus of the central nervous system.

Schneider, O.D., Weiss, A.A., \& Miller, W.E. (2009) Pertussis toxin signals through the TCR to initiate cross-desensitization of the chemokine receptor CXCR4. J. Immunol., 182, 5730-5739.

Schreiber, S.L. \& Crabtree, G.R. (1992) The mechanism of action of cyclosporin A and FK506. Immunol. Today, 13, 136-142.

Shaw, J.P., Utz, P.J., Durand, D.B., Toole, J.J., Emmel, E.A., \& Crabtree, G.R. (1988) Identification of a putative regulator of early $T$ cell activation genes. Science, $\mathbf{2 4 1}, 202-$ 205.

Silber, E., Semra, Y.K., Gregson, N.A., \& Sharief, M.K. (2002) Patients with progressive multiple sclerosis have elevated antibodies to neurofilament subunit. Neurology, 58, 1372-1381.

Sporici, R. \& Issekutz, T.B. (2010) CXCR3 blockade inhibits T-cell migration into the CNS during EAE and prevents development of adoptively transferred, but not actively induced, disease. Eur. J. Immunol., 40, 2751-2761.

Steenwijk, M.D., Geurts, J.J.G., Daams, M., Tijms, B.M., Wink, A.M., Balk, L.J., Tewarie, P.K., 
Uitdehaag, B.M.J., Barkhof, F., Vrenken, H., \& Pouwels, P.J.W. (2016) Cortical atrophy patterns in multiple sclerosis are non-random and clinically relevant. Brain, 139, 115126.

Storch, M.K., Bauer, J., Linington, C., Olsson, T., Weissert, R., \& Lassmann, H. (2006) Cortical Demyelination Can Be Modeled in Specific Rat Models of Autoimmune Encephalomyelitis and Is Major Histocompatability Complex (MHC) Haplotype-Related. J. Neuropathol. Exp. Neurol., 65, 1137-1142.

Stromnes, I.M., Cerretti, L.M., Liggitt, D., Harris, R. a., \& Goverman, J.M. (2008) Differential regulation of central nervous system autoimmunity by TH1 and TH2 cells. Nat. Med., 14, 337-342.

Tambalo, S., Peruzzotti-Jametti, L., Rigolio, R., Fiorini, S., Bontempi, P., Mallucci, G., Balzarotti, B., Marmiroli, P., Sbarbati, A., Cavaletti, G., Pluchino, S., \& Marzola, P. (2015) Functional Magnetic Resonance Imaging of Rats with Experimental Autoimmune Encephalomyelitis Reveals Brain Cortex Remodeling. J. Neurosci., 35, 10088-10100.

Trachtenberg, J.T., Chen, B.E., Knott, G.W., Feng, G., Sanes, J.R., Welker, E., \& Svoboda, K. (2002) Long-term in vivo imaging of experience-dependent synaptic plasticity in adult cortex. Nature, 420, 788-794.

Vajkoczy, P., Laschinger, M., \& Engelhardt, B. (2001) Alpha4-integrin-VCAM-1 binding mediates $\mathrm{G}$ protein-independent capture of encephalitogenic T cell blasts to CNS white matter microvessels. J. Clin. Invest., 108, 557-565.

Vargas, K.J., Makani, S., Davis, T., Westphal, C.H., Castillo, P.E., \& Chandra, S.S. (2014) Synucleins Regulate the Kinetics of Synaptic Vesicle Endocytosis. J. Neurosci., 34, 93649376.

Vargas, K.J., Schrod, N., Davis, T., Fernandez-Busnadiego, R., Taguchi, Y. V., Laugks, U., Lucic, V., \& Chandra, S.S. (2017) Synucleins Have Multiple Effects on Presynaptic Architecture. Cell Rep., 18, 161-173.

Vollmer, T., Huynh, L., Kelley, C., Galebach, P., Signorovitch, J., DiBernardo, A., \& Sasane, R. (2015) Relationship between brain volume loss and cognitive outcomes among patients with multiple sclerosis: a systematic literature review. Neurol. Sci., 37, 165-179.

Vollmer, T., Signorovitch, J., Huynh, L., Galebach, P., Kelley, C., DiBernardo, A., \& Sasane, R. (2015) The natural history of brain volume loss among patients with multiple sclerosis: a systematic literature review and meta-analysis. J. Neurol. Sci., 357, 8-18.

Watanabe, T., Radulovic, J., Spiess, J., Natt, O., Boretius, S., Frahm, J., \& Michaelis, T. (2004) In vivo 3D MRI staining of the mouse hippocampal system using intracerebral injection of $\mathrm{MnCl}$. Neuroimage, 22, 860-867. 
Wegner, C., Esiri, M.M., Chance, S.A., Palace, J., \& Matthews, P.M. (2006) Neocortical neuronal, synaptic, and glial loss in multiple sclerosis. Neurology, 67, 960-967.

Westphal, C.H. \& Chandra, S.S. (2013) Monomeric Synucleins Generate Membrane Curvature. J. Biol. Chem., 288, 1829-1840.

Wilhelm, I., Nyúl-Tóth, Á., Suciu, M., Hermenean, A., \& Krizbai, I.A. (2016) Heterogeneity of the blood-brain barrier. Tissue Barriers, 4, 1-8.

Willer, C.J., Dyment, D.A., Risch, N.J., Sadovnick, A.D., \& Ebers, G.C. (2003) Twin concordance and sibling recurrence rates in multiple sclerosis. Proc. Natl. Acad. Sci., 100, 12877-12882.

Witvliet, M.H., Vogel, M.L., Wiertz, E.J.H.J., \& Poolman, J.T. (1992) Interaction of pertussis toxin with human T lymphocytes. Infect. Immun., 60, 5085-5090.

Wright, J.A., McHugh, P.C., Pan, S., Cunningham, A., \& Brown, D.R. (2013) Counterregulation of alpha- and beta-synuclein expression at the transcriptional level. Mol. Cell. Neurosci., 57, 33-41.

Wucherpfennig, K.W. \& Strominger, J.L. (1995) Molecular mimicry in T cell-mediated autoimmunity: Viral peptides activate human $\mathrm{T}$ cell clones specific for myelin basic protein. Cell, 80, 695-705.

Yang, G., Parkhurst, C.N., Hayes, S., \& Gan, W.-B. (2013) Peripheral elevation of TNF- leads to early synaptic abnormalities in the mouse somatosensory cortex in experimental autoimmune encephalomyelitis. Proc. Natl. Acad. Sci., 110, 10306-10311.

Zhang, Y., McClellan, M., Efros, L., Shi, D., Bielekova, B., Tang, M., Vexler, V., \& Sheridan, J. (2014) Daclizumab reduces CD25 levels on T cells through monocyte-mediated trogocytosis. Mult. Scler. J., 20, 156-164. 


\section{Abbreviations}

aEAE active Experimental Autoimmune Encephalomyelitis

APC Antigen Presenting Cell

BBB Blood-Brain Barrier

CCR5 C-C Chemokine Receptor type 5

CFA Complete Freund's Adjuvant

CIS Clinically Isolated Syndrome

CNS Central Nervous System

ConA Concanavalin A

CXCL12 C-X-C motif Chemokine Ligand 12

CXCR3 C-X-C Chemokine Receptor type 3

CXCR4 C-X-C Chemokine Receptor Type 4

EAE Experimental Autoimmune Encephalomyelitis

EH Eagles HEPES

FACS Fluorescence-Activated Cell Sorting

FCS Fetal Calf Serum

Gad $\quad$ Gadolinium (here: Gadobutrol-solution/Gadovist ${ }^{\circledR}$ )

GFP Green Fluorescent Protein

GWAS Genome-wide Association Studies

i.t. intrathecal

i.v. intravenous

ICAM Intracellular Adhesion Molecule

IFNץ interferon gamma

LFA-1 Lymphocyte function-associated antigen 1

MADCAM1 Mucosal vascular Addressin Cell-Adhesion Molecule 1

MBP Myelin Basic Protein 
MBPTG MBP specific receptor-transgenic rat line

MHC class II Class II Major Histocompatibility Complex

MOG Myelin Oligodendrocyte Protein

MRI Magnetic Resonance Imaging

MS Multiple Sclerosis

NFAT Nuclear Factor of Activated T cells

NGS Next Generation Sequencing

OVA Ovalbumin

PBMC Peripheral blood mononuclear cell

p.r. post recovery

p.t. post transfer

PFA Paraformaldehyde

PLP Proteolipid Protein

PPMS Primary Progressive Multiple Sclerosis

ptEAE passive transfer Experimental Autoimmune Encephalomyelitis

qPCR quantitative real-time Polymerase Chain Reaction

RM Re-stimulation Medium

ROI Region Of Interest

RRMS Relapsing Remitting Multiple Sclerosis

SC Spinal Cord

SI $\quad$ Signal Intensity

SPMS Secondary Progressive Multiple Sclerosis

TAG-1 Contactin-2/Transiently expressed Axonal Glycoprotein 1

TCM T-Cell Medium

TCR T-cell Receptor

TMBP cell MBP-specific T cell 
TNFa Tumour Necrosis Factor alpha

TPLSM Two-Photon Laser Scanning Microscopy

TßSyn cell $\quad \beta$-Synuclein ${ }_{93-111}$ peptide-specific T cell

VCAM Vascular Cell Adhesion Molecule

VLA-4 Very Late Antigen-4

BSyn $\quad \beta$-Synuclein $\quad \beta 3-111$ peptide

BSynTG $\quad \beta$-Synuclein ${ }_{93-111}$ peptide-specific receptor-transgenic rat line 


\section{Acknowledgements}

I wish to express my sincerest gratitude to Prof. Alexander Flügel for his supervision and inspiration during the entire time of my PhD studies and for giving me the opportunity to work on this fascinating project. I further want to thank my supervisor Prof. Francesca Odoardi for her invaluable support, guidance and encouragement.

My gratitude goes to Prof. Holger Reichardt and Prof. Jürgen Wienands who supported me as members of my thesis advisory committee, as well as Prof. Hannelore Ehrenreich, Prof. Wolfgang Brück and Dr. Sebastian Kügler for agreeing to be part of my examination board.

I would like to thank Dr. Henrike Fischer and Dr. Dmitry Lodygin for creating the receptortransgenic rat lines and their constant advice and support.

For all their time and expertise, their advice and kindness during our collaboration, I would like to thank Dr. Marta Zagrebelsky-Holz and Dr. Takashi Watanabe.

I am very grateful to Adriane Stas, Angelika Mönnich, Simon Mole and Simone Hamann for their outstanding support and technical assistance.

Finally, I want to thank everyone else who supported me during the course of my PhD: Angelika, Lothar, Lisa and Dr. Wolfgang Hermann for their unfaltering love and support, not only during the last years, but during my entire life; Jenni, Stefan, Nico, Martin, Hendrik, Sönke and Verena, who I could always rely on; Judith, Leon, Michael, Basti, Henrike², Arianna, Phteven, César, Addi, Guiseppe and all other members of the IMSF for being not only colleagues, but friends. 


\section{Declaration}

I hereby declare that I prepared the doctoral thesis "Analysis of autoimmune lesions in grey matter" on my own and with no other sources and aids than quoted.

Moritz Hermann

Göttingen, December 2017 